\title{
A General Lake Model (GLM 3.0) for linking with high-frequency sensor data from the Global Lake Ecological Observatory Network (GLEON)
}

\author{
Matthew R. Hipsey ${ }^{1}$, Louise C. Bruce ${ }^{1}$, Casper Boon ${ }^{1}$, Brendan Busch ${ }^{1}$, Cayelan C. Carey ${ }^{2}$, David P. Hamilton ${ }^{3}$, \\ Paul C. Hanson ${ }^{4}$, Jordan S. Read ${ }^{5}$, Eduardo de Sousa ${ }^{1}$, Michael Weber ${ }^{6}$, and Luke A. Winslow ${ }^{7}$ \\ ${ }^{1}$ UWA School of Agriculture \& Environment, The University of Western Australia, Crawley WA, 6009, Australia \\ ${ }^{2}$ Department of Biological Sciences, Virginia Tech, Blacksburg, VA, USA \\ ${ }^{3}$ Australian Rivers Institute, Griffith University, Brisbane QLD, Australia \\ ${ }^{4}$ Center for Limnology, University of Wisconsin - Madison, Madison, WI, USA \\ ${ }^{5}$ U.S. Geological Survey, Water Mission Area, Middleton, WI, USA \\ ${ }^{6}$ Department of Lake Research, Helmholtz Centre for Environmental Research - UFZ, Magdeburg, Germany \\ ${ }^{7}$ Department of Biological Sciences, Rensselaer Polytechnic Institute, Troy, NY, USA
}

Correspondence: Matthew R. Hipsey (matt.hipsey@uwa.edu.au)

Received: 15 October 2017 - Discussion started: 20 November 2017

Revised: 22 September 2018 - Accepted: 18 October 2018 - Published: 29 January 2019

\begin{abstract}
The General Lake Model (GLM) is a onedimensional open-source code designed to simulate the hydrodynamics of lakes, reservoirs, and wetlands. GLM was developed to support the science needs of the Global Lake Ecological Observatory Network (GLEON), a network of researchers using sensors to understand lake functioning and address questions about how lakes around the world respond to climate and land use change. The scale and diversity of lake types, locations, and sizes, and the expanding observational datasets created the need for a robust community model of lake dynamics with sufficient flexibility to accommodate a range of scientific and management questions relevant to the GLEON community. This paper summarizes the scientific basis and numerical implementation of the model algorithms, including details of sub-models that simulate surface heat exchange and ice cover dynamics, vertical mixing, and inflow-outflow dynamics. We demonstrate the suitability of the model for different lake types that vary substantially in their morphology, hydrology, and climatic conditions. GLM supports a dynamic coupling with biogeochemical and ecological modelling libraries for integrated simulations of water quality and ecosystem health, and options for integration with other environmental models are outlined. Finally, we discuss utilities for the analysis of model outputs and uncertainty assessments, model operation within a distributed
\end{abstract}

cloud-computing environment, and as a tool to support the learning of network participants.

\section{Introduction}

Lakes and other standing waters support extensive ecosystem services such as water supply, flood mitigation, hydropower, aesthetic and cultural benefits, and fisheries and biodiversity (Mueller et al., 2016). Lakes are often considered to be "sentinels of change", providing a window into the sustainability of activities in their catchments (Williamson et al., 2009). They are also particularly susceptible to impacts from invasive species and land use development, which often lead to water quality deterioration and loss of ecosystem integrity. Recent estimates have demonstrated their significance in the Earth system, contributing to heterogeneity in land surface properties and feedbacks to regional and global climate through energy, water, and biogeochemical transfers (Martynov et al., 2012; Cole et al., 2007). For example, Tranvik et al. (2009) suggest that carbon burial in lakes and reservoirs is substantial on a global scale, of the order of $0.6 \mathrm{Pg} \mathrm{yr}^{-1}$ or 4 times the oceanic burial rate. 
Given the diversity of lakes among continents, regionspecific pressures, and local management approaches, the Global Lake Ecological Observatory Network (GLEON; http://gleon.org, last access: 14 January 2019) was initiated in 2004 as a grass-roots science community with a vision to observe, understand, and predict freshwater systems at a global scale (Hanson et al., 2016). In doing so, GLEON has been a successful example of collaborative research within the hydrological and ecological science disciplines. GLEON aims to bring together environmental sensor networks, numerical models, and information technology to explore ecosystem dynamics across a vast range of scales from individual lakes or reservoirs (Hamilton et al., 2015) to regional (Read et al., 2014; Klug et al., 2012) and global extents (Rigosi et al., 2015; O'Reilly et al., 2015). Ultimately, it is the aim of the network to facilitate discovery and synthesis and to provide an improved scientific basis for sustainable freshwater resource management.

Environmental modelling forms a critical component of observing systems as a way to make sense of the "data deluge" (Porter et al., 2012), allowing users to build virtual domains to support knowledge discovery at the system scale (Ticehurst et al., 2007; Hipsey et al., 2015). In lake ecosystems, the tight coupling between physical processes and water quality and ecological dynamics has long been recognized. Modellers have capitalized on a comprehensive understanding of physical processes (e.g. Imberger and Patterson, 1990; Imboden and Wüest, 1995) to use hydrodynamic models as an underpinning basis for coupling to ecological models. Such models have contributed to our understanding of lake dynamics, including applications associated with climate change (Winslow et al., 2017), eutrophication dynamics (Matzinger et al., 2007), harmful algal bloom dynamics (Chung et al., 2014), and fisheries (Makler-Pick et al., 2011).

In recent decades, a range of one-, two-, and threedimensional hydrodynamic models has emerged for lake simulation. Depending on the dimensionality, the horizontal resolution of these models may vary from metres to tens of kilometres with vertical resolutions from sub-metre to several metres. As in all modelling disciplines, identifying the most parsimonious model structure and degree of complexity and resolution is challenging, and users in the lake modelling community often tend to rely on heuristic rules or practical reasons for model choice (Mooij et al., 2010). Highresolution models are suited to studying events that occur at the timescale of flow dynamics, but are not always desirable for ecological studies over longer timescales due to their computational demands and level of over-parameterization. On the other hand, simple models may be more agile for a particular application and more suited to parameter identification and scenario-testing workflows. However, it has been the case within GLEON that simple models are often less applicable across a wide variety of domains, making them less generalizable, which is a key requirement of synthesis studies across many waterbodies. Despite the fact that there is a relatively large diversity of models and approaches for aquatic ecosystem simulation (Janssen et al., 2015), it is generally agreed that to improve scientific collaboration within the limnological modelling community, there is an increasing need for flexible, open-source community models (Trolle et al., 2012). Whilst acknowledging that there is no single model suitable for all applications, a range of open-source community models and tools can enhance scientific capabilities and foster scientific collaboration and combined efforts (Read et al., 2016). There are examples of such initiatives being successful in the oceanography, hydrology, and climate modelling communities.

With this in mind, the General Lake Model (GLM), a onedimensional (1-D) hydrodynamic model for enclosed aquatic ecosystems, was developed. The lake modelling community has often relied on 1-D models, which originated to capture lake water balance and thermal stratification dynamics (e.g. Imberger and Patterson, 1981; Saloranta and Andersen, 2007; Perroud et al., 2009; Stepanenko et al., 2013). The use of 1-D structure is justified across a diverse range of lake sizes given the dominant role of seasonal changes in vertical stratification in lake dynamics, including oxygen, nutrient, and metal cycling and plankton dynamics (Hamilton and Schladow, 1997; Gal et al., 2009). Despite advances in computing power and more readily available 3-D hydrodynamic drivers, 1-D models continue to remain attractive as they are easily linked with biogeochemical and ecological modelling libraries for complex ecosystem simulations. This allows 1-D models to be used to capture the long-term trajectory and resilience of lakes and reservoirs to climate change, hydrologic change, and land use change. For example, such models have been used to study long-term changes to oxygen, nutrient cycles, and the changing risk of algal blooms (e.g. Peeters et al., 2007; Hu et al., 2016; Snortheim et al., 2017). Furthermore, the low computational requirements of this approach relative to 3-D models is more suited to parameter identification and uncertainty analysis, making it an attractive balance between process complexity and computational intensity.

GLM emerged as a new open-source code in 2012, with the design goal of balancing the complexity of dimensional representation, applicability to a wide range of standing waters, and availability to a broad community (e.g. GLEON has $>700$ members from around 50 countries). The scope and capability of the model have developed rapidly with application to numerous lakes and lake types within the GLEON network and beyond (e.g. Read et al., 2014; Bueche et al., 2017; Snortheim et al., 2017; Weber et al., 2017; Menció et al., 2017; Bruce et al., 2018). It is unique in that its suitability now ranges from ephemeral wetlands and ponds to deep lakes, from natural systems to heavily managed man-made reservoirs, and across climatic regions. Given that individual applications rarely engage the full array of features or describe the full details of the model structure, the aim of this paper is to present a complete description of GLM, including the scientific background (Sect. 2) and model code organiza- 
tion (Sect. 3). The approach to coupling with biogeochemical models is also discussed (Sect. 4), since a main objective of GLM's development is to link its hydrodynamic simulation with water quality models to explore the effects of stratification and vertical mixing on biogeochemical cycles and lake ecology. Finally, an overview of the use of the model within the context of GLEON-specific requirements for model analysis, integration, and education (Sects. 5-6) is described. In order to better define the typical level of model performance across these diverse lake types, a companion paper by Bruce et al. (2018) has undertaken a systematic assessment of the model's error structure against 31 lakes.

\section{Model overview}

\subsection{Background and layer structure}

The 1-D approach adopted by GLM resolves a vertical series of layers that capture the variation in water column properties. Users may configure any number of inflows and outflows, and more advanced options exist for simulating aspects of the water and heat balance (Fig. 1). Depending on the context of the simulation, either daily or hourly meteorological time series data for surface forcing are required, and daily time series of volumetric inflow and outflow rates can also be supplied. The model is suitable for operation in a wide range of climate conditions and is able to simulate ice formation, as well as accommodating a range of atmospheric forcing conditions.

Although GLM is a new model code written in the C programming language, the core layer structure and mixing algorithms are founded on principles and experience from model platforms including the DYnamic REservoir Simulation Model (DYRESM; Imberger and Patterson, 1981; Hamilton and Schladow, 1997) and the Dynamic Lake Model (DLM; Chung et al., 2008). Other variations have been introduced to extend this underlying approach through applications to a variety of lake and reservoir environments (e.g. Hocking and Patterson, 1991; McCord and Schladow, 1998; Gal et al., 2003; Yeates and Imberger, 2003). The layer structure is numbered from the lake bottom to the surface and adopts the flexible Lagrangian layer scheme first introduced by Imberger et al. (1978) and Imberger and Patterson (1981). The approach defines each layer, $i$, as a "control volume" (Fig. 1) that can change thickness by contracting and expanding in response to inflows, outflows, mixing with adjacent layers, and surface mass fluxes. As the model simulation progresses, density changes due to surface heating, vertical mixing, and inflows and outflows lead to dynamic changes in the layer structure associated with layers amalgamating, expanding, contracting, or splitting. Notation used throughout the model description is provided in Table 1.

As layers change, their volumes change based on the sitespecific hypsographic curve, whereby the overall lake vol- ume, $V_{\max }$, is defined as $\int_{H_{0}}^{H_{\max }} A[H] \mathrm{d} H$, with the elevation $(H)$ and area $(A)$ relationship provided as a series of points based on bathymetric data. This computation requires the user to provide a number, $N_{\mathrm{BSN}}$, of elevations with corresponding areas. The cumulative volume at any lake elevation is first estimated as

$V_{\mathrm{b}}=V_{\mathrm{b}-1}+\left[0.5\left(A_{\mathrm{b}}+A_{\mathrm{b}-1}\right)\right]\left(H_{\mathrm{b}}-H_{\mathrm{b}-1}\right)$,

where $2 \leq b \leq N_{\mathrm{BSN}}$. Using these raw hypsographic data, a refined height-area-volume relationship is then internally computed using finer height increments (e.g. $\Delta H_{\mathrm{mi}} \sim$ $0.1 \mathrm{~m}$ ), giving $N_{\mathrm{MORPH}}$ levels that are used for subsequent calculations. The area and volume at the height of each increment, $H_{\mathrm{mi}}$, are interpolated from the supplied information as

$V_{\mathrm{mi}}=V_{\mathrm{b}}\left(\frac{H_{\mathrm{mi}}}{H_{\mathrm{b}}}\right)^{\alpha_{\mathrm{b}}}$ and $A_{\mathrm{mi}}=A_{\mathrm{b}}\left(\frac{H_{\mathrm{mi}}}{H_{\mathrm{b}}}\right)^{\beta_{\mathrm{b}}}$,

where $V_{\mathrm{mi}}$ and $A_{\mathrm{mi}}$ are the volume and area at each of the elevations of the interpolated depth vector, and $V_{\mathrm{b}}$ and $A_{\mathrm{b}}$ refer to the nearest b level below $H_{\mathrm{mi}}$ such that $H_{\mathrm{b}}<H_{\mathrm{mi}}$. The interpolation coefficients are computed as

$\alpha_{\mathrm{b}}=\left(\frac{\log _{10}\left[\frac{V_{\mathrm{b}+1}}{V_{\mathrm{b}}}\right]}{\log _{10}\left[\frac{H_{\mathrm{b}+1}}{H_{\mathrm{b}}}\right]}\right)$ and $\beta_{\mathrm{b}}=\left(\frac{\log _{10}\left[\frac{A_{\mathrm{b}+1}}{A_{\mathrm{b}}}\right]}{\log _{10}\left[\frac{H_{\mathrm{b}+1}}{H_{\mathrm{b}}}\right]}\right)$.

Within this lake domain, the model solves the water balance by including several user-configurable water fluxes that change the layer structure. Initially, the layers are assumed to be of equal thickness, and the initial number of layers, $N_{\mathrm{LEV}}[t=0]$, is computed based on the initial water depth. Water fluxes include surface mass fluxes (evaporation, rainfall, and snowfall), inflows (surface inflows, submerged inflows, and local run-off from the surrounding exposed lakebed area), and outflows (withdrawals, overflow, and seepage). Surface mass fluxes operate on a sub-daily time step, $\Delta t$, by impacting the surface layer thickness (described in Sect. 2.2), whereby the dynamics of inflows and outflows modify the overall lake water balance and layer structure on a daily time step, $\Delta t_{\mathrm{d}}$, by adding, merging, or removing layers (described in Sect. 2.7). Depending on whether a surface (areal) mass flux or volumetric mass flux is being applied, the layer volumes are updated by interpolating changes in layer heights, whereby $V_{i}=f\left[h_{i}\right]$ and $i$ is the layer number, or layer heights are updated by interpolating changes in layer volumes, whereby $h_{i}=f\left[V_{i}\right]$.

Each layer also contains heat, salt $(S)$, and other constituents $(C)$, which are generically referred to as scalars. These are subject to mass conservation as layers change thickness or are merged or split. The specific number of other constituents depends on the configuration of the associated water quality model, but typically includes attributes such as oxygen, nutrients, and phytoplankton. Layer density 


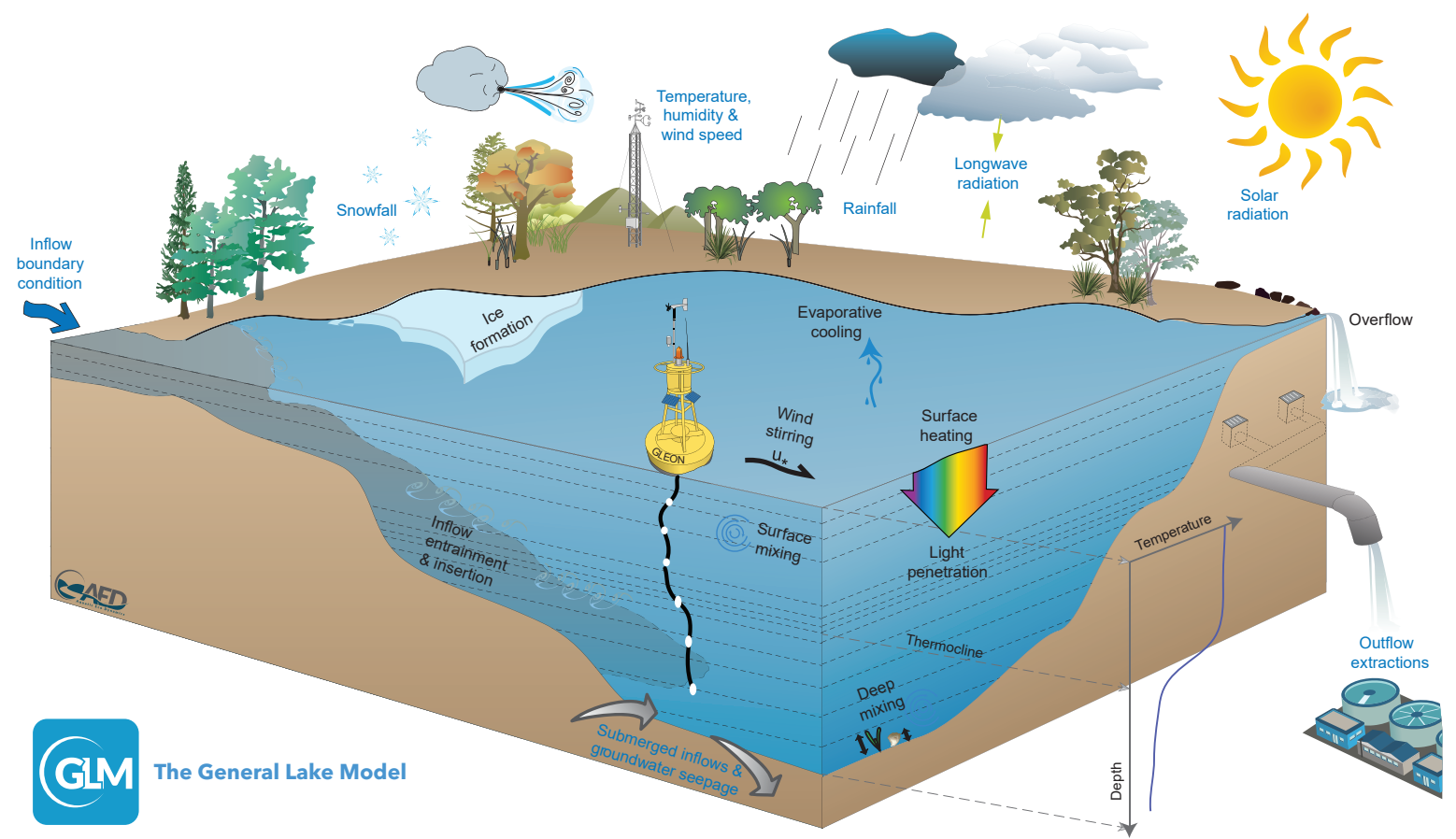

Figure 1. Schematic of a GLM simulation domain, input information (blue text), and key simulated processes (black text).

is computed from the local salinity and temperature according to TEOS-10 (http://teos-10.org, last access: 16 December 2018), whereby $\rho_{i}=\rho\left[T_{i}, S_{i}\right]$. When density instabilities occur between adjacent layers or when sufficient turbulent kinetic energy becomes available to overcome stable density gradients, then layers merge, thereby accounting for the process of mixing (Sect. 2.6). For deeper systems, a stable vertical density gradient forms seasonally in response to periods of high solar radiation creating warm, buoyant water overlying cooler, denser water, separated by a metalimnion region which includes the thermocline. Layer volumes change due to depth-specific changes in mixing, inflows, and outflows. Thickness limits, $\Delta z_{\min }$ and $\Delta z_{\max }$, are enforced to adequately resolve the vertical density gradient, generally with fine resolution occurring in the metalimnion and thicker cells where gradients are weak. The number of layers, $N_{\mathrm{LEV}}[t]$, is adjusted throughout the simulation to maintain homogenous properties within a layer. It has been reported that numerical diffusion at the thermocline can be restricted using this layer structure and mixing algorithm (depending on the minimum and maximum layer thickness limits set by the user), making it particularly suited to longterm investigations and ideally requiring limited site-specific calibration (Patterson et al., 1984; Hamilton and Schladow, 1997; Bruce et al., 2018).

Because this approach assumes layer properties are laterally averaged, the model is suitable for investigations in which resolving the horizontal variability is not a requirement of the study. This is often the case for ecologists and biogeochemists studying central basins of natural lakes (e.g. Gal et al., 2009), managers simulating drinking water reservoirs (e.g. Weber et al., 2017), mining pit lakes (e.g. Salmon et al., 2017), or for analyses exploring the coupling between lakes and regional climate (e.g. Stepanenko et al., 2013). Further, whilst the model is able to resolve vertical stratification, the approach is also able to be used to simulate shallow lakes, wetlands, wastewater ponds, and other small waterbodies that experience well-mixed conditions. In this case, the layer resolution, with upper and lower layer bounds specified by the user, will automatically be reduced, and the mass of water, constituents, and energy will continue to be conserved. The remainder of this section outlines the model components and provides example outputs for five waterbodies that experience a diverse hydrology.

\subsection{Water balance}

The general nature of the model to accommodate a wide diversity of lake types has necessitated flexibility in the configuration of water inputs and outputs (schematically depicted in Fig. 1). The net water flux over the entire lake is summarized as

$$
\begin{aligned}
\frac{\mathrm{d} V_{\mathrm{S}}}{\mathrm{d} t}= & A_{\mathrm{S}} \frac{\mathrm{d} h_{\mathrm{S}}}{\mathrm{d} t}+\sum_{I}^{N_{\mathrm{INF}}} Q_{\text {inf }_{0_{I}}}-\sum_{O}^{N_{\text {OUTF }}} Q_{\text {outf }_{O}} \\
& -Q_{\text {seepage }}-Q_{\text {ovfl }},
\end{aligned}
$$

where $V_{\mathrm{S}}$ is the total lake volume, $t$ is time, and $A_{\mathrm{S}}$ is the lake surface area; the changes due to fluxes at the water sur- 
face, $h_{\mathrm{S}}$, are expanded upon below, and the remaining inflow and outflow terms are described in detail in Sect. 7. For practical reasons the equation is numerically solved in two stages with different times steps for the surface flux change and all other fluxes. Furthermore, in any given application, not all the inputs and outputs are relevant and users may customize the water balance components accordingly; examples demonstrating lake hydrology from wetlands to reservoirs to deep lakes are presented in Fig. 2. Note that Eq. (4) accounts for the liquid water balance, and in cold climates the model will also track the amount of water allocated into an overlying ice layer (Sect. 2.4), which interacts with the surface water balance as indicated next.

The mass balance of the surface layer is computed at each model time step ( $\Delta t$; usually hourly) by modifying the surface layer height, $h_{\mathrm{S}}$, according to

$\frac{\mathrm{d} h_{\mathrm{S}}}{\mathrm{d} t}=R_{\mathrm{F}}+S_{\mathrm{F}}+\frac{Q_{\mathrm{R}}}{A_{\mathrm{S}}}-E-\frac{\mathrm{d} \Delta z_{\text {ice }}}{\mathrm{d} t}$,

where $E$ is the evaporation mass flux computed from the latent heat flux $\phi_{\mathrm{E}}$, described below $\left(E=\phi_{\mathrm{E}} / \lambda_{\mathrm{v}} \rho_{\mathrm{s}} ; \mathrm{m} \mathrm{s}^{-1}\right)$, $R_{\mathrm{F}}$ is rainfall, and $S_{\mathrm{F}}$ is snowfall $\left(\mathrm{m} \mathrm{s}^{-1}\right)$. Depending on the meteorological conditions, precipitation will either be added to the water volume or to the surface of the ice cover (see Sect. 2.4), and $R_{\mathrm{F}}$ and $S_{\mathrm{F}}$ therefore influence the water surface height depending on the presence of ice cover according to

$R_{\mathrm{F}}= \begin{cases}f_{\mathrm{R}} R_{x} / c_{\text {secday }} & \text { if } \Delta z_{\text {ice }}=0 \\ f_{\mathrm{R}} R_{x} / c_{\text {secday }} & \text { if } \Delta z_{\text {ice }}>0 \text { and } T_{\mathrm{a}}>0 \\ 0, & \text { if } \Delta z_{\text {ice }}>0 \text { and } T_{\mathrm{a}} \leq 0\end{cases}$

and

$S_{\mathrm{F}}=\left\{\begin{array}{ll}f_{\mathrm{S}} f_{\mathrm{SWE}} S_{x} / c_{\text {secday }} & \text { if } \Delta z_{\text {ice }}=0 \\ 0, & \text { if } \Delta z_{\text {ice }}>0\end{array}\right.$.

Here, $f_{\mathrm{R}}$ and $f_{\mathrm{S}}$ are user-defined scaling factors that may be applied to adjust the input data values $R_{x}$ and $S_{x}$, respectively. The surface height of the water column is also impacted by ice formation or melting of the ice layer sitting on the lake surface according to $\mathrm{d} \Delta z_{\text {ice }} / \mathrm{d} t$, as described in Sect. 2.4.

$Q_{\mathrm{R}}$ is an optional term to account for run-off to the lake from the exposed riparian banks, which may be important in reservoirs with a large drawdown range or wetlands where periodic drying of the lake may occur. The run-off volume generated is averaged across the area that the active lake surface area $\left(A_{\mathrm{s}}\right)$ is not occupying, and the amount is calculated using a simple model based on exceedance of a rainfall intensity threshold, $R_{L}\left(\mathrm{~m} \mathrm{day}^{-1}\right)$, and run-off coefficient:

$Q_{\mathrm{R}}=\max \left[0, f_{\text {ro }}\left(R_{\mathrm{F}}-R_{L} / c_{\text {secday }}\right)\right]\left(A_{\max }-A_{\mathrm{S}}\right)$,

where $f_{\text {ro }}$ is the run-off coefficient, defined as the fraction of rainfall that is converted to run-off at the lake's edge, and $A_{\text {max }}$ is the maximum possible area of inundation of the lake (the area provided by the user as the $N_{\mathrm{BSN}}$ value).
Note that mixing dynamics (i.e. the merging or splitting of layers to enforce the layer thickness limits) will impact the thickness of the surface mixed layer, $z_{\mathrm{SML}}$, but not change the overall lake height. However, in addition to the terms in Eq. (5), $h_{\mathrm{S}}$ is modified due to volume changes associated with river inflows, withdrawals, seepage, or overflows, which are described in subsequent sections.

\subsection{Surface energy balance}

A balance of shortwave and longwave radiation fluxes and sensible and evaporative heat fluxes (all $\mathrm{W} \mathrm{m}^{-2}$ ) determines the net cooling and heating across the surface. The general heat budget equation for the uppermost layer is described as

$c_{\mathrm{w}} \rho_{\mathrm{s}} z_{\mathrm{s}} \frac{\mathrm{d} T_{\mathrm{s}}}{\mathrm{d} t}=\phi_{\mathrm{SW}}-\phi_{\mathrm{E}}+\phi_{\mathrm{H}}+\phi_{\mathrm{LWin}}-\phi_{\mathrm{LWout}}$,

where $c_{\mathrm{W}}$ is the specific heat capacity of water, $T_{\mathrm{S}}$ is the surface temperature, and $z_{\mathrm{s}}$ and $\rho_{\mathrm{s}}$ are the depth and density of the surface layer ( $i=N_{\mathrm{LEV}}$ ), respectively. The right-hand side (RHS) heat flux terms are numerically computed at each time step and include several options for customizing the individual surface heat flux components, which are expanded upon below.

\subsubsection{Solar heating and light penetration}

Solar radiation is the key driver of lake thermodynamics and may be input based on daily or hourly measurements from a nearby pyranometer. If data are not available then users may choose to have GLM compute surface irradiance from a theoretical approximation based on the Bird Clear Sky Model (BCSM) (Bird, 1984) modified for cloud cover and latitude. The options for input are summarized as

$$
\begin{aligned}
& \phi_{\mathrm{SW}_{0}}= \\
& \left\{\begin{array}{l}
\text { Option 1: daily insolation data provided } \\
\left(1-\alpha_{\mathrm{SW}}\right) f_{\mathrm{SW}} \phi_{\mathrm{SW}_{x}} f[d, t-\lfloor t\rfloor], \\
\text { Option 2: sub-daily insolation data provided } \\
\left(1-\alpha_{\mathrm{SW}}\right) f_{\mathrm{SW}} \phi_{\mathrm{SW}_{x}}, \\
\text { Option 3: insolation computed from the BCSM } \\
\left(1-\alpha_{\mathrm{SW}}\right) f_{\mathrm{SW}} \hat{\phi}_{\mathrm{SW}},
\end{array}\right.
\end{aligned}
$$

where $\phi_{\mathrm{SW}_{0}}$ is the solar radiation flux entering the surface layer, $\phi_{\mathrm{SW}_{x}}$ is the incoming shortwave radiation flux supplied by the user, $f_{\mathrm{SW}}$ is a scaling factor that may be applied and adjusted as part of the calibration process (for example, to capture the effects of shading), and $\alpha_{\mathrm{SW}}$ is the albedo for shortwave radiation. If daily data are supplied (option 1 ), the model continues to run at a sub-daily time step, but applies the algorithm outlined in Hamilton and Schladow (1997) to distribute the daily solar energy flux over a diurnal cycle based on the day of the year, $d$, and time of day, $t-\lfloor t\rfloor$. For 

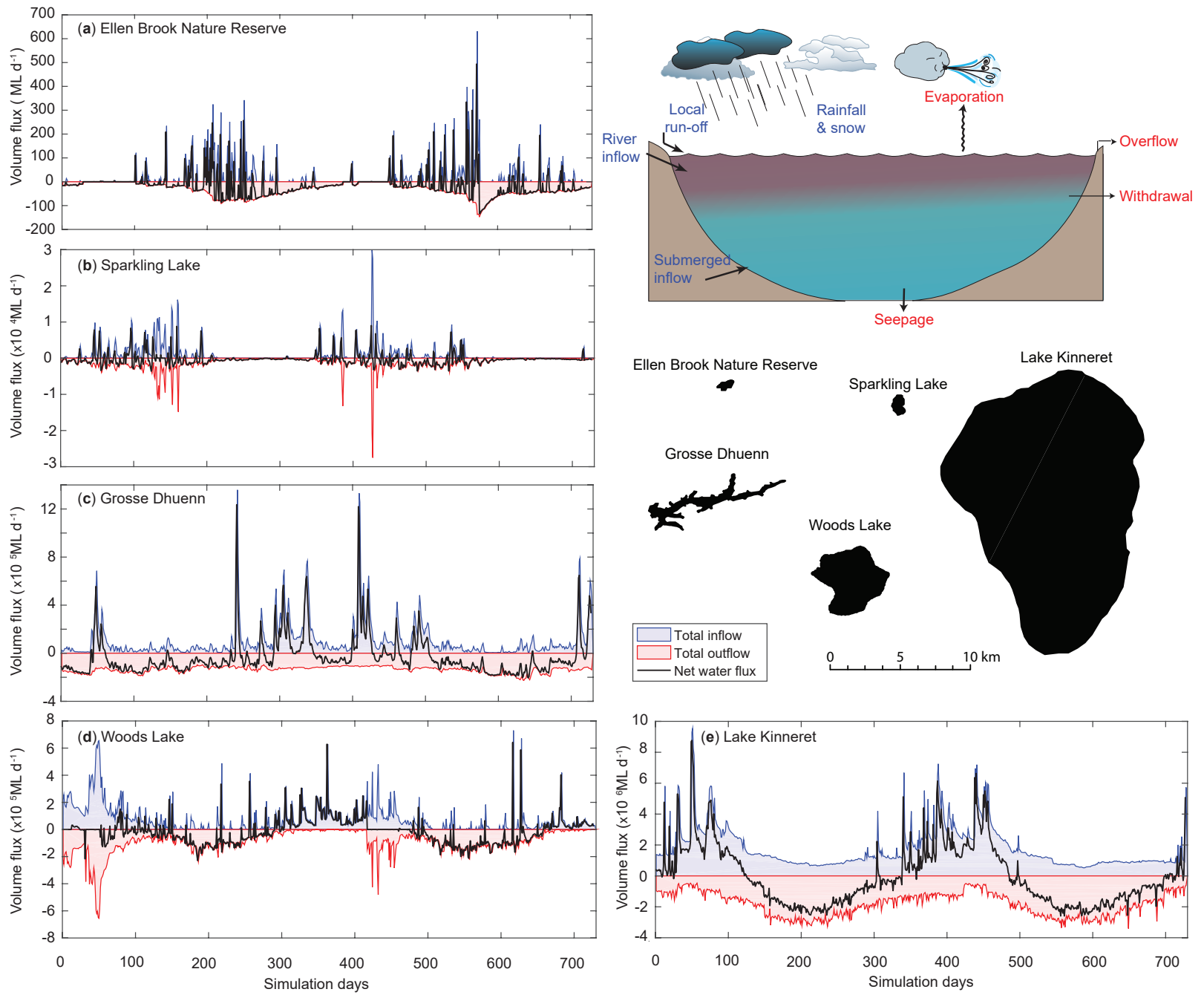

Figure 2. A 2-year times series of the simulated daily water balance for five example lakes (a-e) that range in size and hydrology. The water balance components summarized are depicted schematically in the inset and partitioned into inputs and outputs. The daily net water flux is computed from Eq. (4). For more information about each lake, the simulation configuration, and input data, refer to the "Data availability" section.

option 3 the BCSM is used (Bird, 1984; Luo et al., 2010):

$\hat{\phi}_{\mathrm{SW}}=\frac{\hat{\phi}_{\mathrm{DB}}+\hat{\phi}_{\mathrm{AS}}}{1-\left(\alpha_{\mathrm{SW}} \alpha_{\mathrm{SKY}}\right)} f\left[C_{x}\right]$

where the total irradiance, $\hat{\phi}_{\mathrm{SW}}$, is computed from direct beam $\hat{\phi}_{\mathrm{DB}}$ and atmospheric scattering $\hat{\phi}_{\mathrm{AS}}$ components (refer to Appendix A for a detailed outline of the BCSM equations and parameters). In GLM, the clear-sky value is then reduced according to the cloud cover data provided by the user, $C_{x}$, according to

$f\left[C_{x}\right]=0.66182 C_{x}^{2}-1.5236 C_{x}+0.98475$,

which is based on a polynomial regression of cloud data from Perth Airport, Australia, compared against nearby sen- sor data $\left(R^{2}=0.952\right.$; see also a similar relationship by Luo et al., 2010).

The albedo, $\alpha_{\mathrm{SW}}$, is the reflected fraction of the incoming radiation and depends on surface conditions, including the presence of ice, waves, and the angle of incident radiation. For open water conditions, users may configure the following. 
Option 1 : daily approximation from Hamilton and

Schladow (1997)

$$
\alpha_{\mathrm{SW}}=\left\{\begin{array}{c}
\alpha_{\mathrm{SW}_{\text {mean }}}-\delta \alpha_{\mathrm{SW}} \sin \left[\frac{2 \pi}{365} d-\frac{\pi}{2}\right] \\
: \text { northern hemisphere, Lat }>0 \\
\alpha_{\mathrm{SW}} \text { mean } \\
: \text { equator } \\
\alpha_{\mathrm{SW}_{\text {mean }}}-\delta \alpha_{\mathrm{SW}} \sin \left[\frac{2 \pi}{365} d+\frac{\pi}{2}\right] \\
\quad: \text { southern hemisphere, Lat }<0
\end{array}\right.
$$

Option 2: sub-daily approximation from Briegleb

et al. (1986)

$$
\begin{aligned}
\alpha_{\mathrm{SW}} & =\frac{1}{100}\left(\frac{2.6}{\cos \left[\Phi_{\mathrm{zen}}\right]^{1.7}+0.065}+15\left(\cos \left[\Phi_{\mathrm{zen}}\right]-0.1\right)\right. \\
& \left.\left(\cos \left[\Phi_{\mathrm{zen}}\right]-0.5\right)\left(\cos \left[\Phi_{\mathrm{zen}}\right]-1\right)\right)
\end{aligned}
$$

Option 3: sub-daily approximation from Yajima and Yamamoto (2015)

$$
\begin{aligned}
\alpha_{\mathrm{SW}}= & \max \left[0.02,0.001 f_{\mathrm{RH}} \mathrm{RH}_{x}\left(1-\cos \left[\Phi_{\text {zen }}\right]\right)^{0.33}\right. \\
& -0.001 U_{10}\left(1-\cos \left[\Phi_{\text {zen }}\right]\right)^{-0.57}-0.001 \varsigma \\
& \left.\left(1-\cos \left[\Phi_{\text {zen }}\right]\right)^{0.829}\right]
\end{aligned}
$$

Option 4: daily approximation from Grischenko look-up table in Cogley (1979)

$\alpha_{\mathrm{SW}}=\alpha_{\mathrm{SW}_{G}}[$ Lat,$d]$

Here, $\Phi_{\text {zen }}$ is the solar zenith angle (radians) as outlined in Appendix A, $\mathrm{RH}_{x}$ is the relative humidity, $\varsigma$ is the percentage of atmospheric diffuse radiation, $d$ is the day of year, and $U_{10}$ is wind speed. The second (oceanic) and third (lacustrine) options are included to allow for diel and seasonal variation of albedo from approximately 0.01 to 0.4 depending on the sun angle (Fig. 3). Option 4 may be better for higher-latitude sites; also note that albedo is calculated separately during ice cover conditions using a customized algorithm, as outlined below in Sect. 2.4.

The depth of penetration of shortwave radiation into the lake is wavelength specific and depends on the water clarity via the light extinction coefficient, $K_{\mathrm{w}}\left(\mathrm{m}^{-1}\right)$. Two approaches are supported in GLM. The first option assumes that the photosynthetically active radiation (PAR) fraction of the incoming light is the most penetrative and follows the BeerLambert law:

$\phi_{\mathrm{PAR}}[z]=f_{\mathrm{PAR}} \phi_{\mathrm{SW}_{0}} \exp \left[-K_{\mathrm{w}} z\right]$

where $z$ is the depth of any layer from the surface. $K_{\mathrm{w}}$ may be set by the user as constant, read in from a time series file, or linked with the water quality model (e.g. FABM

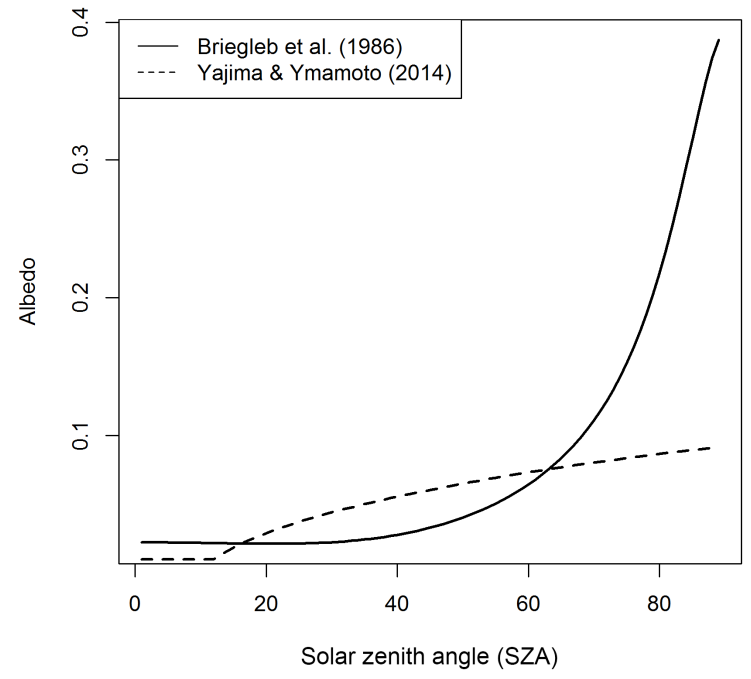

Figure 3. Variation of albedo $\left(\alpha_{\mathrm{SW}}\right)$ with solar zenith angle (SZA $=\Phi_{\text {zen }} 180 / \pi$, degrees) for options 2 and 3 (Eq. 13). For option 3 , settings of $\mathrm{RH}_{x}=80 \%$ and $U_{10}=6 \mathrm{~m} \mathrm{~s}^{-1}$ were assumed.

or AED2; see Sect. 4); in the latter case the extinction coefficient will change as a function of depth and time according to the concentration of dissolved and particulate constituents. For this option Beer's law is only applied for the photosynthetically active fraction, $f_{\mathrm{PAR}}$, which is set as $45 \%$ of the incident light. The amount of radiation heating the surface layer, $\phi_{\mathrm{SW}_{\mathrm{S}}}$, is therefore the photosynthetically active fraction that is attenuated across $z_{\mathrm{s}}$, plus the entire $\left(1-f_{\mathrm{PAR}}\right)$ fraction, $\phi_{\mathrm{SW}_{\mathrm{S}}}=\phi_{\mathrm{SW}_{0}}-\phi_{\mathrm{PAR}}\left[z_{\mathrm{s}}\right]$, which implicitly assumes that the near-infrared and ultraviolet bandwidths of the incident shortwave radiation have significantly higher attenuation coefficients (Kirk, 1994). The second option adopts a more complete light absorption algorithm that integrates the attenuated light intensity across the bandwidth spectrum:

$c_{\mathrm{w}} \rho_{i} \Delta z_{i} \frac{\mathrm{d} T_{i}}{\mathrm{~d} t}=\sum_{l=1}^{N_{\mathrm{SW}}} \phi_{\mathrm{SW}_{i_{l}}}\left[z_{i}\right]-\sum_{l=1}^{N_{\mathrm{SW}}} \phi_{\mathrm{SW}_{i-1_{l}}}\left[z_{i-1}\right]$,

where $l$ is the bandwidth index and $\phi_{\mathrm{SW}_{i_{l}}}\left[z_{i}\right]$ is the radiation flux at the top of the $i$ th layer for the $l$ th bandwidth fraction. For this option, the model by Cengel and Ozisk (1984) is adopted to compute the penetration of individual bandwidth fractions, which more comprehensively resolves the incident and diffuse radiation components of the light climate, taking into account the angle of incident light, transmission across the light surface (based on the Fresnel equations), and reflection off the bottom. These processes are wavelength specific and the user specifies the number of simulated bandwidths, $N_{\mathrm{SW}}$, their respective absorption coefficients, $K_{\mathrm{w}_{l}}$, and reflectivity of light at the sediment, $\alpha_{\text {sed }}$.

The light reaching the benthos is relevant in some applications as an indicator of benthic productivity or as a proxy 
for the type of benthic habitat that might emerge. In addition to the light profiles, GLM therefore predicts the benthic area of the lake in which light intensity exceeds a user-defined fraction of the surface irradiance, $f_{\mathrm{BEN}_{\text {crit }}}$, (Fig. 4):

$A_{\mathrm{BEN}}=A_{\mathrm{S}}-A\left[h_{\mathrm{BEN}}\right]$,

where $h_{\mathrm{BEN}}=h_{\mathrm{S}}-z_{\mathrm{BEN}}, z_{\mathrm{BEN}}$ is calculated from Beer's law,

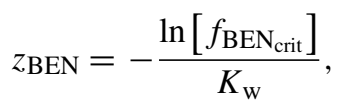

and the daily average benthic area above the threshold is then reported as a percentage $\left(100 \times A_{\mathrm{BEN}} / A_{\mathrm{s}}\right)$.

\subsubsection{Longwave radiation}

Longwave radiation can be provided as a net flux, an incoming flux, or, if there are no radiation data from which longwave radiation can be computed, then it may be calculated by the model internally from the cloud cover fraction and air temperature. Net longwave radiation is described as

$\phi_{\mathrm{LW}_{\text {net }}}=\phi_{\mathrm{LW}_{\text {in }}}-\phi_{\mathrm{LW}_{\text {out }}}$,

where

$\phi_{\mathrm{LW}_{\mathrm{out}}}=\varepsilon_{\mathrm{W}} \sigma\left(\theta_{\mathrm{S}}\right)^{4} ;$

$\sigma$ is the Stefan-Boltzmann constant and $\varepsilon_{\mathrm{W}}$ the emissivity of the water surface, assumed to be 0.985 . If the net or incoming longwave flux is not provided, the model will compute the incoming flux from

$\phi_{\mathrm{LW}_{\text {in }}}=\left(1-\alpha_{\mathrm{LW}}\right) \varepsilon_{\mathrm{a}}^{*} \sigma\left(\theta_{\mathrm{a}}\right)^{4}$,

where $\alpha_{\mathrm{LW}}$ is the longwave albedo (0.03). The emissivity of the atmosphere can be computed considering emissivity for cloud-free conditions $\left(\varepsilon_{\mathrm{a}}\right)$ based on air temperature $\left(T_{\mathrm{a}}\right)$ and vapour pressure and extended to account for reflection from clouds such that $\varepsilon_{\mathrm{a}}^{*}=f\left[T_{\mathrm{a}}, e_{\mathrm{a}}, C_{x}\right]$ (see Henderson-Sellers, 1986; Flerchinger et al., 2009). Options adapted from a range of authors include the following:

$$
\begin{aligned}
& \varepsilon_{\mathrm{a}}^{*}= \\
& \left\{\begin{array}{l}
\text { Option } 1: \text { Idso and Jackson }(1969) \\
\left(1+0.275 C_{x}\right)\left(1-0.261 \exp \left[-0.000777 T_{\mathrm{a}}^{2}\right]\right) \\
\text { Option } 2: \text { Swinbank }(1963) \\
\left(1+0.17 C_{x}^{2}\right)\left(9.365 \times 10^{-6}\left(\theta_{\mathrm{a}}\right)^{2}\right), \\
\text { Option } 3: \text { Brutsaert }(1975) \\
\left(1+0.275 C_{x}\right) 1.24\left(e_{\mathrm{a}} / \theta_{\mathrm{a}}\right)^{1 / 7}, \\
\text { Option } 4: \text { Yajima and Yamamoto }(2015) \\
\left(1-C_{x}^{2.796}\right) 1.24\left(e_{\mathrm{a}} / \theta_{\mathrm{a}}\right)^{1 / 7}+0.955 C_{x}^{2.796},
\end{array}\right.
\end{aligned}
$$

where $C_{x}$ is the cloud cover fraction $(0-1)$ and $e_{\mathrm{a}}$ the air vapour pressure calculated from relative humidity. Note that cloud cover is typically reported in octals $(0-8)$, and thus a value of 1 would correspond to a fraction of 0.125 . Some data may also include cloud type and their respective heights. If this is the case, good correspondence has been reported by averaging the octal values for all cloud types to get an average cloud cover.

If longwave radiation data do not exist and cloud data are also not available, but solar irradiance is measured, then GLM rad_mode setting 3 will instruct the model to compare the measured and theoretical clear-sky solar irradiance (estimated by the BCSM; Eq. 11) to approximate the cloud cover fraction by assuming that $\phi_{\mathrm{SW}_{x}} / \hat{\phi}_{\mathrm{SW}}=f\left[C_{x}\right]$. Note that if neither shortwave or longwave radiation is provided, then the model will use the BCSM to compute incoming solar irradiance, and cloud cover will be assumed to be 0 (noting that this is likely to overestimate downwelling shortwave radiation).

\subsubsection{Sensible and latent heat transfer}

The model accounts for the surface fluxes of sensible heat and latent heat using commonly adopted bulk aerodynamic formulae. For sensible heat,

$\phi_{\mathrm{H}}=-\rho_{\mathrm{a}} c_{\mathrm{a}} C_{\mathrm{H}} U_{10}\left(T_{\mathrm{s}}-T_{\mathrm{a}}\right)$,

where $c_{\mathrm{a}}$ is the specific heat capacity of air, $C_{\mathrm{H}}$ is the bulk aerodynamic coefficient for sensible heat transfer, $T_{\mathrm{a}}$ the air temperature, and $T_{\mathrm{S}}$ the temperature of the water surface layer. The air density $\left(\mathrm{kg} \mathrm{m}^{-3}\right)$ is computed from $\rho_{\mathrm{a}}=0.348(1+r) /(1+1.61 r) p / T_{\mathrm{a}}$, where $p$ is air pressure (hPa) and $r$ is the water vapour mixing ratio, which is used to compute the gas constant.

For latent heat,

$\phi_{\mathrm{E}}=-\rho_{\mathrm{a}} C_{\mathrm{E}} \lambda_{\mathrm{V}} U_{10} \frac{\omega}{p}\left(e_{\mathrm{s}}\left[T_{\mathrm{S}}\right]-e_{\mathrm{a}}\left[T_{\mathrm{a}}\right]\right)$,

where $C_{\mathrm{E}}$ is the bulk aerodynamic coefficient for latent heat transfer, $e_{\mathrm{a}}$ the air vapour pressure, $e_{\mathrm{S}}$ the saturation vapour pressure $(\mathrm{hPa})$ at the surface layer temperature $\left({ }^{\circ} \mathrm{C}\right), \omega$ the ratio of the molecular mass of water to the molecular mass of dry air $(=0.622)$, and $\lambda_{\mathrm{v}}$ the latent heat of vaporization. The vapour pressure is calculated by the linear formula from Tabata (1973):

$e_{\mathrm{S}}\left[T_{\mathrm{S}}\right]=10^{\left(9.28603523-\frac{2322.37885}{T_{\mathrm{S}}+273.15}\right)}$

and

$e_{\mathrm{a}}\left[T_{\mathrm{a}}\right]=\left(f_{\mathrm{RH}} \mathrm{RH}_{x} / 100\right) e_{\mathrm{S}}\left[T_{\mathrm{a}}\right]$

The net heat fluxes for the example lakes are shown in Fig. 5. 

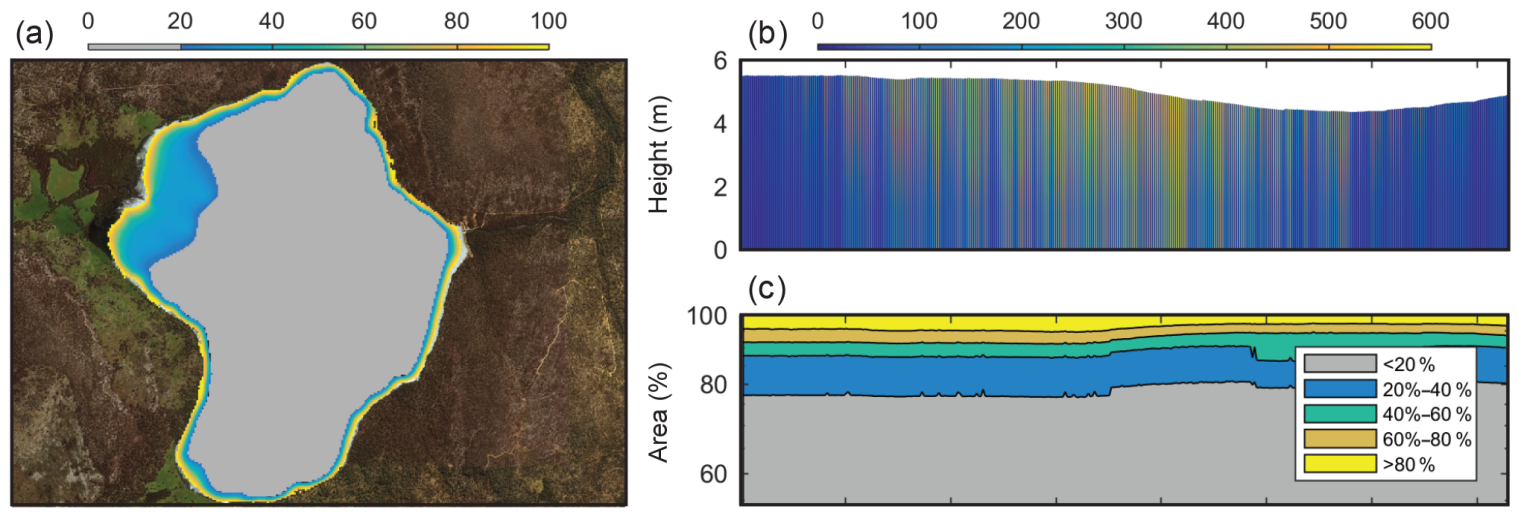

(c)

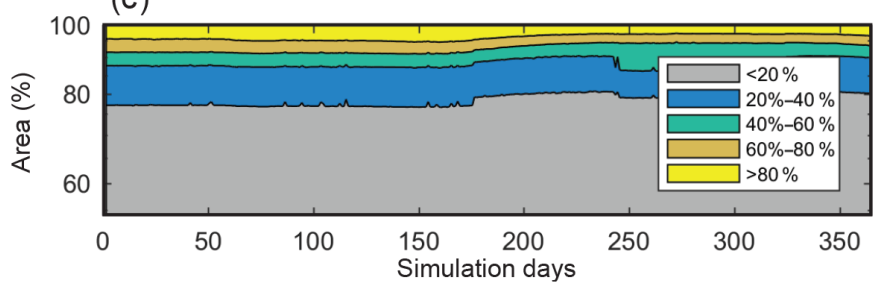

Figure 4. Example light data outputs from a GLM application to Woods Lake, Australia, showing (a) the ratio of benthic to surface light, $100 \phi_{\mathrm{PAR}_{\mathrm{BEN}}} / \phi_{\mathrm{SW}_{0}}(\%)$, overlain on the lake map based on the bathymetry, with the area where $f_{\mathrm{BEN}_{\text {crit }}}<0.2$ (i.e. less than $20 \%$ of surface irradiance) depicted in grey, (b) a time series of the depth variation in light $\left(\mathrm{W} \mathrm{m}^{-2}\right)$, and (c) a time series of $A_{\mathrm{BEN}} / A_{\mathrm{S}}$ (as \%) for various $f_{\mathrm{BEN}_{\text {crit }}}$. Note that the 2-D projection of the 1-D lake model in (a) can assist in managing the lake condition but assumes uniformity of $K_{\mathrm{w}}$.

\section{Correction for non-neutral atmospheric stability}

For long time integrations (e.g. seasonal), the bulk-transfer coefficients for momentum, $C_{\mathrm{D}}$, sensible heat, $C_{\mathrm{H}}$, and latent heat, $C_{\mathrm{E}}$, can be assumed approximately constant because of the negative feedback between surface forcing and the temperature response of the waterbody (e.g. Strub and Powell, 1987). At finer timescales (hours to weeks), the thermal inertia of the waterbody is too great, so the transfer coefficients should be specified as a function of the degree of atmospheric stratification experienced in the internal boundary layer that develops over the water (Woolway et al., 2017). Monin and Obukhov (1954) parameterized the stratification in the air column using the now well-known stability parameter, $z / L$, which is used to define corrections to the bulk aerodynamic coefficients $C_{\mathrm{H}}$ and $C_{\mathrm{E}}$ using the numerical scheme presented in Appendix B. The corrections may be optionally applied within a simulation, and if enabled, the transfer coefficients used above are automatically updated. To ensure that the data provided are from within the internal boundary layer over the lake surface, users should preferably provide wind speed, air temperature, and relative humidity data that have been collected over the lake surface (at a height of 2-10 m, depending on lake size), supplied at approximately hourly resolution.

\section{Wind sheltering}

Wind sheltering may be important depending on the lake size and shoreline complexity and is parameterized according to several methods based on the context of the simulation and data available. For example, Hipsey and Sivapalan (2003) presented a simple adjustment to the bulk-transfer equation to account for the effect of wind sheltering in small reser- voirs using a shelter index to account for the length scale associated with the vertical obstacle relative to the horizontal length scale associated with the waterbody itself. Markfort et al. (2010) estimate the effect of a similar sheltering length scale on the overall lake area calculated based on surrounding topography and canopy heights relative to the water surface. Therefore, within GLM, users may specify the degree of sheltering or fetch limitation using either constant or direction-specific options for computing an "effective" area.

$$
\begin{aligned}
& A_{\mathrm{E}}= \\
& A_{\mathrm{S}}, \\
& \text { Option 0: no sheltering (default) } \\
& A_{\mathrm{S}} \tanh \left[\frac{A_{\mathrm{S}}}{A_{\mathrm{WS}}}\right], \\
& \text { Option 2: Markfort et al. }(2010) \\
& \frac{L_{\mathrm{D}}^{2}}{2} \arccos \left[\frac{x_{\mathrm{WS}}^{\Phi}}{L_{\mathrm{D}}}\right]-\frac{x_{\mathrm{WS}}^{\Phi}}{2} \sqrt{L_{\mathrm{D}}^{2}-\left(x_{\mathrm{WS}}^{\Phi}\right)^{2}}, \\
& \text { Option 3: user-defined shelter index } \\
& f_{\mathrm{WS}}\left[\Phi_{\mathrm{wind}}\right] A_{\mathrm{S}},
\end{aligned}
$$

Here, $A_{\mathrm{Ws}}$ is a user-defined critical lake area for wind sheltering to dominate, $x_{\mathrm{WS}}$ is a user-defined sheltering distance, and $L_{\mathrm{D}}$ the lake diameter $\left(L_{\mathrm{D}}=0.5\left(L_{\text {crest }}+W_{\text {crest }}\right)\right)$. For option 1 , the sheltering factor is held constant for the simulation 
based on the size of the lake, whereas options 2 and 3 require users to additionally input wind direction data and a direction function, $f_{\mathrm{WS}}\left[\Phi_{\text {wind }}\right]$, to allow for a variable sheltering effect over time. In the case of option 2, this function scales the sheltering distance, $x_{\mathrm{WS}}$, as a function of wind direction, $x_{\mathrm{WS}}^{\Phi}=x_{\mathrm{WS}}\left(1-\min \left(f_{\mathrm{WS}}\left[\Phi_{\mathrm{wind}}\right], 1\right)\right)$, whereas in the case of option 3 the function reads in an effective area scaling fraction directly based on a precalculated shelter index.

The ratio of the effective area to the total area of the lake, $A_{\mathrm{E}} / A_{\mathrm{S}}$, is then used to scale the wind speed data input by the user, $U_{x}$, as a means of capturing the average wind speed over the entire lake surface such that $U_{10}=f_{U} U_{x} A_{\mathrm{E}} / A_{\mathrm{S}}$, where $f_{U}$ is a wind speed adjustment factor that can be used to assist calibration or to correct the raw wind speed data to the reference height of $10 \mathrm{~m}$.

\section{Still-air limit}

The above formulations apply when sufficient wind exists to create a defined boundary layer over the surface of the water. As the wind tends to zero (the "still-air limit"), Eqs. (22)(23) become less appropriate as they do not account for free convection directly from the water surface. This is a relatively important phenomenon for small lakes, cooling ponds, and wetlands since they tend to have small fetches that limit the energy input from wind. These waterbodies may also have large areas sheltered from the wind and will develop surface temperatures warmer than the atmosphere for considerable periods. Therefore, users can optionally augment Eqs. (22)-(23) with calculations for low wind speed conditions by calculating the evaporative and sensible heat flux values for both the given $U_{10}$ and for an assumed $U_{10}=0$. The chosen value for the surface energy balance (as applied in Eq. 9) is found by taking the maximum value of the two calculations:

$\phi_{X}^{*}=\left\{\begin{array}{l}\text { Option 1: no-sheltering area } \\ \max \left[\phi_{X}, \phi_{X_{0}}\right] \\ \text { Option 2: still-air sheltered area } \\ \max \left[\phi_{X}, \phi_{X_{0}}\right] A_{\mathrm{E}} / A_{\mathrm{S}}+\phi_{X_{0}}\left(A_{\mathrm{S}}-A_{\mathrm{E}}\right) / A_{\mathrm{S}}\end{array}\right.$

where $\phi_{X_{0}}$ is the zero-wind flux for either the evaporative or sensible heat flux ( $\phi_{\mathrm{E}_{0}}$ and $\phi_{\mathrm{H}_{0}}$, respectively) and $\phi_{X}$ is calculated from Eqs. (22)-(23). The two zero-wind-speed heat flux equations are from TVA (1972), but modified to return energy flux in SI units $\left(\mathrm{W} \mathrm{m}^{-2}\right)$.

$$
\begin{aligned}
& \phi_{\mathrm{E}_{0}}=\rho_{\mathrm{s}} \lambda_{\mathrm{v}} \alpha_{\mathrm{e}}\left(\vartheta_{\mathrm{s}}-\vartheta_{\mathrm{a}}\right) \\
& \phi_{\mathrm{H}_{0}}=\alpha_{\mathrm{h}}\left(T_{\mathrm{s}}-T_{\mathrm{a}}\right) \\
& \alpha_{\mathrm{e}}=0.137 f_{0} \frac{K_{\mathrm{air}}}{c_{\mathrm{a}} \rho_{\mathrm{s}}}\left(g \frac{\left|\rho_{\mathrm{a}}-\rho_{o}\right|}{\rho_{\mathrm{a}} \nu_{\mathrm{a}} D_{\mathrm{a}}}\right)^{1 / 3} \\
& \alpha_{\mathrm{h}}=0.137 f_{0} K_{\mathrm{air}}\left(g \frac{\left|\rho_{\mathrm{a}}-\rho_{o}\right|}{\rho_{\mathrm{a}} \nu_{\mathrm{a}} D_{\mathrm{a}}}\right)^{1 / 3}
\end{aligned}
$$

Here, $v=\kappa e / p$, with the appropriate vapour pressure values, $e$, for both surface and ambient atmospheric values. $K_{\text {air }}$ is the molecular heat conductivity of air $\left(\mathrm{J} \mathrm{m}^{-1} \mathrm{~s}^{-1} \mathrm{C}^{-1}\right), v_{\mathrm{a}}$ is the kinematic viscosity of the air $\left(\mathrm{m}^{2} \mathrm{~s}^{-1}\right), \rho_{o}$ is the density of the saturated air at the water surface temperature, $\rho_{\mathrm{S}}$ is the density of the surface water, $f_{0}$ is a dimensionless roughness correction coefficient for the lake surface, and $D_{\mathrm{a}}$ is the molecular heat diffusivity of air $\left(\mathrm{m}^{2} \mathrm{~s}^{-1}\right)$. Note that the impact of low wind speeds on the drag coefficient is captured by the modified Charnock relation (Eqs. B2-B3), which includes an additional term for the smooth flow transition (see also Fig. A1).

\subsection{Snow and ice dynamics}

The extent of ice and snow cover can significantly impact the lake water balance and mixing regime depending on the prevailing environmental conditions. The algorithms for GLM ice and snow dynamics are based on previous ice modelling studies that adopt a three-layer scheme for resolving ice and snow split into blue ice (or black ice), white ice (or snow ice), and snow layers (Patterson and Hamblin, 1988; Gu and Stefan, 1993; Rogers et al., 1995; Vavrus et al., 1996; Launiainen and Cheng, 1998; Magee et al., 2016). Blue ice is formed through direct freezing of lake water into ice, whereas white ice is generated in response to seeping of lake water onto the ice surface when the mass of snow that can be supported by the buoyancy of the ice cover is exceeded (see below; Rogers et al., 1995). The snow layer is subject to compaction and melting based on surface meteorological conditions and the ice layers are affected by the lake water temperature at the lower boundary.

Blue ice initially forms when the water at the lake surface goes below $0^{\circ} \mathrm{C}$. Once fresh snow deposits on the surface it is subject to densification, which depends on the air temperature and amount of rainfall (Fig. 6); the density of fresh snowfall is determined as the ratio of measured snowfall height to water-equivalent height, with any values exceeding the assigned maximum or minimum snow density (defaults: $\rho_{\mathrm{s}, \max }=300 \mathrm{~kg} \mathrm{~m}^{-3}, \rho_{\mathrm{s}, \min }=50 \mathrm{~kg} \mathrm{~m}^{-3}$ ) truncated to the appropriate limit. The snow compaction equation is based on the exponential decay formula of McKay (1968), with the selection of snow compaction parameters based on air temperature and depending on whether rainfall or snowfall is being added. When the weight of snow exceeds the buoyancy of the ice layer,

$$
\begin{aligned}
\Delta z_{\text {snow }} \rho_{\text {snow }}> & \left\{\Delta z_{\text {blue }}\left(\rho_{\mathrm{w}}-\rho_{\text {blue }}\right)\right. \\
& \left.+\Delta z_{\text {white }}\left(\rho_{\mathrm{w}}-\rho_{\text {white }}\right)\right\},
\end{aligned}
$$

the ice will be forced downward and lake water will seep into the snow layer, leading to formation of white ice. This downward movement and white ice formation is limited to the snow amount matching the buoyancy deficit of the ice layer, and the lake height is reduced accordingly. 

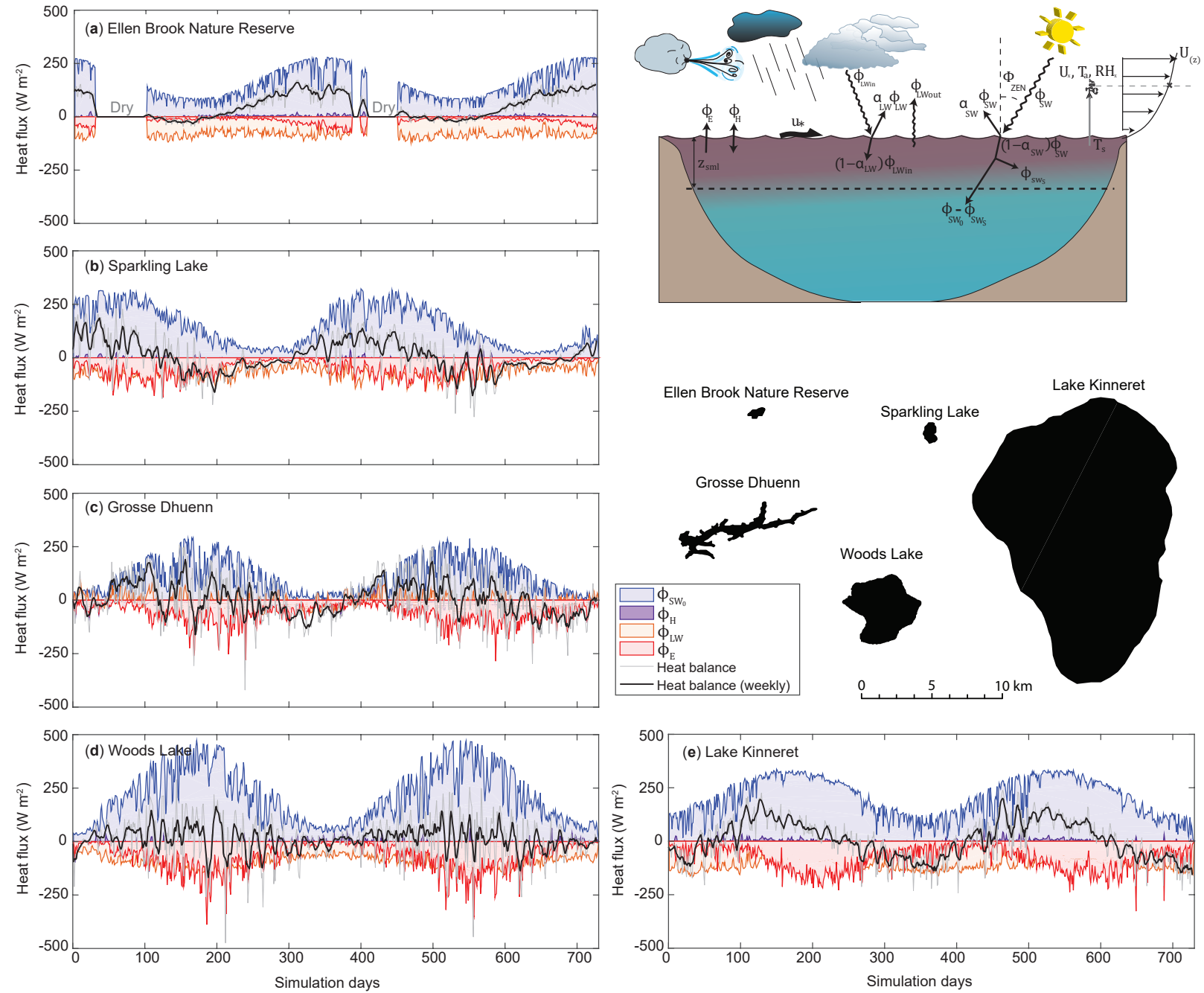

Figure 5. A 2-year times series of the simulated daily heat fluxes for the five example lakes (a-e) that were depicted in Fig. 2. The heat balance components summarized are depicted schematically in the inset, as described in Sect. 2.3, and the "heat balance" line refers to the LHS of Eq. (9).

To capture the changing thickness of the ice and snow layers due to melting or freezing, the model employs a quasisteady-state assumption to solve the heat transfer equation through the layers by assuming that the timescale for heat conduction is short relative to the timescale of changes in meteorological forcing (Patterson and Hamblin, 1988; Rogers et al., 1995). By assigning appropriate boundary conditions at the ice-atmosphere and ice-water interfaces, the model computes the upward conductive heat flux through the ice and snow cover to the atmosphere, termed $\phi_{0}$.

At the upper surface (which could be ice or snow), a heat flux balance is employed to provide the condition for surface melting:

$$
\begin{aligned}
& \phi_{0}\left[T_{0}\right]+\phi_{\text {net }}\left[T_{0}\right]=0 \quad T_{0}<T_{\mathrm{m}}, \\
& \phi_{\text {net }}\left[T_{0}\right]=-\rho_{\text {ice, snow }} \lambda_{\mathrm{f}} \frac{\mathrm{d} \Delta z_{\text {ice, snow }}}{\mathrm{d} t},
\end{aligned}
$$

where $\lambda_{\mathrm{f}}$ is the latent heat of fusion, $\Delta z_{\text {ice, snow }}$ is the height of either the upper snow or ice layer, $\rho_{\text {ice,snow }}$ is the density of the relevant snow or ice layer determined from the surface medium properties, $T_{0}$ is the temperature at the solid surface, and $T_{\mathrm{m}}$ is the meltwater temperature $\left(0^{\circ} \mathrm{C}\right) . \phi_{\text {net }}\left[T_{0}\right]$ is the net incoming heat flux for non-penetrative radiation at the solid surface:

$$
\begin{aligned}
\phi_{\text {net }}\left[T_{0}\right]= & \phi_{\mathrm{LWin}}-\phi_{\mathrm{LWout}}\left[T_{0}\right]+\phi_{\mathrm{H}}\left[T_{0}\right] \\
& +\phi_{\mathrm{E}}\left[T_{0}\right]+\phi_{\mathrm{R}}\left[T_{0}\right],
\end{aligned}
$$

where the heat fluxes between the solid boundary and the atmosphere are calculated as outlined previously, but with modification for the determination of vapour pressure over ice or snow $\left(e_{\text {sice }}\left[T_{0}\right]=e_{\mathrm{s}}\left[T_{0}\right]\left(1+9.72 \times 10^{-3} T_{0}+4.2 \times 10^{-5} T_{0}^{2}\right)\right.$ Jeong, 2009) and the addition of the rainfall heat flux, $\phi_{\mathrm{R}}$, 

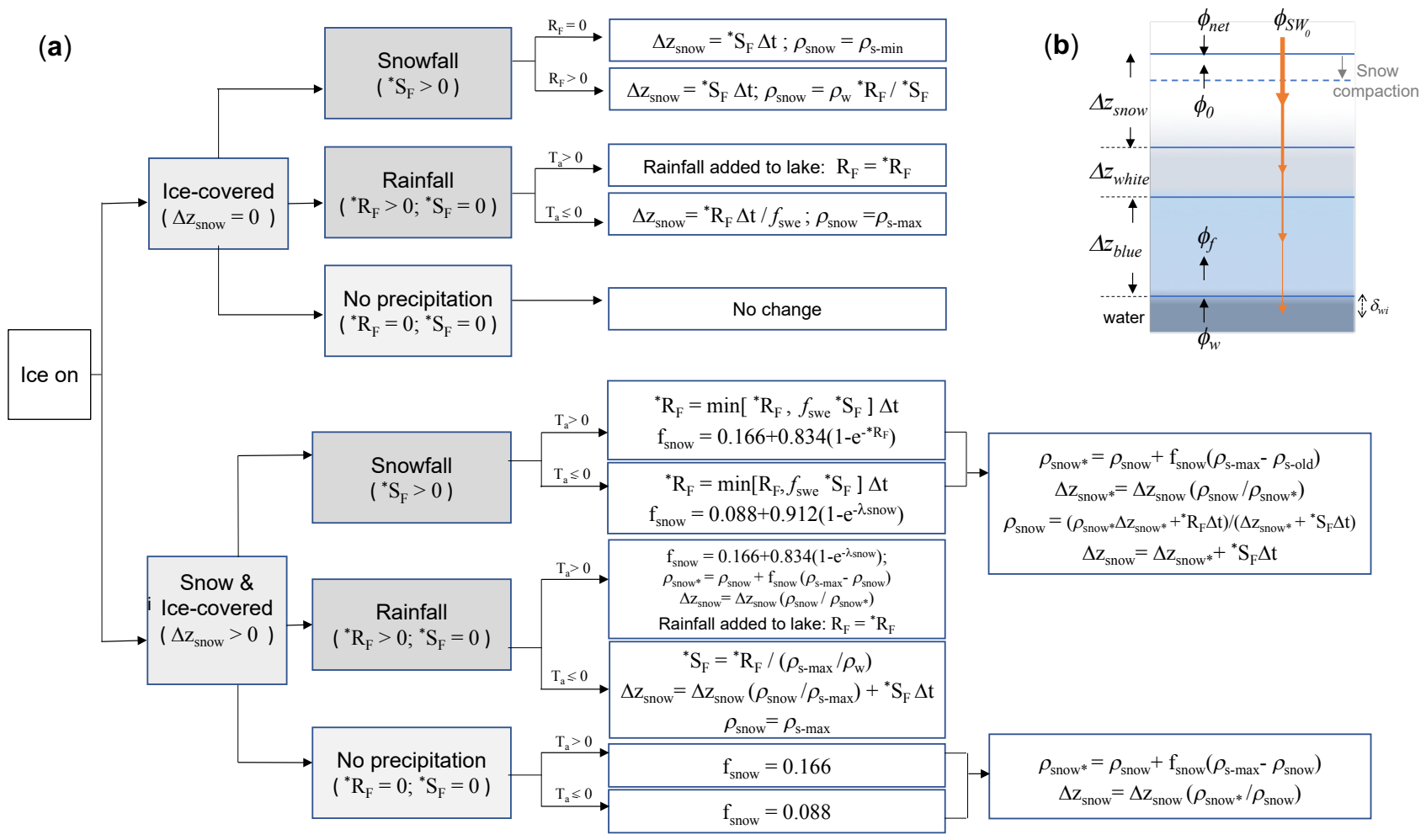

Figure 6. (a) Decision tree describing updates to the snow cover each time step according to the amount of incident rainfall $\left(* R_{\mathrm{F}}\right)$ and snowfall $\left({ }^{*} S_{\mathrm{F}}\right)$, air temperature $\left(T_{\mathrm{a}}\right)$, and snow compaction rules. (b) Schematic of ice and snow layers and heat fluxes. Refer to the text and Table 1 for definitions of other variables. Here, ${ }^{*} R_{\mathrm{F}}=f_{R} R_{x} / c_{\text {secday }}$ and ${ }^{*} S_{\mathrm{F}}=f_{S} S_{x} / c_{\text {secday }}$ if ice cover is present; otherwise they are set to 0 and the model reverts to Eqs. (6)-(7).

( $\phi_{\mathrm{R}}={ }^{*} R_{\mathrm{F}} \rho_{\mathrm{w}} \lambda_{\mathrm{f}}$ to capture the freezing effect if $T_{0}<T_{\mathrm{m}}$ or simply as ${ }^{*} R_{\mathrm{F}} c_{\mathrm{w}} \rho_{\mathrm{W}}\left(T_{\mathrm{a}}-T_{0}\right)$ if $T_{0}=T_{\mathrm{m}}$; Rogers et al., 1995). To determine the flow of heat through the layers, Rogers et al. (1995) derived the following.

$$
\begin{aligned}
& \Lambda\left(\phi_{0}-\phi_{\mathrm{SW}_{0}}\right)=T_{\mathrm{m}}-T_{0} \\
& -\left\{f _ { \mathrm { VIS } _ { \mathrm { S } } } \phi _ { \mathrm { SW } _ { 0 } } \left(\frac{\left(1-e^{-K_{\mathrm{s} 1} \Delta z_{\text {snow }}}\right)}{K_{\mathrm{snow}} K_{\mathrm{s} 1}}\right.\right. \\
& +e^{-K_{\mathrm{s} 1} \Delta z_{\text {snow }}} \frac{\left(1-e^{-K_{\mathrm{w} 1} \Delta z_{\text {white }}}\right)}{K_{\mathrm{w} 1} \Delta z_{\text {white }}}+e^{-K_{\mathrm{s} 1} \Delta z_{\text {snow }}-K_{\mathrm{w} 1} \Delta z_{\text {white }}} \\
& \left.\left.\frac{\left(1-e^{-K_{\mathrm{b} 1} \Delta z_{\text {blue }}}\right)}{K_{\mathrm{b} 1} \Delta z_{\text {blue }}}\right)\right\}-\left\{( 1 - f _ { \mathrm { VIS } } ) \phi _ { \mathrm { SW } _ { 0 } } \left(\frac{\left(1-e^{-K_{\mathrm{s} 2} \Delta z_{\text {snow }}}\right)}{K_{\mathrm{snow}} K_{\mathrm{s} 2}}\right.\right. \\
& +e^{-K_{\mathrm{s} 2} \Delta z_{\text {snow }}} \frac{\left(1-e^{-K_{\mathrm{w} 2} \Delta z_{\text {white }}}\right)}{K_{\mathrm{w} 2} \Delta z_{\text {white }}} \\
& \left.\left.+e^{-K_{\mathrm{s} 2} \Delta z_{\text {snow }}-K_{\mathrm{w} 2} \Delta z_{\text {white }}} \frac{\left(1-e^{-K_{\mathrm{b} 2} \Delta z_{\text {blue }}}\right)}{K_{\mathrm{b} 2} \Delta z_{\text {blue }}}\right)\right\} \\
& +\phi_{\text {si }} \Delta z_{\text {snow }} \Lambda-\frac{\phi_{\text {si }} \Delta z_{\text {snow }}^{2}}{2 K_{\text {snow }}}
\end{aligned}
$$

Here, $\Lambda=\left(\frac{\Delta z_{\text {snow }}}{K_{\text {snow }}}+\frac{\Delta z_{\text {white }}}{K_{\text {white }}}+\frac{\Delta z_{\text {blue }}}{K_{\text {blue }}}\right), \phi_{\mathrm{SW}_{0}}$ is the shortwave radiation penetrating the ice-snow surface, $K$ refers to the light attenuation coefficient of the ice and snow components designated with subscripts $\mathrm{s}, \mathrm{w}$, and $\mathrm{b}$ for snow, white ice, and blue ice, respectively, and the $\Delta z$ terms refer to the thickness of snow, white ice, and blue ice. This is rearranged and solved for $T_{0}$ and $\phi_{0}$ by using a bilinear iteration until surface heat fluxes are balanced (i.e. $\left.\phi_{0}\left[T_{0}\right]=-\phi_{\text {net }}\left[T_{0}\right]\right)$ and $T_{0}$ is stable $\left( \pm 0.001{ }^{\circ} \mathrm{C}\right)$. In the presence of ice (or snow) cover, a surface temperature $T_{0}>T_{\mathrm{m}}$ indicates that energy is available for melting. The amount of energy for melting is calculated by setting $T_{0}=T_{\mathrm{m}}$ to determine the reduced thickness of snow or ice (as shown in Eq. 32). The estimation of $\phi_{0}$ applies an empirical equation to estimate snow conductivity, $K_{\text {snow }}$, from its density (Ashton, 1986):

$K_{\text {snow }}=0.021+0.0042 \rho_{\text {snow }}+\left(2.2 \times 10^{-9} \rho_{\text {snow }}^{3}\right)$.

The heat flux in the ice at the ice-water interface is

$$
\begin{aligned}
\phi_{\mathrm{f}} & =\phi_{0}-f_{\mathrm{VIS}} \phi_{\mathrm{SW}_{0}}\left(1-\exp \left[-K_{\mathrm{s} 1} \Delta z_{\text {snow }}-K_{\mathrm{w} 1} \Delta z_{\text {white }}\right.\right. \\
& \left.\left.-K_{\mathrm{b} 1} \Delta z_{\text {blue }}\right]\right)-\left(1-f_{\mathrm{VIS}}\right) \phi_{\mathrm{SW}_{0}}\left(1-\exp \left[-K_{\mathrm{s} 2} \Delta z_{\text {snow }}\right.\right. \\
& \left.\left.-K_{\mathrm{w} 2} \Delta z_{\text {white }}-K_{\mathrm{b} 2} \Delta z_{\text {blue }}\right]\right)-\phi_{\mathrm{si}} \Delta z_{\text {snow }},
\end{aligned}
$$

where $\phi_{\mathrm{si}}$ is a volumetric heat flux for the formation of white ice, which is given in Eq. (14) of Rogers et al. (1995), and ice 
and snow light attenuation coefficients in GLM are also fixed to the same values as those given by Rogers et al. (1995). Shortwave albedo for the ice or snow surface (required for Eq. 10) is a function of surface medium (see Table 1 of Vavrus et al., 1996) with values varying from 0.08 to 0.6 for ice and from 0.08 to 0.7 for snow, depending on the surface temperature and the layer thicknesses; an additional scaling factor for the snow albedo, $f_{\alpha}$, is also implemented to aid calibration.

Accretion or ablation of blue ice occurs at the ice-water boundary based on the conductive heat flux from water into the ice, $\phi_{\mathrm{w}}$, as given by the finite-difference approximation:

$\phi_{\mathrm{w}}=-K_{\mathrm{water}} \frac{\Delta T}{\delta_{\mathrm{wi}}}$,

where $K_{\text {water }}$ is the molecular conductivity of water (assuming the water is stagnant under the ice), and $\Delta T$ is the temperature difference between the surface water of the lake and the bottom of the blue ice layer, $T_{\mathrm{m}}-T_{\mathrm{s}}$. This occurs across an assigned length scale, $\delta_{w i}$, for which a value of $0.1-0.5 \mathrm{~m}$ is usual based on the reasoning given in Rogers et al. (1995) and the typical vertical water layer resolution of a model simulation (0.125-1.5 m). Note that a wide variation in techniques and values is used to determine the basal heat flux immediately beneath the ice pack (e.g. Harvey, 1990), which suggests that this may need careful consideration during calibration.

The imbalance between $\phi_{\mathrm{f}}$ moving through the blue ice layer and the heat flux from the water into the ice, $\phi_{\mathrm{w}}$, gives the rate of change of ice thickness at the interface with water:

$$
\frac{\mathrm{d} \Delta z_{\text {blue }}}{\mathrm{d} t}=\frac{\phi_{\mathrm{f}}-\phi_{\mathrm{w}}}{\rho_{\text {blue }} \lambda_{\mathrm{f}}} .
$$

The ice thickness is set to its minimum value of $0.05 \mathrm{~m}$, which is suggested by Patterson and Hamblin (1988) and Vavrus et al. (1996). The need for a minimum ice thickness relates primarily to horizontal variability of the ice cover during formation and closure (ice-on) periods. The ice cover equations are discontinued and open water conditions are restored in the model when the thermodynamic balance first produces ice thickness $<0.05 \mathrm{~m}$. Example outputs are shown in Fig. 7; see also Yao et al. (2014) for a previous application.

\subsection{Sediment heating}

The water column thermal budget may also be affected by heating or cooling from the soil-sediment below. For each layer, the rate of temperature change depends on the temperature gradient and the relative area of the layer volume in contact with bottom sediment:

$c_{\mathrm{w}} \rho_{i} \Delta V_{i} \frac{\mathrm{d} T_{i}}{\mathrm{~d} t}=K_{\text {soil }} \frac{\left(T_{z_{i}}-T_{i}\right)}{\delta z_{\text {soil }}}\left(A_{i}-A_{i-1}\right)$,

where $K_{\text {soil }}$ is the soil-sediment thermal conductivity and $\delta z_{\text {soil }}$ is the length scale associated with the heat flux. The temperature of the bottom sediment varies seasonally and also depending on its depth below the water surface such that

$T_{z_{i}}=T_{z_{\text {mean }}}+\delta T_{z} \cos \left[\frac{2 \pi}{365}\left(d-d_{T_{z}}\right)\right]$

where $z$ is the soil-sediment zone that the $i$ th layer overlays (see Sect. 4 for details), $T_{z}$ is the temperature of this zone, $T_{z_{\text {mean }}}$ is the annual mean sediment zone temperature, $\delta T_{z}$ is the seasonal amplitude of the sediment temperature variation, and $d_{T_{z}}$ is the day of the year when the sediment temperature peaks. By defining different sediment zones, the model can therefore allow for a different mean and amplitude of littoral waters compared to deeper waters. A dynamic sediment temperature diffusion model is also under development, which will be suitable when empirical data for the above parameters in Eq. (40) are not available.

\subsection{Stratification and vertical mixing}

Mixing processes in lakes are varied and depend upon the degree of meteorological and hydrological forcing, the lake morphometry, and the nature of thermal stratification experienced by the lake at the time of forcing. Numerous models adopt an eddy-diffusivity approach whereby mixing is captured using the advection-dispersion equation (e.g. Riley and Stefan, 1988). GLM adopts an energy balance approach as used in DYRESM whereby the mixing dynamics are based on estimating the amount of turbulent energy available, which is separately computed for the surface mixed layer (surface mixing) and for mixing below the thermocline (deep mixing).

\subsubsection{Surface mixed layer}

To compute mixing of layers, GLM works on the premise that the balance between the available energy, $E_{\mathrm{TKE}}$, and the energy required for mixing to occur, $E_{\mathrm{PE}}$, provides the surface mixed layer (SML) deepening rate $\mathrm{d} z_{\mathrm{SML}} / \mathrm{d} t$, where $z_{\mathrm{SML}}$ is the depth from the surface to the bottom of the surface mixed layer. For an overview of the dynamics, readers are referred to early works on bulk mixed layer depth models by Kraus and Turner (1967) and Kim (1976), which were subsequently extended by Imberger and Patterson (1981) and Spigel et al. (1986) as a basis for hydrodynamic model design. Using this approach, the available kinetic energy is calculated due to contributions from wind stirring, convective overturn, shear production between layers, and Kelvin-Helmholtz $(\mathrm{K}-\mathrm{H})$ billowing. Overall, the turbulent energy generated for mixing is summarized as (Hamilton and Schladow, 1997)

$$
E_{\mathrm{TKE}}=\underbrace{0.5 C_{\mathrm{K}}\left(w_{*}^{3}\right) \Delta t}_{\text {convective overturn }}+\underbrace{0.5 C_{\mathrm{K}}\left(C_{\mathrm{W}} u_{*}^{3}\right) \Delta t}_{\text {wind stirring }}
$$



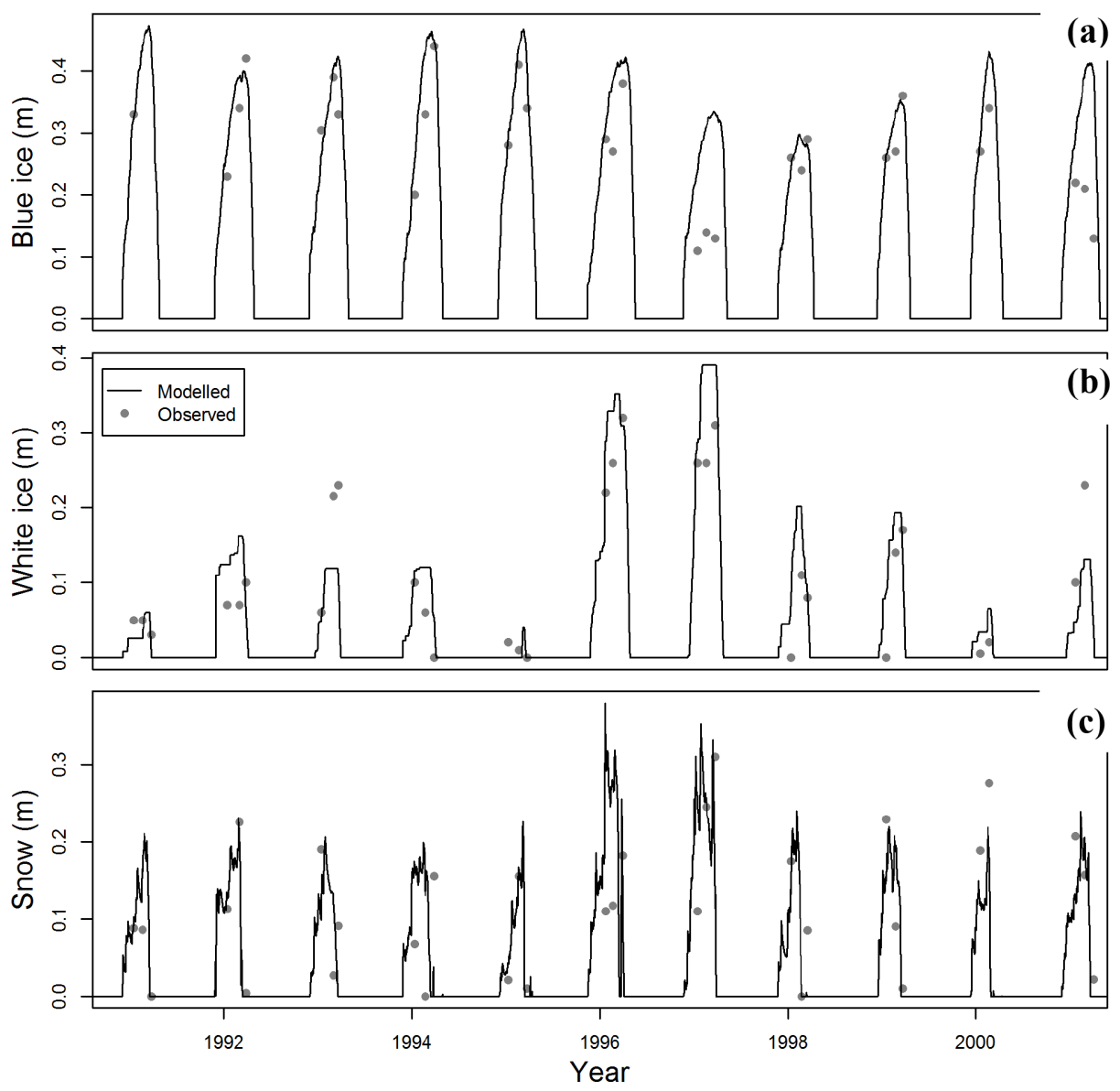

Figure 7. Example of modelled and observed thickness of (a) blue ice, $\Delta z_{\text {blue }}$, (b) white ice, $\Delta z_{\text {white }}$, and (c) snow, $\Delta z_{\text {snow }}$, for Sparkling Lake, Wisconsin. Points are the average observed thicknesses.

$$
\underbrace{0.5 C_{\mathrm{S}}\left[u_{\mathrm{b}}^{2}+\frac{u_{\mathrm{b}}^{2}}{6} \frac{d \delta_{\mathrm{KH}}}{\mathrm{d} z_{\mathrm{SML}}}+\frac{u_{\mathrm{b}} \delta_{\mathrm{KH}}}{3} \frac{\mathrm{d} u_{\mathrm{b}}}{\mathrm{d} z_{\mathrm{SML}}}\right]}_{\begin{array}{c}
\text { shear production } \\
\mathrm{K}-\mathrm{H} \text { production }
\end{array}} \Delta z_{k-1},
$$

where $\delta_{\mathrm{KH}}$ is the $\mathrm{K}-\mathrm{H}$ billow length scale (described below), $u_{\mathrm{b}}$ is the shear velocity at the interface of the mixed layer, and $C_{\mathrm{K}}, C_{\mathrm{W}}$, and $C_{\mathrm{S}}$ are mixing efficiency constants. For mixing to occur, the energy must be sufficient to lift up water in the layer below the bottom of the mixed layer, denoted here as the layer $k-1$ with thickness $\Delta z_{k-1}$, and accelerate it to the mixed layer velocity, $u_{*}$. This must also account for energy consumption associated with $\mathrm{K}-\mathrm{H}$ billowing. In total, the energy required to entrain a layer into the mixed layer is expressed as $E_{\mathrm{PE}}$ :

$E_{\mathrm{PE}}=[\underbrace{0.5 C_{\mathrm{T}}\left(w_{*}^{3}+C_{\mathrm{W}} u_{*}^{3}\right)^{2 / 3}}_{\text {acceleration }}+\underbrace{\frac{\Delta \rho}{\rho_{o}} g z_{\mathrm{SML}}}_{\text {lifting }}$

$$
+\underbrace{\frac{g \delta_{\mathrm{KH}}^{2}}{24 \rho_{o}} \frac{d(\Delta \rho)}{\mathrm{d} z_{\mathrm{SML}}}+\frac{g \delta_{\mathrm{KH}} \Delta \rho}{12 \rho_{o}} \frac{d \delta_{\mathrm{KH}}}{\mathrm{d} z_{\mathrm{SML}}}}_{\mathrm{K}-\mathrm{H} \text { consumption }}] \Delta z_{k-1},
$$

where $C_{\mathrm{T}}$ is a mixing efficiency constant to account for unsteady turbulence. To numerically resolve Eqs. (41) and (42) the model sequentially computes the different components of the above expressions with respect to the layer structure, thereby checking the available energy relative to the required amount (depicted schematically in Fig. 8). GLM follows the sequence of the algorithm presented in detail in Imberger and Patterson (1981), whereby layers are combined due to convection and wind stirring first, and then the resultant mixed layer properties are used when subsequently computing the extent of shear mixing and the effect of $\mathrm{K}-\mathrm{H}$ instabilities. Plots indicating the role of mixing in shaping the thermal structure of the example lakes are shown in Fig. 9.

To compute the mixing energy available due to convection, in the first step, the value for $w_{*}$ is calculated, which is the turbulent velocity scale associated with convection 
brought about by cooling at the air-water interface. The model adopts the algorithm used in Imberger and Patterson (1981), whereby the potential energy that would be released by mixed layer deepening is computed from the first moment of layer masses in the epilimnion (surface mixed layer) about the lake bottom relative to the well-mixed condition. This is numerically computed by summing from the bottom-most layer of the epilimnion, $k$, up to $N_{\mathrm{LEV}}$ :

$w_{*}^{3}=\frac{g}{\rho_{\mathrm{SML}} \Delta t} \sum_{i=k}^{N_{\mathrm{LEV}}}\left[\left(\rho_{i} \Delta z_{i}\right)\left(\widetilde{h_{i}}-\widetilde{h_{\mathrm{SML}}}\right)\right]$,

where $\rho_{\mathrm{SML}}$ is the mean density of the mixed layer including the combined layer, $\rho_{i}$ is the density of the $i$ th layer, $\Delta \mathrm{z}_{i}$ is the height difference between two consecutive layers within the loop $\left(\Delta z_{i}=h_{i}-h_{i-1}\right), \widetilde{h_{i}}$ is the mean height of layers to be mixed $\left(\widetilde{h_{i}}=0.5\left[h_{i}+h_{i-1}\right]\right)$, and $\widetilde{h_{\mathrm{SML}}}$ is the epilimnion mid-height calculated as $h_{\mathrm{SML}}=0.5\left(h_{\mathrm{S}}+h_{k-1}\right)$, where $h_{\mathrm{S}}$ is the height of the surface water level.

The velocity scale $u_{*}$ of the surface layer is associated with wind stress and calculated according to the wind strength:

$u_{*}^{2}=\frac{\rho_{\mathrm{a}}}{\rho_{\mathrm{SML}}} C_{\mathrm{D}} U_{10}^{2}$,

where $C_{\mathrm{D}}$ is the drag coefficient for momentum. The model first checks to see if the energy available (Eqs. 43 and 44) can overcome the energy required to mix the $k-1$ layer into the surface mixed layer (Fig. 8e); i.e. mixing of $k-1$ occurs if

$$
\begin{aligned}
& C_{\mathrm{K}}\left(w_{*}^{3}+C_{\mathrm{W}} u_{*}^{3}\right) \Delta t \geq \\
& \quad\left(g_{k^{\prime}} \mathrm{z}_{\mathrm{SML}}+C_{\mathrm{T}}\left(w_{*}^{3}+C_{\mathrm{W}} u_{*}^{3}\right)^{2 / 3}\right) \Delta z_{k-1},
\end{aligned}
$$

where $g_{k^{\prime}}=g \frac{\Delta \rho}{\rho_{o}}$ is the reduced gravity between the mixed layer and the $k-1$ layer calculated as $g\left(\rho_{\mathrm{SML}}-\rho_{k-1}\right) /\left(0.5\left(\rho_{\mathrm{SML}}+\rho_{k-1}\right)\right)$. If the mixing condition is met, the layers are combined, the energy required to combine the layer is removed from the available energy, $k$ is adjusted, and the loop continues to the next layer. When the mixing energy is substantial and the mixing reaches the bottom layer, the mixing routine ends. If the condition in Eq. (45) is not met, then any residual energy is stored for the next time step, and the mixing algorithm continues as outlined below.

Once stirring is completed, mixing generated due to velocity shear is then accounted for. Parameterizing the shear velocity, denoted $u_{\mathrm{b}}$, in a one-dimensional model can be problematic; however, the approximation used in Imberger and Patterson (1981) is applied:

$u_{\mathrm{b}}= \begin{cases}\frac{u_{*}^{2} \Delta t}{z_{\mathrm{SML}}}+u_{\mathrm{b}_{\mathrm{old}}}, & t \leq t_{\mathrm{b}}+\delta t_{\text {shear }}, \\ 0, & t>t_{\mathrm{b}}+\delta t_{\text {shear }}\end{cases}$

where $u_{\mathrm{b}_{\text {old }}}$ is from the previous time step and zeroed between shear (wind) events. Therefore, this model yields a simple linear increase in the shear velocity over time for a constant wind stress. This is considered relative to $\delta t_{\text {shear }}$, which is the cut-off time beyond which it is assumed that no further shear-induced mixing occurs for that event. This cut-off time assumes the use of only the energy produced by shear at the interface during a period equivalent to half the basin-scale seiche duration, $\delta t_{\text {iw }}$, which can be modified to account for damping (Spigel, 1978):

$\delta t_{\text {shear }}=$
$\begin{cases}1.59 \delta t_{\mathrm{iw}} & \frac{\delta t_{\mathrm{damp}}}{\delta t_{\mathrm{iw}}} \geq 10 \\ \left(1+0.59\left(1-\cosh \left[\frac{\delta t_{\mathrm{damp}}}{\delta t_{\mathrm{iw}}}-1\right]^{-1}\right)\right) \delta t_{\mathrm{iw}} & \frac{\delta t_{\mathrm{damp}}}{\delta t_{\mathrm{iw}}}<10\end{cases}$

where $\delta t_{\text {damp }}$ is the timescale of damping. The wave period is approximated based on the stratification as $\delta t_{\mathrm{iw}}=$ $L_{\text {META }} / 2 c$, where $L_{\text {META }}$ is the length of the basin at the thermocline calculated from $\sqrt{A_{k-1}(4 / \pi)\left(L_{\text {crest }} / W_{\text {crest }}\right)}$, whereby an ellipse shape is assumed and $c$ is the internal wave speed,

$$
c=\sqrt{\left|g_{\mathrm{EH}^{\prime}}\right| \frac{\delta_{\text {epi }} \delta_{\text {hyp }}}{\left(\delta_{\text {epi }}+\delta_{\text {hyp }}\right)}},
$$

where $\delta_{\text {epi }}$ and $\delta_{\text {hyp }}$ are characteristic vertical length scales associated with the epilimnion and hypolimnion:

$\delta_{\text {epi }}=\frac{\Delta V_{\text {epi }}}{0.5\left(A_{\mathrm{s}}+A_{k-1}\right)} ; \delta_{\text {hyp }}=\frac{V_{k-1}}{0.5 A_{k-1}}$,

where $\Delta V_{\text {epi }}$ and $V_{k-1}$ are the associated volumes.

The time for damping of internal waves in a two-layer system can be parameterized by estimating the length scale of the oscillating boundary layer, through which the wave energy dissipates, and the period of the internal standing wave (see Spigel and Imberger, 1980):

$$
\delta t_{\mathrm{damp}}=\frac{\sqrt{\nu_{\mathrm{w}}}}{c_{\mathrm{damp}} \delta_{\mathrm{ss}}} \frac{2\left(\delta_{\mathrm{epi}}+\delta_{\mathrm{hyp}}\right)}{u_{*}^{2}} \sqrt{\frac{c}{2 L_{\mathrm{META}}}} \frac{\delta_{\mathrm{hyp}}}{\delta_{\mathrm{epi}}}\left(\delta_{\mathrm{epi}}+\delta_{\mathrm{hyp}}\right) .
$$

Once the velocity is computed from Eq. (46), the energy for mixing from velocity shear is compared to that required for lifting and accelerating the next layer down, and layers are combined if there is sufficient energy (Fig. 6f), i.e. when

$$
\begin{aligned}
0.5 C_{\mathrm{S}}\left[\frac{u_{\mathrm{b}}^{2}\left(\widetilde{z_{\mathrm{SML}}}+\Delta \delta_{\mathrm{KH}}\right)}{6}+\frac{u_{\mathrm{b}} \delta_{\mathrm{KH}} \Delta u_{\mathrm{b}}}{3}\right] \\
+\left[g_{k^{\prime}} \delta_{\mathrm{KH}}\left(\frac{\delta_{\mathrm{KH}} \Delta z_{k-1}}{24 z_{\mathrm{SML}}}-\frac{\Delta \delta_{\mathrm{KH}}}{12}\right)\right] \\
\geq\left(g_{k^{\prime}} z_{\mathrm{SML}}+C_{\mathrm{T}}\left(w_{*}^{3}+C_{\mathrm{W}} u_{*}^{3}\right)^{2 / 3}\right) \Delta z_{k-1},
\end{aligned}
$$

where the billow length scale is $\delta_{\mathrm{KH}}=C_{\mathrm{KH}} u_{\mathrm{b}}^{2} / g_{\mathrm{EH}^{\prime}}$ and $\Delta \delta_{\mathrm{KH}}=2 C_{\mathrm{KH}} u_{\mathrm{b}} \Delta u_{\mathrm{b}} / g_{\mathrm{EH}^{\prime}}$; in this case the reduced gravity 
is computed from the difference between the bulk epilimnion and hypolimnion waters (Eq. 49), and $C_{\mathrm{KH}}$ is a measure of the billow mixing efficiency.

Once energy from shear mixing is exhausted, the model checks the resultant density interface to see if it remains unstable to shear such that K-H billows would be expected to form, i.e. if the metalimnion thickness is less than the $\mathrm{K}-\mathrm{H}$ length scale, $\delta_{\mathrm{KH}}$. If this condition is met, a six-layer set is created about the thermocline to relax the stratification, set to have a linear density profile over $\delta_{\mathrm{KH}}$ (Fig. $8 \mathrm{~g}$ ), and the surface layer properties are updated.

\subsubsection{Deep mixing}

Mixing below the thermocline in lakes, in the deeper hypolimnion, is modelled using a characteristic vertical diffusivity, $D_{Z}=D_{\varepsilon}+D_{\mathrm{m}}$, where $D_{\mathrm{m}}$ is a constant molecular diffusivity for scalars and $D_{\varepsilon}$ is the turbulent diffusivity. Three hypolimnetic mixing options are possible in GLM including (1) no diffusivity, $D_{Z}=0$, (2) a constant vertical diffusivity $D_{Z}$ over the water depth below the surface mixed layer, or (3) a derivation by Weinstock (1981) used in DYRESM, which is described as being suitable for regions displaying weak or strong stratification, whereby diffusivity increases with dissipation and decreases with heightened stratification. For the constant vertical diffusivity option, the coefficient $C_{\mathrm{HYP}}$ is interpreted as the vertical diffusivity $\left(\mathrm{m}^{2} \mathrm{~s}^{-1}\right)$, i.e. $D_{z}=C_{\mathrm{HYP}}$, and applied uniformly below the surface mixed layer. For the Weinstock (1981) model, the diffusivity varies depending on the strength of stratification and the rate of turbulent dissipation according to

$D_{z}=\frac{C_{\mathrm{HYP}} \varepsilon_{\mathrm{TKE}}}{N^{2}+0.6 k_{\mathrm{TKE}}^{2} u_{*}^{2}}$,

where $C_{\mathrm{HYP}}$ in this case is the mixing efficiency of hypolimnetic TKE ( $\sim 0.8$ in Weinstock, 1981), $k_{\mathrm{TKE}}$ is the turbulence wavenumber defined below, and $u_{*}$ is defined as above. The stratification strength is computed using the Brunt-Väisälä (buoyancy) frequency, $N^{2}$, defined for a given layer $i$ as

$N_{i}^{2}=\frac{g \Delta \rho}{\rho \Delta z} \approx \frac{g\left(\rho_{i-2}-\rho_{i+2}\right)}{\rho_{\mathrm{ref}}\left(h_{i+2}-h_{i-2}\right)}$,

where $\rho_{\text {ref }}$ is the average of the layer densities. This is computed from layer three upwards, averaging over the span of five layers until the vertical density gradient exceeds a set tolerance. $N^{2}$ varies following an approximate normal distribution with height, centred at the height at which the centre of buoyancy is located and computed each time step from the first moment of the vertical $N^{2}$ distribution. Additionally, GLM estimates the vertical length scale associated with 1 standard deviation about the centre of the $N^{2}$ distribution, denoted $\delta z_{\sigma}$.

The diffusivity increases in line with the turbulent dissipation rate. This can be complex to estimate in stratified lakes; however, GLM adopts a simple approach as described in Fischer et al. (1979) in which a "net dissipation" is approximated by assuming that dissipation is in equilibrium with energy inputs from external forcing:

$\varepsilon_{\mathrm{TKE}} \approx \overline{\varepsilon_{\mathrm{TKE}}}=\varepsilon_{\mathrm{WIND}}+\varepsilon_{\mathrm{INFLOW}}$,

which is expanded and calculated per unit mass as

$\bar{\varepsilon} \mathrm{TKE}=\underbrace{\frac{1}{\widetilde{V}_{N^{2}} \bar{\rho}} m C_{\mathrm{D}} \rho_{\mathrm{a}} U_{10}^{3} A_{\mathrm{s}}+}_{\text {rate of working by wind }}$

$\underbrace{\frac{1}{\left(\widetilde{V}_{N^{2}}-\Delta V_{\mathrm{S}}\right) \bar{\rho}} \sum_{I}^{N_{\mathrm{INF}}} g\left(\rho_{\text {ins }_{I}}-\rho_{\text {ins }_{I}}\right) Q_{\text {inf }_{\text {ins }_{I}}}\left(\left(h_{\mathrm{S}}-z_{\text {inf }_{\text {ins }_{I}}}\right)-h_{\text {ins }_{I}-1}\right)}_{\text {rate of work done by inflows }}$,

where $\bar{\rho}=0.5\left(\rho_{1}+\rho_{N_{\mathrm{LEV}}}\right)$ is the mean density of the water column. The work done by inflows is computed based on the flow rate and considers the depth to which the inflow plunges and the difference in density between the inflow water and layer into which it inserts, summed over all configured inflows (refer Sect. 2.7). These sources are normalized over the mass of water contained above the area of mixing. This is estimated as $\widetilde{V}_{N^{2}}$, the fractional volume of the lake that is contained above the height that corresponds to 1 standard deviation below the centre of buoyancy and is therefore the volume of the lake over which $85 \%$ of the $N^{2}$ variance is captured. The turbulence wavenumber, $k_{\mathrm{TKE}}$, is then estimated from

$k_{\mathrm{TKE}}^{2}=\frac{c_{\mathrm{wn}} A_{\mathrm{s}}}{\widetilde{V}_{N^{2}} \Delta z_{\mathrm{SML}}}$,

where $c_{\mathrm{wn}}$ is a coefficient. Since the dissipation is assumed to concentrate close to the level of strongest stratification, the "mean" diffusivity suggested by Eq. (52) is modified to decay exponentially within the layers as they increase their distance from the thermocline:

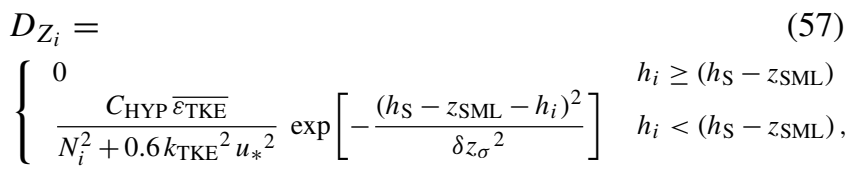

where $\delta z_{\sigma}$ is used to scale the depth over which the mixing is assumed to decay below the bottom of the mixed layer, $h_{\mathrm{S}}-z_{\mathrm{SML}}$.

Once the diffusivity is approximated (either using a constant value or Eq. 57), the diffusion of any scalar, $C$ (including temperature, salinity, and any water quality attributes), between two layers is numerically accounted for by the following mass transfer expressions:

$$
\begin{gathered}
C_{i+1}=\bar{C}-e^{-f_{\mathrm{dif}}} \frac{\Delta z_{i} \Delta C}{\left(\Delta z_{i+1}+\Delta z_{i}\right)}, \\
C_{i}=\bar{C}+e^{-f_{\mathrm{dif}}} \frac{\Delta z_{i+1} \Delta C}{\left(\Delta z_{i+1}+\Delta z_{i}\right)},
\end{gathered}
$$


(a) Initial profile

(b) Heating

(c) Cooling

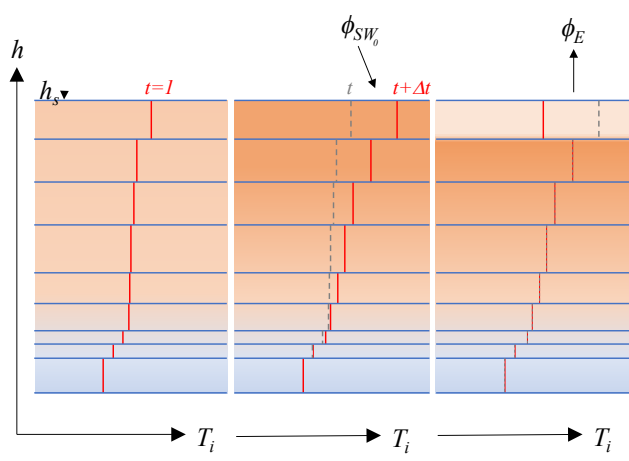

(d) Convective deepening

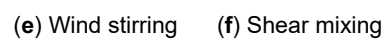

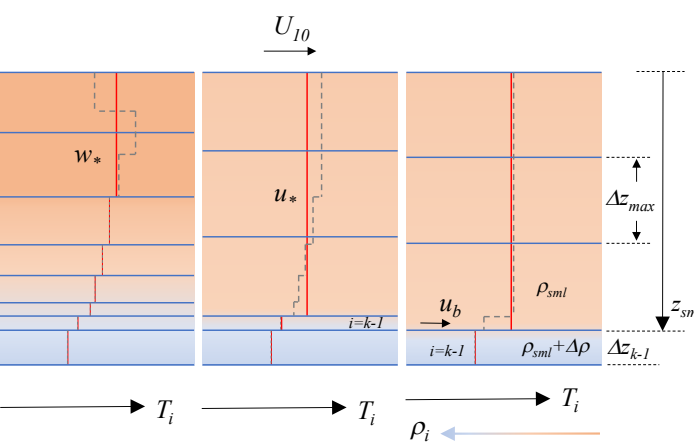

(g) K-H mixing

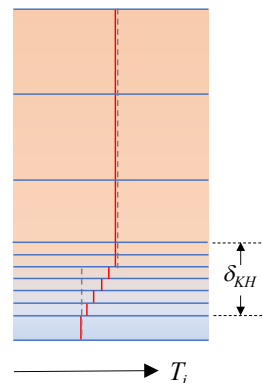

Figure 8. Schematic depiction of layer changes during stratification and mixing. Consecutive panels show changes from (a) the initial layer and thermal profile, to (b) heating due to solar radiation, to (c) evaporative cooling, which creates (d) convective mixing followed by (e) a wind event causing stirring and (f) shear mixing across the thermocline. If the metalimnion remains unstable to shear it may be subjected to mixing from $\mathrm{K}-\mathrm{H}$ billowing, which opens up the thermocline as depicted in panel (g).

where $\bar{C}$ is the weighted mean concentration of $C$ for the two layers, and $\Delta C$ is the concentration difference between them. The smoothing function, $f_{\text {dif }}$, is related to the diffusivity according to

$f_{\text {dif }}=\frac{D_{Z_{i+1}}+D_{Z_{i}}}{\left(\Delta z_{i+1}+\Delta z_{i}\right)^{2}} \Delta t$,

and the above diffusion algorithm is run once up the water column and once down the water column as a simple explicit method for capturing diffusion of mass to both the upper and lower layers. An example of the effect of hypolimnetic mixing on a hypothetical scalar concentration released from the sediment to the water column layers and accumulating in the hypolimnion is shown in Fig. 10.

\subsection{Inflows and outflows}

Aside from the surface fluxes of water described above, the water balance of a lake is controlled by inflows and outflows. Inflows can be specified as local run-off from the surrounding (dry) lake domain $\left(Q_{\mathrm{R}}\right.$ described separately above; Eq. 8), rivers entering at the surface of the lake that will be buoyant or plunge depending on their momentum and density (Sect. 2.7.1), or submerged inflows (including groundwater) that enter at depth (Sect. 2.7.2). Four options for outflows are included in GLM. These include withdrawals from a specified depth (Sect. 2.7.3), adaptive offtake (Sect. 2.7.4), vertical groundwater seepage (Sect. 2.7.5), and river outflowoverflow from the surface of the lake (Sect. 2.7.6). Any number of lake inflows and outflows can be specified, and, except for the local run-off term, all are applied at a daily time step. Depending on the specific settings of each, these water fluxes can impact the volume of the individual layers, $\Delta V_{i}$, and the overall lake volume (Eq. 4). Inflows have a prescribed composition (temperature, salinity, and scalars), except local run-off, which is assumed to be at air temperature with zero salinity.

\subsubsection{River inflows}

As water from an inflowing river connects with a lake or reservoir environment, it will form a positively or negatively buoyant intrusion depending on the density of the incoming river water in the context of the water column stratification. As the inflow progresses towards insertion, it will entrain water at a rate depending on the turbulence created by the inflowing water mass (Fischer et al., 1979). For each configured inflow the entrainment coefficient, $E_{\text {inf }}$, is computed based on the bottom drag being experienced by the inflowing water, $C_{\mathrm{D}_{\text {inf }}}$, and the water stability using the approximation given in Imberger and Patterson (1981) as written in Ayala et al. (2014):

$E_{\mathrm{inf}}=1.6 \frac{C_{\mathrm{D}_{\mathrm{inf}}}^{3 / 2}}{R i_{\mathrm{inf}}}$,

where the inflow Richardson number, $R i_{\text {inf }}$, characterizes the stability of the water in the context of the inflow. Imberger and Patterson (1981) derived a simple estimate of $R i_{\text {inf }}$ based on the drag coefficient by assuming the velocity (and Froude number) is typically small and considering the channel geometry, which is adapted in GLM as

$R i_{\text {inf }}=\frac{C_{\mathrm{D}_{\text {inf }}}\left(1+0.21 \sqrt{C_{\mathrm{D}_{\mathrm{inf}}}} \sin \alpha_{\mathrm{inf}}\right)}{\sin \alpha_{\mathrm{inf}} \tan \Phi_{\mathrm{inf}}}$,

where $\alpha_{\text {inf }}$ is the stream half-angle assuming an approximate triangular cross section, and $\Phi_{\text {inf }}$ is the angle of the slope of the inflow thalweg relative to horizontal in the region where it meets the waterbody (Fig. 11). Therefore, using Eqs. (60) and (61), a simple approximation of stream geometry and 

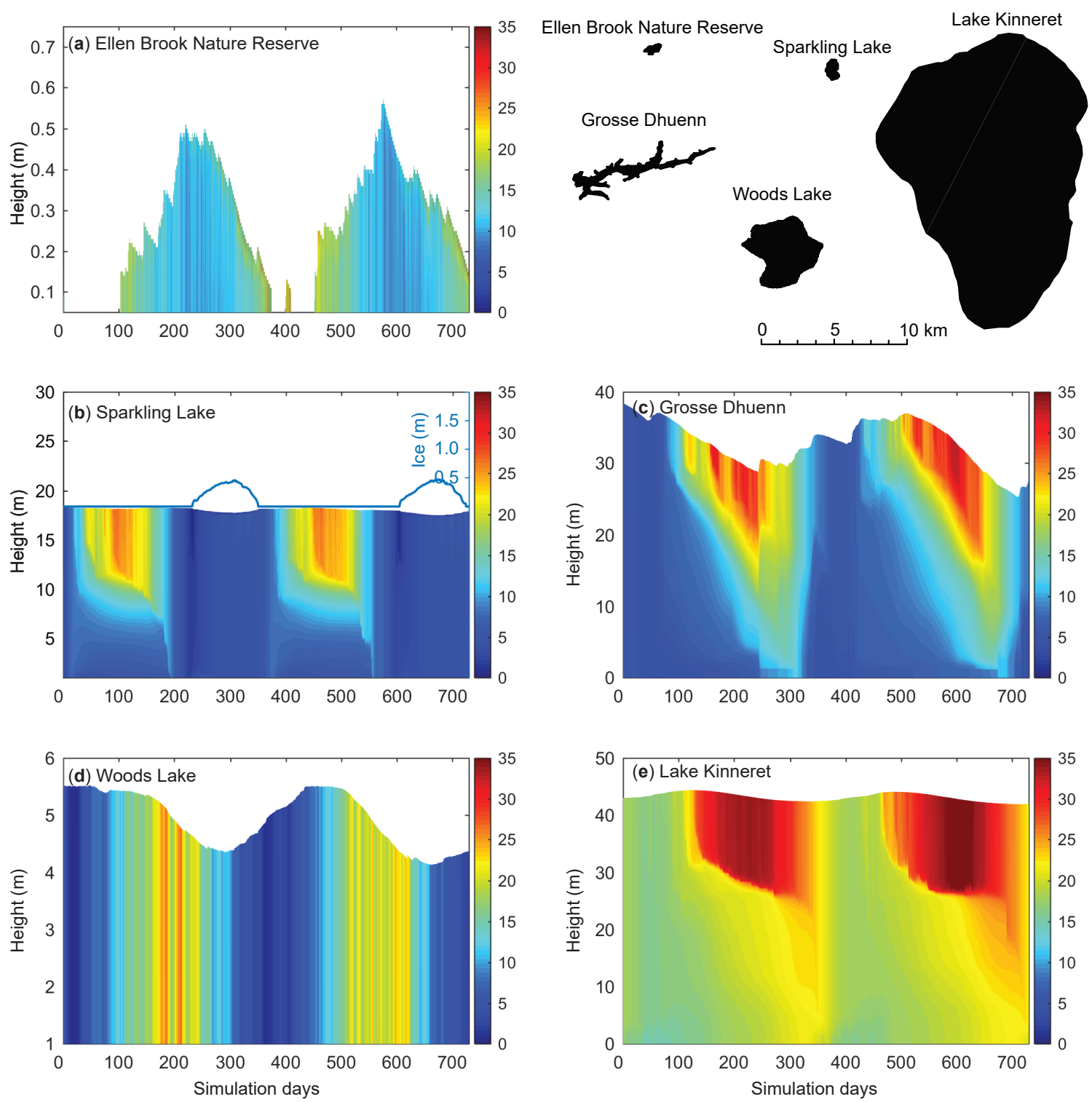

Figure 9. A 2-year time series of the simulated temperature profiles for five example lakes (a-e) that range in size and hydrology. For more information about each lake and the simulation configuration, refer to the "Data availability" section (refer also to Figs. 2 and 5). Sparkling Lake (b) also indicates the simulated depth of ice on the RHS scale.

bottom roughness can be used to parameterize the characteristic rate of entrainment as it enters the waterbody.

On entry, the inflow algorithm captures two phases: first, the inflowing water crosses the layers of the lake until it reaches a level of neutral buoyancy, and second, it then undergoes insertion. In the first part of the algorithm, the daily inflow parcel is tracked down the lakebed and its mixing with layers is updated until it is deemed ready for insertion. The initial estimate of the intrusion thickness, $\Delta z_{\inf _{0}}$, is computed as in Antenucci et al. (2005) and Ayala et al. (2014):

$$
\Delta z_{\text {inf }_{0}}=\left(2 \frac{R i_{\text {inf }}}{g_{\text {inf }}^{\prime}}\left(\frac{Q_{\text {inf }_{0}}}{\tan \alpha_{\text {inf }}}\right)^{2}\right)^{1 / 5},
$$

where $Q_{\text {inf }_{0}}=f_{\text {inf }} Q_{\text {inf }_{x}}$ is the inflow discharge entering the domain based on the data provided as a boundary condition, $Q_{\text {inf }}$, and $g_{\text {inf }}^{\prime}$ is the reduced gravity of the inflow as it enters.

$g_{\text {inf }}^{\prime}=g \frac{\left(\rho_{\text {inf }}-\rho_{\mathrm{s}}\right)}{\rho_{\mathrm{s}}}$, 

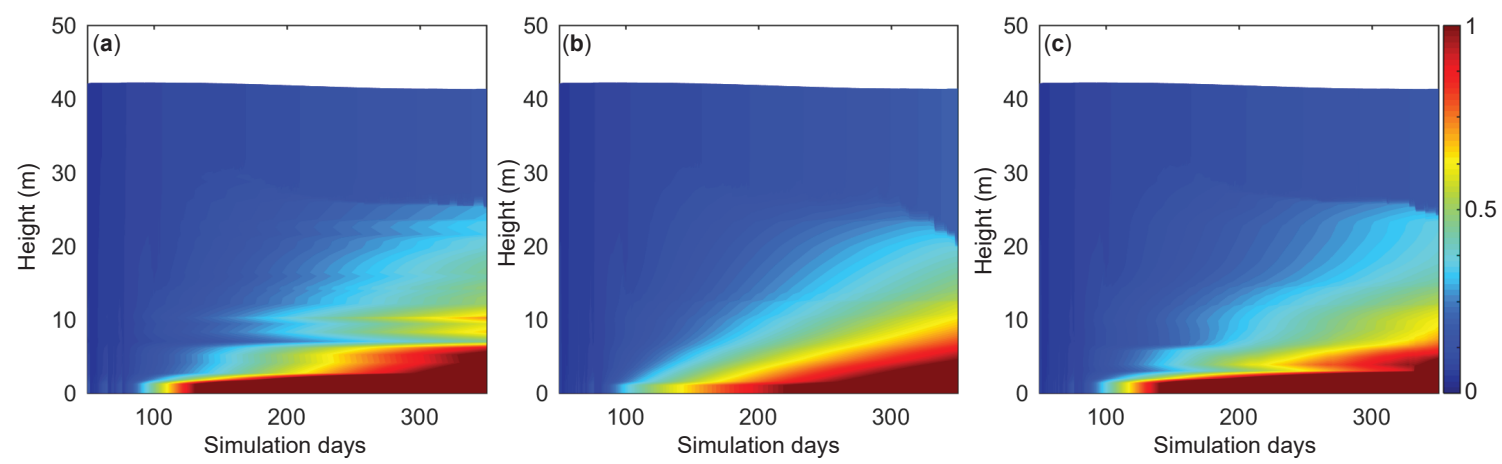

Figure 10. Example simulations for Lake Kinneret showing the hypolimnetic concentration of a passive tracer (normalized units) released from the sediment into the water layers at a constant rate for the case (a) without deep mixing, (b) with a constant vertical diffusivity, $D_{z}=2 \times 10^{-6} \mathrm{~m}^{2} \mathrm{~s}^{-1}$, and (c) with the depth-dependent vertical diffusivity formulation (Eq. 57). The thermal structure for this case is in Fig. 9e.

Here, $\rho_{\text {inf }}$ is the density of the inflow computed from the supplied inflow properties of temperature and salinity $\left(T_{\mathrm{inf}_{x}}, S_{\mathrm{inf}_{x}}\right)$, and $\rho_{\mathrm{s}}$ is the density of the surface layer. If the inflowing water is deemed to be positively buoyant $\left(\rho_{\text {inf }}<\rho_{\mathrm{s}}\right)$ or the model only has one layer $\left(N_{\mathrm{LEV}}=1\right)$, then the inflow water over the daily time step is added to the surface layer volume $\left(\Delta V_{N_{\mathrm{LEV}}}=Q_{\mathrm{inf}_{0}} \Delta t_{\mathrm{d}}\right)$, and $h_{\mathrm{S}}$ is updated accordingly. Otherwise, this inflow volume is treated as a parcel which travels down through the lake layers, and its properties are subsequently incremented over each time step, $j$ (currently daily), until it inserts. The thickness of an inflow parcel increases over each increment due to entrainment, assuming

$\Delta z_{\text {inf }_{j}}=1.2 E_{\text {inf }} \Delta x_{\text {inf }_{j}}+\Delta z_{\text {inf }_{j-1}}$,

where $\Delta z_{\text {inf }_{j}}$ is the inflow thickness and $\Delta x_{\text {inf }_{j}}$ is the distance travelled by the inflowing water parcel over the $j$ th time step. The distance travelled is estimated based on the change in the vertical height of the inflow, $\delta z_{\text {inf }}$, and the angle of the inflow river, $\phi_{\text {inf }}$, as given by

$\Delta x_{\text {inf }_{j}}=\frac{\delta z_{\text {inf }_{j}}}{\sin \Phi_{\text {inf }}}$.

The vertical excursion for the step is approximated as the difference between its starting height and the bottom of the nearest layer that it sits above, $h_{i_{j}-1}$, such that $\delta z_{\text {inf }_{j}}=$ $\left(h_{\mathrm{S}}-z_{\text {inf }_{j-1}}\right)-h_{i_{j}-1}$, where $z_{\text {inf }_{j-1}}$ is the depth of the inflow from the surface at the start of the time step, and this is subsequently updated from $z_{\text {inf }_{j}}=z_{\text {inf }_{j-1}}+\Delta x_{\text {inf }_{j}} \sin \Phi_{\text {inf. }}$. The average velocity of the inflow parcel is updated based on the incoming flow rate from

$u_{\text {inf }_{j}}=\frac{Q_{\text {inf }_{j-1}}}{\left(\Delta z_{\text {inf }_{j}}\right)^{2} \tan \alpha_{\text {inf }}}$,

where the denominator links the relationship between inflow height and channel width in order to define the crosssectional area of the flow. This velocity is used to estimate the timescale of transport of the parcel $\left(\delta t_{\mathrm{d}}=\Delta x_{\text {inf }_{j}} / u_{\text {inf }_{j}}\right)$. Following the conservation of mass, the flow is estimated to increase according to Fischer et al. (1979) (see also Antenucci et al., 2005):

$\Delta Q_{\text {inf }_{j}}=Q_{\text {inf }_{j-1}}\left[\left(\frac{\Delta z_{\text {inf }_{j}}}{\Delta z_{\text {inf }_{j-1}}}\right)^{5 / 3}-1\right]$,

whereby $\Delta Q_{\text {inf }_{j}}$ is removed from the volume of the corresponding layer, $i_{j}$, and added to the previous time step inflow $Q_{\text {inf }_{j-1}}$ to capture the entrainment effect on the inflow for the next increment. The properties associated with $\Delta Q_{\text {inf }_{j}}$ are assumed to match those of the $i_{j}$ layer and mixed into the inflow parcel to update temperature, salinity, and density, $\rho_{\text {inf }_{j}}$. The inflow travel algorithm (Eqs. 62-67) increments through $j$ until the density of the inflow first reaches its depth of neutral buoyancy: $\rho_{\mathrm{inf}_{j}} \leq \rho_{i_{j}}$. Once this condition is met, the insertion depth is defined as $z_{\text {inf }}$ ins $_{I}$, its density as $\rho_{\text {inf }}$ ins $_{I}$, and the second part of the algorithm then creates a new layer of thickness dependent on the inflow's volume at that time, $Q_{\text {inf }_{\text {ins }}{ }_{I}} c_{\text {secday }}$, which includes the successive layer additions from entrainment; Eq. (67).

Since a new inflow parcel is created each day and the user may configure multiple inflows, $N_{\mathrm{INF}}$, a complex set of parcels being tracked via Eqs. (60)-(67), and a queue of new layers to be inserted are created. Following the creation of a new layer for an inflow parcel, $N_{\mathrm{LEV}}$ is incremented and all layer heights above the new layer are updated, paying attention to the lake hypsography. The new inflow layer is then subject to the thickness limit criteria within the layer-limitchecking routine and may amalgamate with adjacent layers or be divided into thinner layers.

Aside from importing mass into the lake, river inflows also contribute turbulent kinetic energy that may dissipate in the hypolimnion, as discussed in Sect. 2.6.2 (e.g. see Eq. 55), and they contribute to the scalar transport in the water column 


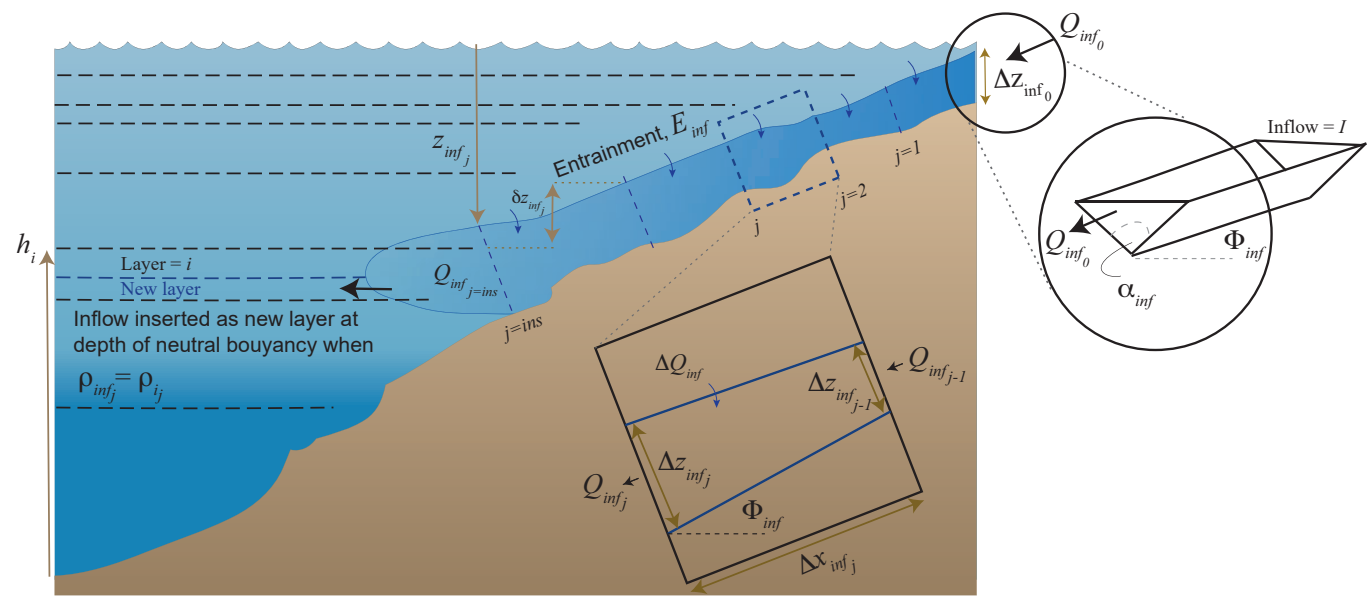

Figure 11. Schematic showing inflow insertion depth, entrainment, $E_{\text {inf }}$, slope, $\Phi_{\text {inf }}$, and bottom slope angle, $\alpha_{\text {inf }}$, of an inflowing river, $I$, entering at a flow rate of $Q_{\text {inf }_{0}}$ and an estimated starting thickness of $\Delta z_{\text {inf }_{0}}$.

by adding mass contained within the inserted inflow parcels and contributing to mixing of properties via entrainment as described above (Fig. 12a); see also Fenocchi et al. (2017).

\subsubsection{Submerged inflows}

Submerged inflows are inserted at the user-specified depth, $h_{\text {inf }}$, with zero entrainment by utilizing the second part of the algorithm described in Sect. 2.7.1. Once the submerged inflow volume is added as a new layer it may then be mixed with adjacent layers (above or below) depending on the density difference and layer thickness criteria (Fig. 12b). This option can be used across one or more inflow elevations to account for groundwater input to a lake or for capturing a piped inflow, for example.

\subsubsection{Withdrawals}

Outflows from a specific depth can include outlets from a dam wall offtake, other piped withdrawal, or removal of water that may be lost due to groundwater recharge. For a stratified water column, the water will be removed from the layer corresponding to the specified withdrawal height, $h_{\text {outf }}$, and layers above or below depending on the strength of discharge and stability of the water column. Accordingly, the model assumes an algorithm in which the thickness of the withdrawal envelope is dependent on the internal Froude $(F r)$ and Grashof $(G r)$ numbers and the parameter $R$ (see Fischer et al., 1979; Imberger and Patterson, 1981):

$$
\begin{aligned}
& F r=\frac{f_{\text {outf }} Q_{\text {outf }_{x}}}{N_{\text {outf }} W_{\text {outf }} L_{\text {outf }}^{2}}, \\
& G r=\frac{N_{\text {outf }}^{2} A_{\text {outf }}^{2}}{D_{\text {outf }}^{2}}, \\
& R=F r G r^{1 / 3},
\end{aligned}
$$

where $W_{\text {outf }}, L_{\text {outf }}$, and $A_{\text {outf }}$ are the width, length, and area of the lake at the outlet elevation, and $D_{\text {outf }}^{2}$ is the vertical diffusivity averaged over the layers corresponding to the withdrawal thickness, $\delta_{\text {outf }}$ (described below). To calculate the width and length of the lake at the height of the outflow, it is assumed, firstly, that the lake shape can be approximated as an ellipse and, secondly, that the ratio of length to width at the height of the outflow is the same as that at the lake crest. The length of the lake at the outflow height, $L_{\text {outf }}$, and the lake width, $W_{\text {outf }}$, are given by

$$
\begin{aligned}
L_{\text {outf }} & =\sqrt{A_{\text {outf }} \frac{4}{\pi} \frac{L_{\text {crest }}}{W_{\text {crest }}},} \\
W_{\text {outf }} & =L_{\text {outf }} \frac{W_{\text {crest }}}{L_{\text {crest }}},
\end{aligned}
$$

where $A_{\text {outf }}$ is the area of the lake at the outflow height, $L_{\text {crest }}$ is the length, and $W_{\text {crest }}$ the width of the lake at the crest height.

The thickness of the withdrawal layer is calculated depending on the value of $R$ (Fischer et al., 1979) such that

$\delta_{\text {outf }}=\left\{\begin{array}{ll}2 L_{\text {outf }} G r^{-1 / 6} & R \leq 1 \\ 2 L_{\text {outf }} F r^{1 / 2} & R>1\end{array}\right.$.

If stratification is apparent near $h_{\text {outf }}$, either above or below this elevation, then the thickness computed in Eq. (73) may not be symmetric about the offtake level (Imberger and Patterson, 1981); therefore the algorithm separately computes the thickness of the withdrawal layer above and below, denoted $\delta_{\text {outf }}$ and $\delta_{\text {outf }}$ bot , respectively. The Brunt-Väisälä frequency is averaged over the relevant thickness, $N_{\text {outf }}^{2}$, and calculated as

$N_{\text {outf }}^{2}=\frac{g}{\delta_{\text {outf }}} \frac{\rho_{\text {outf }}-\rho_{i}}{\rho_{\text {outf }}}$, 

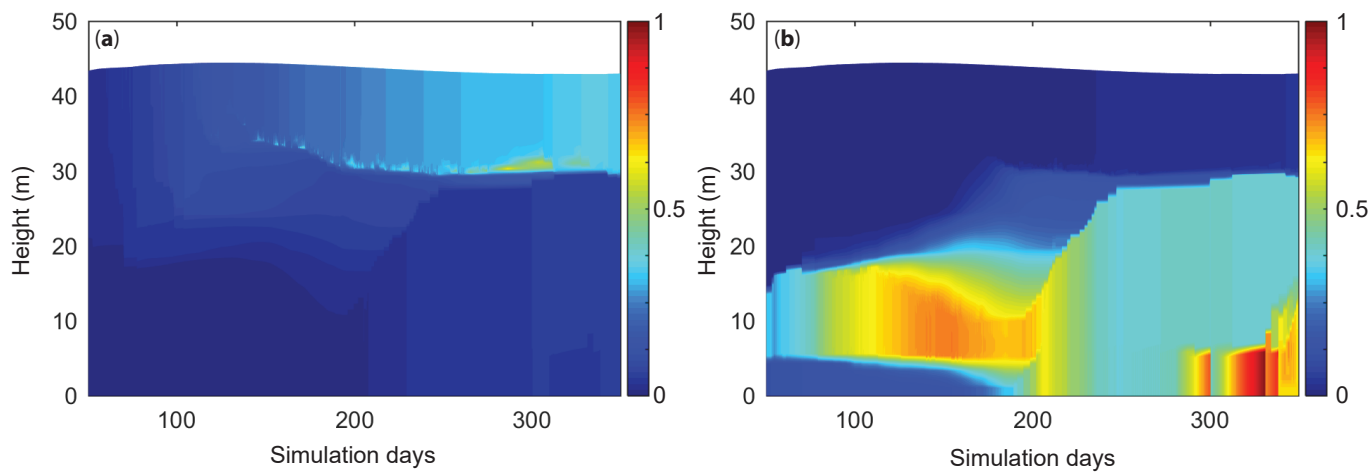

Figure 12. Example simulations with tracers demonstrating inflow insertion example for the case in which (a) the inflow was set as a surface river inflow and subject to the insertion algorithm (Eqs. 60-67) prior to insertion, and (b) the inflow was set as a submerged inflow at a specified height $\left(h_{\mathrm{inf}}=5 \mathrm{~m}\right)$. Once entering the water column, the tracer, $C$, is subject to mixing during inflow entrainment in case (a) and by surface and/or deep mixing once inserted for both cases (a) and (b). The colour scale represents an arbitrary inflow concentration which entered with a value of 1 .

where $\rho_{\text {outf }}$ is the density of the layer corresponding to the height of the withdrawal, $i_{\text {outf }}$, and $\rho_{i}$ is the density of the water column at the edge of the withdrawal layer, as determined below. The flow of water taken from each layer influenced by the withdrawal, $Q_{\text {outf }_{i}}$, either above or below the layer of the outlet elevation requires identification of the uppermost and lowermost layer indices influenced by the outflow, denoted $i_{\text {top }}$ and $i_{\text {bot }}$. Once the layer range is defined, $Q_{\text {outf }_{i}}$ is computed for the layers between $i_{\text {outf }}$ and $i_{\text {top }}$ and between $i_{\text {outf }}$ and $i_{\text {bot }}$ by partitioning the total outflow using a function to calculate the proportion of water withdrawn from any layer that fits the region of water drawn in a given time $\left(Q_{\text {ouff }_{i}}=f\left[f_{\text {outf }} Q_{\text {outf }_{x}}, h_{i}, h_{i-1}, h_{\text {outf }}, \delta_{\text {outf }_{\text {bot }}}, \delta_{\text {outf }_{\text {top }}}\right]\right.$; see Imberger and Patterson, 1981, Eq. 65). Given that users configure any height for a withdrawal outlet and flow rates of variable strength, the upper $\left(h_{\text {outf }}+\delta_{\text {outf }}\right.$ top $)$ and lower $\left(h_{\text {outf }}-\delta_{\text {outf }_{\text {bot }}}\right)$ elevation limits computed by the algorithm are limited to the lake surface layer or bottom layer. Once computed, the volumes are removed from the identified layer set, and their height and volumes updated accordingly. $Q_{\text {outf }_{i}}$ is constrained within the model to ensure no more than $90 \%$ of a layer can be removed in a single time step. Depending on the fractional contribution from each of the layers from which the water is withdrawn, the water taken will have the associated weighted average of the relevant scalar concentrations ( $T_{\text {outf }}, S_{\text {outf }}, C_{\text {outf }}$ ), which are reported in the outlet file for the particular withdrawal. This routine is repeated for each withdrawal considered, denoted $O$, and the model optionally produces a summary file of the combined outflow water and its properties.

\subsubsection{Adaptive offtake dynamics}

For reservoir applications, a special outflow option has been implemented that extends the dynamics in Sect. 2.7.3 to simulate an adaptive offtake or selective withdrawal. This ap- proach is used for accommodating flexible reservoir withdrawal regimes and their effects on the thermal structure within a reservoir. For this option, a target temperature is specified by the user and GLM identifies the corresponding withdrawal height within a predefined (facility) range to meet this target temperature during the runtime of the simulation; i.e. the withdrawal height adaptively follows the thermal stratification in the reservoir. The target temperature can be defined as a constant temperature or a time series (via a *.csv file), such as a measured water temperature from an upstream river that could be used to plan environmental releases from the reservoir to the downstream river. The selected height of the adaptive offtake is printed out in a *.txt file to assist reservoir operation. In addition to the basic adaptive offtake function, GLM can also simulate withdrawal mixing; i.e. water from the adaptive offtake is mixed with water from another predefined height (e.g. the bottom outlet). For this option, the discharges at both locations need to be predefined by the user (via the standard outflow *.csv files) and GLM chooses the adaptive withdrawal from a height at which the water temperature is such that the resulting mixing temperature meets the target temperature. This withdrawal mixing is a common strategy in reservoir operation in which deep water withdrawal and temperature control are required simultaneously to prevent deleterious downstream impacts.

An example of the adaptive offtake function with and without withdrawal mixing, assuming a constant water temperature of $14^{\circ} \mathrm{C}$ for the outflow water, shows that GLM is able to deliver a constant outflow temperature of $14^{\circ} \mathrm{C}$ during the stratified period (Fig. 13). In winter when the water column is cooler than $14{ }^{\circ} \mathrm{C}$, the model withdraws surface water. The adaptive offtake functionality can be used in a standalone mode or also linked to the dissolved oxygen concentration (when operated with the coupled water quality model AED2; see Sect. 4). In the latter case, the effect of the withdrawal regime on the oxygen dynamics in the hypolimnion 
can be simulated (see Weber et al., 2017). In this setting, the simulated hypolimnetic dissolved oxygen concentration at a specified height is checked against a user-defined critical threshold. If the hypolimnetic oxygen falls below the critical threshold, the height of the adaptive offtake will be automatically switched to a defined height (usually deep outlets in order to remove the oxygen-depleted water) to withdraw water from this layer until the oxygen concentrations have recovered.

\subsubsection{Seepage}

Seepage of water from the lake can also be configured within the model, for example, as might be required in a wetland simulation or for small reservoirs perched above the water table that experience leakage to the soil below. The seepage rate, $Q_{\text {seepage }}$, can be assumed constant or dependent on the overlying lake head:

$$
\begin{aligned}
& Q_{\text {seepage }}= \\
& \left\{\begin{array}{l}
\text { Option 1: constant rate } \\
-\mathrm{GA}_{\mathrm{S}} / c_{\text {secday }} \\
\text { Option 2: Darcy flux based on water height } \\
-\left(\frac{K_{\text {seep }}}{\delta z_{\text {soil }}}\right) \frac{A_{\mathrm{S}} h_{\mathrm{S}}}{c_{\text {secday }}}
\end{array}\right.
\end{aligned}
$$

where $G$ is the seepage rate $\left(\mathrm{mday}^{-1}\right), K_{\text {seep }}$ is the sediment hydraulic conductivity (m day ${ }^{-1}$ ), and $\delta z_{\text {soil }}$ is an assumed sediment thickness over which the seepage is assumed to occur. The water leaving the lake is treated as a "vertical withdrawal" whereby the water exits via the bottommost layer(s), and the amount $\Delta V_{G}=Q_{\text {seepage }} \Delta t_{\mathrm{d}}$ is generally all taken from the bottom-most layer $(i=1)$; however, it is constrained within the model to ensure no more than $90 \%$ of the layer can be reduced in any one time step; where $\Delta V_{G}>0.9 V_{i=1}$, the routine sequentially loops up through the above layers until enough lake volume has been identified to cover the seepage demand. Once the individual layer volumes are incremented due to the seepage flux, $\Delta V_{G_{i}}$, the heights of all layers $\left(h_{1}: h_{\mathrm{s}}\right)$ are recomputed based on the hypsographic curve using $h_{i}=f\left[V_{i}\right]$. Where seepage reduces the lake below $0.05 \mathrm{~m}$, the lake becomes dry and will continue to have zero volume until there are new inputs from rain or inflows (e.g. Fig. 9a).

\subsubsection{Overflows}

Once the lake volume exceeds the maximum volume, the excess water is assumed to leave the domain as an overflow. The flow rate, $Q_{\text {ovfl, }}$ is computed based on the interim volume, $V_{\mathrm{S}}^{*}$, prior to the end of the daily time step, where $V_{\mathrm{S}}^{*}=V_{\mathrm{S}}^{t}+\Delta h_{\mathrm{S}} A_{\mathrm{S}}+$ $\Delta t\left(\sum_{I}^{N_{\mathrm{INF}}} Q_{\text {inf }_{0_{I}}}-\sum_{O}^{N_{\text {OUT }}} Q_{\text {outf }_{O}}-Q_{\text {seepage }}\right)$, and $\Delta h_{\mathrm{S}}$ is the cumulative change in the daily water level over the day. Users can optionally also specify a crest elevation which lies below the elevation of maximum lake volume and support a rating curve linking the height of water above the crest level with the overflow volume:

$$
\begin{aligned}
& Q_{\text {weir }}= \\
& \begin{cases}0, & V_{\mathrm{S}}^{*} \leq V_{\text {crest }}, \\
\frac{2}{3} C_{\mathrm{D}_{\text {weir }}} \sqrt{2 g} W_{\text {weir }}\left(h_{\mathrm{S}}^{*}-h_{\text {crest }}\right)^{3 / 2}, & V_{\mathrm{S}}^{*}>V_{\text {crest }},\end{cases}
\end{aligned}
$$

where $h_{\mathrm{S}}^{*}$ is the interim update to the water surface height prior to the overflow computation, $C_{\mathrm{D}_{\text {weir }}}$ is a coefficient related to the drag of the weir, $W_{\text {weir }}$ is the width of the weir crest, and $h_{\text {crest }}$ is the height of the crest level. The overflow rate is then computed as the sum of the flow over the weir crest and the volume of water exceeding the volume of the domain:

$Q_{\text {ovfl }}=\left\{\begin{array}{ll}Q_{\text {weir }}, & V_{\mathrm{S}}^{*} \leq V_{\max } \\ Q_{\text {weir }}+\left(V_{\mathrm{S}}^{*}-V_{\max }\right) / \Delta t_{\mathrm{d}}, & V_{\mathrm{S}}^{*}>V_{\max }\end{array}\right.$.

If no crest is configured below the maximum lake height, then Eq. (77) assumes $Q_{\text {weir }}=0$.

\subsection{Wave height and bottom stress}

Resuspension of sediment from the bed of lakes depends on the stresses created by water movement across the lake bottom. Wind-induced resuspension, in particular, is sporadic and occurs as the waves at the water surface create oscillatory currents that propagate down to the lakebed and exceed a critical threshold. The wave climate that exists on a lake can be complex and depend on the fetch over which the wind has blown, the time period over which the wind has blown, and complicating factors such as wind sheltering and variations in bottom topography. The horizontally averaged nature of GLM means that only a single set of wave characteristics across the entire lake surface can be computed for a given time step and these are assumed to be at steady state. Note that GLM does not predict resuspension and sediment concentration directly, but computes the bottom shear stress for later use in coupled sediment and water quality modules. Since each layer has a component that is considered to overlay sediment (Sect. 4), the stress experienced at the sediment-water interface is able to approximated as a function of depth in relation to the surface wave climate. The model can therefore identify the depth range and areal extent to which there is potential for bed-sediment resuspension to occur, i.e. by computing the area of the lake over which the bed shear stress exceeds some critical value required for resuspension.

The model estimates surface wave conditions using a simple, fetch-based, steady-state wave model (Laenen and LeTourneau, 1996; Ji, 2008). The average wave geometry (wave period, significant wave height, and wavelength) is predicted 

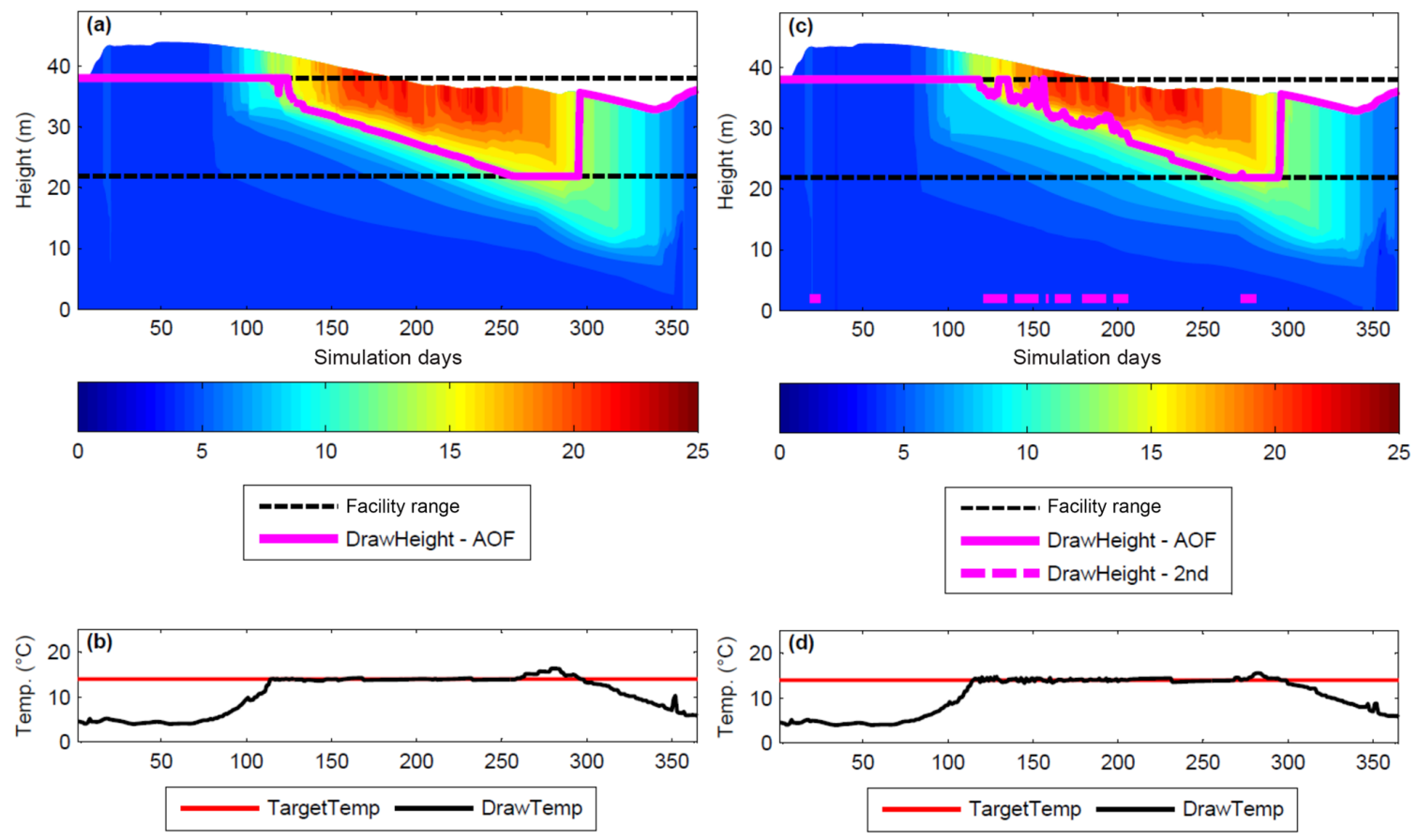

Figure 13. Adaptive offtake reservoir simulation; water temperatures of the adaptive offtake model assuming a constant target temperature of $14{ }^{\circ} \mathrm{C}(\mathbf{a}, \mathbf{b})$ without and $(\mathbf{c}, \mathbf{d})$ with mixing with the bottom outlet withdrawal. The black dashed line (a, c) represents the height range of the variable withdrawal facility (AOF) and the magenta lines the adaptive offtake and second withdrawal height (here: bottom outlet). In the scenario with the second withdrawal activated (c), the bottom outlet was periodically opened during flooding conditions. Panels (b) and (d) indicate where the actual withdrawal temperature (DrawTemp, $T_{\text {outf }}$ ) was able to meet the target (TargetTemp).

based on the wind speed and fetch over which the waves develop (Fig. 14), whereby the average fetch is approximated in the one-dimensional model formulation from the lake area,

$F=2 \sqrt{A_{\mathrm{s}} / \pi}$

and the wave period, $\delta t_{\mathrm{wave}}$, is calculated from fetch based on

$\delta t_{\text {wave }}=7.54\left(\frac{U_{10}}{g}\right) \tanh [\xi] \tanh \left[\frac{0.0379\left(\frac{g F}{U_{10}^{2}}\right)^{0.333}}{\tanh [\xi]}\right]$,

where

$\xi=0.833\left(\frac{g z_{\mathrm{avg}}}{U_{10}^{2}}\right)^{0.375}$

and $z_{\text {avg }}=h_{\mathrm{S}} / 2$ is the average lake depth. The typical wavelength is then estimated from

$\delta x_{\text {wave }}=\frac{g\left(\delta t_{\text {wave }}\right)^{2}}{2 \pi} \tanh \left[\frac{2 \pi z_{\mathrm{avg}}}{\frac{g\left(\delta t_{\mathrm{wave}}\right)^{2}}{2 \pi}}\right]$ and the significant wave height from

$$
\delta z_{\text {wave }}=0.283\left(\frac{U_{10}^{2}}{g}\right) \tanh [\zeta] \tanh \left[\frac{0.00565\left(\frac{g F}{U_{10}^{2}}\right)^{0.5}}{\tanh [\zeta]}\right] \text {, }
$$

where

$\zeta=0.53\left(\frac{g z_{\mathrm{avg}}}{U_{10}^{2}}\right)^{0.75}$.

Based on these properties the orbital wave velocity at the surface can be translated down the depth of the water column such that in the $i$ th layer it is calculated as (Sheng and Lick, 1979)

$U_{\mathrm{orb}_{i}}=\frac{\pi \delta z_{\text {wave }}}{\delta t_{\text {wave }} \sinh \left[\frac{2 \pi z_{i-1}}{\delta x_{\text {wave }}}\right]}$.

For each layer, the total shear stress experienced at the lakebed portion of that layer (equivalent in area to $A_{i}-A_{i-1}$ ) is calculated from

$\tau_{i}=\frac{1}{2} \rho_{i}\left(f_{\mathrm{w}_{i}} U_{\mathrm{orb}_{i}}^{2}+f_{\mathrm{c}_{\mathrm{i}}} U_{\mathrm{m}_{i}}^{2}\right)$ 


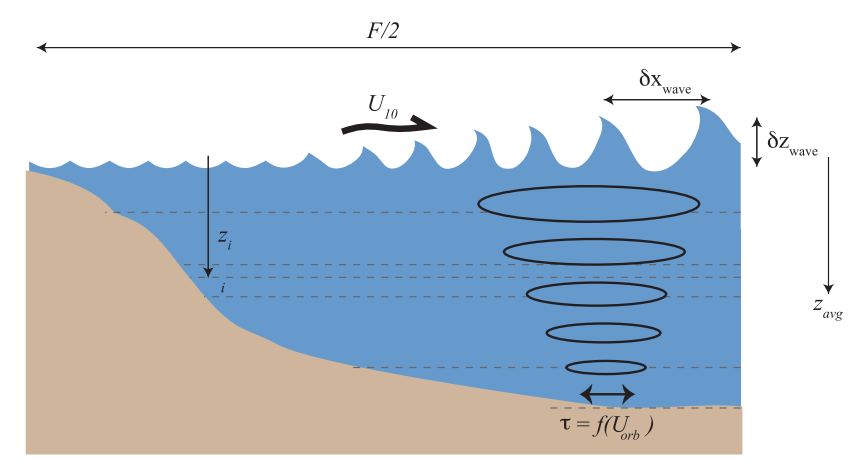

Figure 14. Schematic of the wave estimation approach depicting the lake fetch, surface wind speed, wave height, wavelength, and bottom stress created by the orbital velocity.

where $U_{\mathrm{m}}$ is the mean layer velocity, which for simplicity is assumed based on the velocity estimate made during the mixing calculations (Eq. 44) in the surface mixed layer such that

$U_{\mathrm{m}_{i}}=\left\{\begin{array}{ll}u_{*}, & i \geq k \\ 0, & i<k\end{array}\right.$.

The friction factors depend upon the characteristic particle diameter of the lake bottom sediments, $\delta_{\mathrm{ss}}$, and the fluid velocity. For the current-induced stress, we compute $f_{\mathrm{c}_{\mathrm{i}}}=0.24 / \log \left[12 z_{\mathrm{avg}} / 2.5 \delta_{\mathrm{ss}_{z_{i}}}\right]$ and for waves (Kleinhans and Grasmeijer, 2006)

$f_{\mathrm{w}_{i}}=\exp \left[-5.977+5.213\left(\frac{U_{\mathrm{orb}_{i}} \delta t_{\mathrm{wave}}}{5 \pi \delta_{\mathrm{ss}_{z_{i}}}}\right)^{-0.194}\right]$,

where $\delta_{\mathrm{ss}_{z_{i}}}$ is specific for each layer $i$, depending on which sediment zone it overlays (see Sect. 4). The current- and wave-induced stresses at the lake bottom manifest differently within the lake, as demonstrated in Fig. 15 for a shallow lake.

\section{Code organization and model operation}

Aside from the core water balance and mixing functionality, the model features numerous options and extensions in order to make it a fast and easy-to-use package suitable for a wide range of contemporary applications. Accommodating these requirements has led to the modular code structure outlined in Fig. 16. The model is written in C, with a Fortran-based interface module to link with the Fortran-based water quality modelling libraries described in Sect. 4. The model compiles with GCC, GFortran, and commercial compilers, with support for Windows, OS X, and Linux.

The model may also be compiled as a library, termed libGLM, that can be called as a plug-in to other models (e.g. see Sect. 5.4). Whilst the model is not object oriented, users may easily customize the specific modules described in Sect. 2 by adding or extending options for alternate schemes or functions.

To facilitate the use of the model in teaching environments and for users with limited technical support, it may be operated without any third-party software, as the input files consist of "namelist" (nml) text files for configuration and csv files for meteorological and flow time series data (Fig. 17). The outputs from predictions are stored into a structured NetCDF file, which can be visualized in real time through the simple inbuilt plotting library (libplot) or may be opened for post-processing in MATLAB, R, or any other tool supporting the open NetCDF format (see Sect. 5.1). Parameters and configuration details are input through the main glm.nml text file (Fig. 17) and default parameters and their associated descriptions are outlined in Table 1.

\section{Dynamic coupling with biogeochemical and ecological model libraries}

Beyond modelling the vertical temperature distribution, the water, ice, and heat balance, and the transport and mixing in a lake, the model has been designed to couple with biogeochemical and ecological model libraries. Currently the model is distributed pre-linked with the AED2 simulation library (Hipsey et al., 2019c) and the Framework for Aquatic Biogeochemical Models (FABM; Bruggeman and Bolding, 2014). Through connection with these libraries, GLM creates a set $\mathbb{C}$ of scalar variables, where $C \in \mathbb{C}$, which resolve the vertical profiles and mass balance of turbidity, oxygen, nutrients, phytoplankton, zooplankton, pathogens, and other water quality variables of interest. Documentation of these models is beyond the scope of the present paper; however, two features associated with the coupling are highlighted here as relevant to managing physical-ecological interactions.

Firstly, the model is designed to allow for a user-defined number of sediment zones that span the depth of the lake. Using this approach, the current set-up allows for depthdependent sediment properties, both for physical properties such as roughness or sediment heat flux (as outlined in previous sections) and also biogeochemical properties such as sediment nutrient fluxes and benthic ecological interactions. Since the GLM layer structure is flexible over time (i.e. layer heights are not fixed), any interactions between the water and sediment-benthos must be managed at each time step. The model supports the disaggregation and/or aggregation of layer properties for mapping individual water layers to one or more sediment zones (Fig. 18). The weightings provided by each layer to the sediment are based on the relative depth overlap of a layer with the depth range of the sediment zone, with the heights of zone boundaries denoted $h_{z}$. This approach makes the model suitable for long-term assessments of wetland, lake, and reservoir biogeochemical budgets, as is 

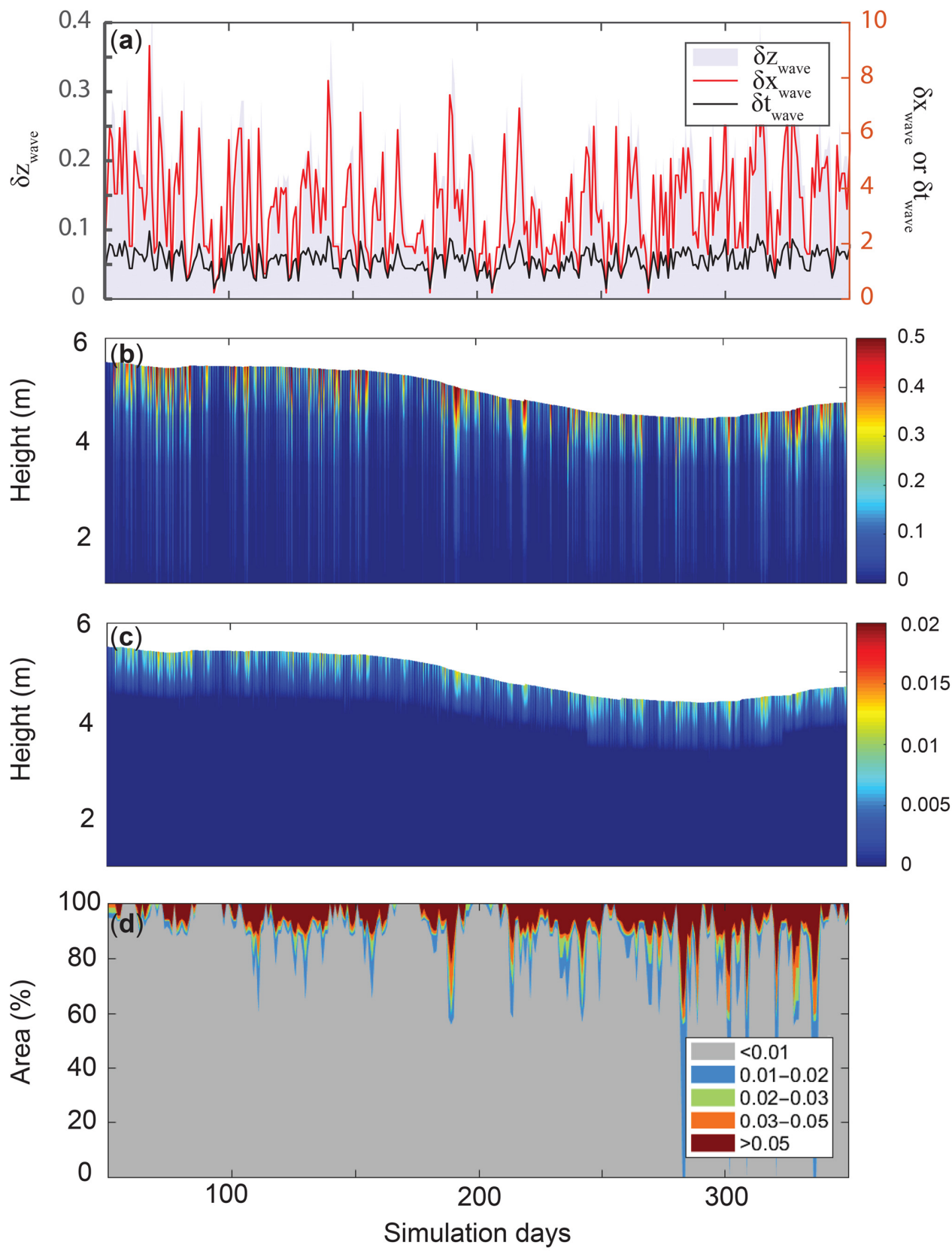

Figure 15. Simulation from Woods Lake, Australia, showing (a) time series of surface wave properties, (b) orbital velocity, $U_{\text {orb }}\left(\mathrm{m} \mathrm{s}^{-1}\right)$, (c) layer mean velocities, $U_{\mathrm{m}}\left(\mathrm{m} \mathrm{s}^{-1}\right)$, and (d) lakebed area percentage within each of the five depicted shear stress categories (based on $\tau_{i}$, $\mathrm{N} \mathrm{m}^{-2}$ ).

required for $\mathrm{C}, \mathrm{N}$, and other attribute balances (Stepanenko et al., 2016).

Secondly, the water quality modules feed back to GLM properties related to the water and/or heat balance. Feedback options are included for external libraries to provide water density additions and to modify bottom friction, $f_{\mathrm{w}}$, the light attenuation coefficient, $K_{\mathrm{w}}$, solar shading, $f_{\mathrm{SW}}$, and rainfall interception, $f_{\mathrm{R}}$.

\section{Workflow tools for integrating GLM with sensor data and supporting models}

The GLM has been designed to support the integration of large volumes of data coming from instrumented lakes, including many GLEON sites. These data consist of highfrequency and discrete time series observations of hydrologic fluxes, meteorology, temperature, and water quality (e.g. Hamilton et al., 2015). To facilitate research that re- 


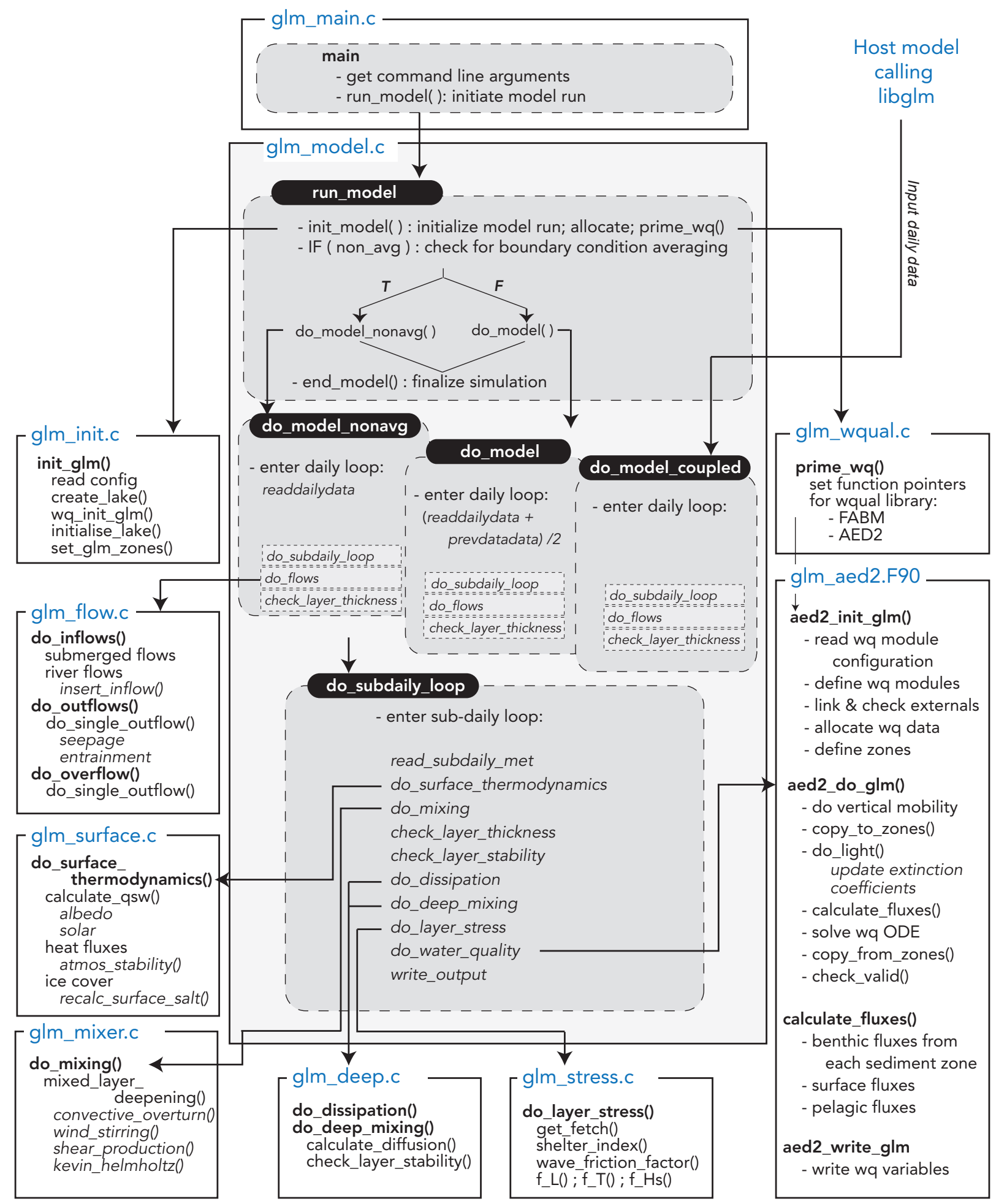

Figure 16. Overview of GLM code structure and programme flow. Modules are depicted as a box with the main routines and functions summarized. Three entry points to the main model routines are possible depending on the desired treatment of the inflow and outflow boundary condition data: do_model uses the flow boundary condition data over the present and previous day in order to get the midday value, do_model_nonavg uses that from the present day only, and do_model_coupled passes in the present day flows from the host. 
Table 1. Summary of GLM notation with values for constants, suggested (default) values for parameters, and supporting information and references, where relevant.

\begin{tabular}{|c|c|c|c|c|c|}
\hline Symbol & Description & Units & Value* & Comments & Reference \\
\hline \multicolumn{6}{|l|}{ Indices } \\
\hline$N_{\mathrm{BSN}}$ & user-provided number of basin elevation points & & configurable & set in \&morphometry & \\
\hline$N_{\mathrm{MORPH}}$ & $\begin{array}{l}\text { internally computed number of vertical elevation- } \\
\text { height increments for the hypsographic curve }\end{array}$ & & computed & $H_{b=N_{\mathrm{BSN}}} \Delta H_{\mathrm{mi}}+10$ & \\
\hline$N_{\mathrm{LEV}}$ & number of layers & & variable & $\begin{array}{l}\text { active layers vary over } \\
\text { time }\end{array}$ & \\
\hline$N_{\text {INF }}$ & number of inflows configured & & configurable & set in \&inflows & \\
\hline$N_{\text {OUTF }}$ & number of outlets configured & & configurable & set in \&outflows & \\
\hline$N_{\text {SW }}$ & number of shortwave radiation bands configured & & configurable & set in \&light & \\
\hline$N_{\mathrm{SZ}}$ & number of sediment zones configured & & configurable & set in $\&$ sediment & \\
\hline$b$ & hypsographic data point index & & index & & \\
\hline $\mathrm{mi}$ & internal hypsographic curve increment & & index & & \\
\hline$i$ & index of computational layer & & index & & \\
\hline$i_{j}$ & $\begin{array}{l}\text { index of the lake layer at an equivalent depth to inflow } \\
\text { parcel } j\end{array}$ & & index & & \\
\hline$i_{\text {bot }}$ & $\begin{array}{l}\text { index of lowermost layer impacted by a given } \\
\text { withdrawal-outflow }\end{array}$ & & index & & \\
\hline$i_{\text {top }}$ & $\begin{array}{l}\text { index of the uppermost layer impacted by a given } \\
\text { withdrawal-outflow }\end{array}$ & & index & & \\
\hline$i_{\text {outf }}$ & $\begin{array}{l}\text { index of the lake layer aligning with a withdrawal- } \\
\text { outflow extraction point }\end{array}$ & & index & & \\
\hline$S$ & layer index of the layer at the surface of the lake & & index & & \\
\hline$k$ & $\begin{array}{l}\text { layer index of the layer at the bottom of the surface } \\
\text { mixed layer (SML; epilimnion) }\end{array}$ & & index & & \\
\hline$j$ & index of inflow parcel transport step, prior to insertion & & index & & \\
\hline$z$ & index of sediment zone & & index & & \\
\hline$l$ & index of light bandwidth fraction & & index & & \\
\hline$I$ & inflow index & & index & & \\
\hline$O$ & outflow index & & index & & \\
\hline \multicolumn{6}{|l|}{ Time } \\
\hline$t$ & time & $\mathrm{s}$ & - & & \\
\hline$t_{\mathrm{b}}$ & time when a shear event begins & $\mathrm{s}$ & - & & \\
\hline$\lfloor t\rfloor$ & time marker, beginning of the day & $\mathrm{s}$ & - & $\begin{array}{l}\text { used to compute the time } \\
\text { within a day }\end{array}$ & \\
\hline$\Delta t$ & sub-daily time step used by the model & $\mathrm{s}$ & 3600 & $\begin{array}{l}\text { numerical time incre- } \\
\text { ment the model uses }\end{array}$ & \\
\hline$\Delta_{t_{\mathrm{d}}}$ & daily time step & $\mathrm{s}$ & 86400 & & \\
\hline $\mathrm{TZ}$ & time zone indicated by number of hours from GMT & $\mathrm{h}$ & configurable & set in \& time & \\
\hline$N_{\Delta t}$ & number of time steps to simulate & - & configurable & set in \& $i m e$ & \\
\hline$c_{\text {secday }}$ & number of seconds per day & s day $^{-1}$ & 86400 & & \\
\hline & day of the year & - & variable & & \\
\hline$\delta t_{\mathrm{d}}$ & timescale of inflow parcel transport & $\mathrm{s}$ & computed & & \\
\hline$\delta t_{\text {wave }}$ & period of surface waves & $\mathrm{s}$ & computed & Eq. (79) & \\
\hline$\delta t_{\mathrm{iw}}$ & period for internal waves & $\mathrm{s}$ & computed & $\delta t_{\mathrm{iw}}=L_{\mathrm{META}} / 2 c$ & $\begin{array}{l}\text { Spigel and Im- } \\
\text { berger (1980) }\end{array}$ \\
\hline$\delta t_{\text {shear }}$ & cut-off time for internal-wave-induced velocity shear & $\mathrm{s}$ & computed & Eq. (47) & \\
\hline$\delta t_{\text {damp }}$ & timescale of internal wave damping & $\mathrm{s}$ & computed & Eq. (50) & $\begin{array}{l}\text { Spigel and Im- } \\
\text { berger (1980) }\end{array}$ \\
\hline \multicolumn{6}{|c|}{ Lake setting (volumes, areas, and lengths) } \\
\hline$V_{\max }$ & maximum volume of the lake & $\mathrm{m}^{3}$ & computed & $\begin{array}{l}\text { once exceeded, excess } \\
\text { water is passed to over- } \\
\text { flow }\end{array}$ & \\
\hline$V_{\text {crest }}$ & volume of the lake at the crest height & $\mathrm{m}^{3}$ & computed & $\begin{array}{l}\text { volume corresponds to } \\
\text { height, } h_{\text {crest }}\end{array}$ & \\
\hline$V_{\mathrm{b}}$ & lake volume at the hypsographic data point $b$ & $\mathrm{~m}^{3}$ & configurable & Eq. (1) & \\
\hline
\end{tabular}


Table 1. Continued.

\begin{tabular}{|c|c|c|c|c|c|}
\hline Symbol & Description & Units & Value* & Comments & Reference \\
\hline$V_{\mathrm{mi}}$ & $\begin{array}{l}\text { interpolated volume at internal morphometry } \\
\text { table increment mi }\end{array}$ & $\mathrm{m}^{3}$ & computed & Eq. (2) & \\
\hline$V_{i}$ & volume of the lake at the top of the $i$ th layer & $\mathrm{m}^{3}$ & variable & $V_{i}=\sum_{j=1}^{i} \Delta V_{j}$ & \\
\hline$V_{\mathrm{S}}$ & $\begin{array}{l}\text { volume of the lake at the top of the surface layer } \\
\left(i=N_{\mathrm{LEV}}\right)\end{array}$ & $\mathrm{m}^{3}$ & variable & $V\left[h_{i=N_{\mathrm{LEV}}}\right]$ & \\
\hline$V_{\mathrm{S}}^{*}$ & $\begin{array}{l}\text { interim calculation of the volume of the lake at } \\
\text { the top of the surface layer }\end{array}$ & $\mathrm{m}^{3}$ & variable & $\begin{array}{l}\text { used to estimate lake vol- } \\
\text { ume prior to overflow } \\
\text { calculation }\end{array}$ & \\
\hline$\widetilde{V}_{N^{2}}$ & $\begin{array}{l}\text { a fractional volume of the lake that contains } \\
85 \% \text { of } N^{2} \text { variance }\end{array}$ & $\mathrm{m}^{3}$ & variable & $\begin{array}{l}\text { computed as the volume } \\
\text { of the lake above the } \\
\text { height which is } 1 \text { stan- } \\
\text { dard deviation }\left(\delta z_{\sigma}\right) \text { be- } \\
\text { low the height at the cen- } \\
\text { tre of buoyancy }\end{array}$ & \\
\hline$\Delta V_{i}$ & volume of the $i$ th layer & $\mathrm{m}^{3}$ & variable & $V\left[h_{i}\right]-V\left[h_{i-1}\right]$ & \\
\hline$\Delta V_{\text {epi }}$ & volume of the epilimnion & $\mathrm{m}^{3}$ & variable & $\Delta V_{\text {epi }}=V_{\mathrm{S}}-V_{k-1}$ & \\
\hline$\Delta V_{k-1}$ & $\begin{array}{l}\text { volume of the layer below the surface mixed } \\
\text { layer-epilimnion }\end{array}$ & $\mathrm{m}^{3}$ & variable & $V\left[h_{i=k-1}\right]$ & \\
\hline$\Delta V_{G}$ & volume of water lost to seepage & $\mathrm{m}^{3}$ & variable & $\Delta V_{G}=Q_{\text {seepage }} \Delta t_{\mathrm{d}}$ & \\
\hline$A_{\max }$ & maximum possible area of the lake & $\mathrm{m}^{2}$ & configurable & $A_{\max }=A_{\mathrm{b}=N_{\mathrm{BSN}}}$ & \\
\hline$A_{\mathrm{b}}$ & $\begin{array}{l}\text { lake area above datum at the hypsographic data } \\
\text { point b }\end{array}$ & $\mathrm{m}^{2}$ & configurable & set in \&morphometry & \\
\hline$A_{\mathrm{mi}}$ & $\begin{array}{l}\text { lake area at internal morphometry table incre- } \\
\text { ment mi }\end{array}$ & $\mathrm{m}^{2}$ & computed & & \\
\hline$A_{i}$ & lake area of the $i$ th layer & $\mathrm{m}^{2}$ & variable & & \\
\hline \multirow[t]{3}{*}{$A[H]$} & lake area at a given height-elevation & $\mathrm{m}^{2}$ & configurable & area-elevation & \\
\hline & & & & lationship; set & \\
\hline & & & & \&morphometry & \\
\hline$A_{\mathrm{S}}$ & area of the lake surface & $\mathrm{m}^{2}$ & variable & & \\
\hline$A_{\mathrm{BEN}}$ & $\begin{array}{l}\text { lake bottom (benthic) area exceeding the critical } \\
\text { light threshold } \phi_{\mathrm{BEN}_{\mathrm{crit}}}\end{array}$ & $\mathrm{m}^{2}$ & variable & Eq. (16) & \\
\hline$A_{\mathrm{E}}$ & $\begin{array}{l}\text { effective area of the lake surface exposed to } \\
\text { wind stress }\end{array}$ & $\mathrm{m}^{2}$ & computed & Eq. (26) & \\
\hline$A_{\mathrm{WS}}$ & $\begin{array}{l}\text { critical area below which wind sheltering may } \\
\text { occur }\end{array}$ & $\mathrm{m}^{2}$ & $10^{7}$ & set in \& fetch & $\begin{array}{l}\text { Xenopoulos } \\
\text { and Schindler } \\
(2001)\end{array}$ \\
\hline$A_{\text {outf }}$ & $\begin{array}{l}\text { area of the lake at the height of the relevant out- } \\
\text { flow }\end{array}$ & $\mathrm{m}^{2}$ & computed & & \\
\hline$A_{k-1}$ & lake area at the top of the metalimnion & $\mathrm{m}^{2}$ & variable & & \\
\hline$H$ & $\begin{array}{l}\text { variable referring to elevation; height above da- } \\
\text { tum }\end{array}$ & $\mathrm{m}$ above datum & & $H=H_{0}+h$ & \\
\hline$H_{\max }$ & $\begin{array}{l}\text { maximum elevation of the lake above which } \\
\text { water will overflow }\end{array}$ & $\mathrm{m}$ above datum & configurable & set in \&morphometry & \\
\hline$H_{\text {crest }}$ & elevation at the lake crest & m above datum & configurable & & \\
\hline$H_{0}$ & bottom elevation of the lake & $\mathrm{m}$ above datum & configurable & & \\
\hline$H_{\mathrm{b}}$ & $\begin{array}{l}\text { elevation above datum at the hypsographic data } \\
\text { point } b\end{array}$ & $\mathrm{~m}$ above datum & configurable & & \\
\hline$H_{\mathrm{mi}}$ & $\begin{array}{l}\text { elevation above datum at internal morphometry } \\
\text { table increment mi }\end{array}$ & $\mathrm{m}$ above datum & computed & & \\
\hline$\Delta H_{\mathrm{mi}}$ & $\begin{array}{l}\text { elevation increment used for the model's inter- } \\
\text { nal hypsographic curve interpolation function }\end{array}$ & $\mathrm{m}$ & 0.1 & & \\
\hline$h$ & height & $\mathrm{m}$ above lake bottom & & & \\
\hline$h_{i}$ & height at the top of layer $i$ & $\mathrm{~m}$ above lake bottom & variable & & \\
\hline$h_{\mathrm{S}}$ & $\begin{array}{l}\text { height of the top surface of the uppermost (sur- } \\
\text { face) layer }\end{array}$ & $\mathrm{m}$ above lake bottom & variable & Eq. (5) & \\
\hline$h_{\mathrm{S}}^{*}$ & $\begin{array}{l}\text { interim surface height computed prior to over- } \\
\text { flow calculation }\end{array}$ & $\mathrm{m}$ above lake bottom & computed & & \\
\hline
\end{tabular}


Table 1. Continued.

\begin{tabular}{|c|c|c|c|c|c|}
\hline Symbol & Description & Units & Value* & Comments & Reference \\
\hline$h_{\mathrm{B}}$ & $\begin{array}{l}\text { height of the top surface of the bottom-most } \\
\text { layer }\end{array}$ & $\mathrm{m}$ above lake bottom & variable & & \\
\hline$h_{\mathrm{BEN}}$ & height at which the $\phi_{\mathrm{BEN}_{\text {crit }}}$ is reached & $\mathrm{m}$ above lake bottom & variable & & \\
\hline$h_{z}$ & $\begin{array}{l}\text { height of the uppermost limit of the sediment } \\
\text { zone } z\end{array}$ & $\mathrm{~m}$ above lake bottom & configurable & $\begin{array}{l}\text { set in \&sediment if } \\
\text { benthic_mode }=2\end{array}$ & \\
\hline$\widetilde{h_{i}}$ & height of the middle of the $i$ th layer & $\mathrm{m}$ above lake bottom & variable & & \\
\hline$\widetilde{h_{\text {SML }}}$ & height of the middle of the epilimnion & $\mathrm{m}$ above lake bottom & variable & & \\
\hline$h_{\text {outf }}$ & height of a configured outflow & $\mathrm{m}$ above lake bottom & configurable & set in \&out flow & \\
\hline$h_{\text {inf }}$ & height of a submerged inflow & $\mathrm{m}$ above lake bottom & configurable & set in \&inflow & \\
\hline$h_{i_{j}-1}$ & $\begin{array}{l}\text { bottom of the nearest layer that inflow parcel } j \\
\text { sits above }\end{array}$ & $\mathrm{m}$ above lake bottom & variable & & \\
\hline$h_{i_{\mathrm{ins}_{I}}-1}$ & $\begin{array}{l}\text { height of the bottom of the layer where an in- } \\
\text { flow parcel associated with the } I \text { th inflow in- } \\
\text { serted }\end{array}$ & $\mathrm{m}$ above lake bottom & variable & & \\
\hline$h_{\text {crest }}$ & $\begin{array}{l}\text { height of the lake crest where water begins to } \\
\text { overflow }\end{array}$ & $\mathrm{m}$ above lake bottom & computed & $h_{\text {crest }}=H_{\text {crest }}-H_{0}$ & \\
\hline$z$ & $\begin{array}{l}\text { depth from the lake surface or height above the } \\
\text { lake surface }\end{array}$ & $\mathrm{m}$ from water surface & & & \\
\hline$z_{\text {avg }}$ & average depth of the lake & $\mathrm{m}$ & variable & & \\
\hline$z_{\mathrm{BEN}}$ & $\begin{array}{l}\text { depth to the lake at which critical light threshold } \\
\text { is exceeded }\end{array}$ & $\mathrm{m}$ from water surface & variable & Eq. (17) & \\
\hline$z_{\text {SML }}$ & depth to the metalimnion from the surface & $\mathrm{m}$ from water surface & variable & $\begin{array}{l}\text { equivalent to vertical } \\
\text { thickness of the surface } \\
\text { mixed layer (SML) }\end{array}$ & \\
\hline$z / L$ & Monin-Obukhov stability parameter & - & computed & Eq. (B4) & \\
\hline$z_{o}$ & water surface roughness length & $\mathrm{m}$ & computed & Eq. (B2) & \\
\hline$z_{\theta}$ & water surface heat roughness length & $\mathrm{m}$ & computed & & \\
\hline$z_{q}$ & water surface moisture roughness length & $\mathrm{m}$ & computed & & \\
\hline$z_{\text {inf }_{j}}$ & depth of an inflow parcel during its transit & $\mathrm{m}$ & computed & $\begin{array}{l}z_{\text {inf }_{j}}=z_{\text {inf }_{j-1}}+ \\
\Delta x_{\text {inf }_{j}} \sin \Phi_{\text {inf }}\end{array}$ & \\
\hline$z_{\text {inf }_{\text {ins }_{I}}}$ & $\begin{array}{l}\text { depth that an inflow parcel associated with in- } \\
\text { flow } I \text { inserts }\end{array}$ & $\mathrm{m}$ from water surface & variable & $\begin{array}{l}\text { depth from the surface at } \\
\text { which an inflow reaches } \\
\text { its level of neutral buoy- } \\
\text { ancy }\end{array}$ & \\
\hline$\Delta z_{i}$ & thickness of the $i$ th layer & $\mathrm{m}$ & variable & & \\
\hline$\Delta z_{k-1}$ & thickness of the layer below the epilimnion & $\mathrm{m}$ & variable & & \\
\hline$\Delta z_{\min }$ & minimum layer thickness & $\mathrm{m}$ & 0.5 & $\begin{array}{l}\text { should be estimated rela- } \\
\text { tive to lake depth; } \\
\text { set in \&glm_setup }\end{array}$ & $\begin{array}{l}\text { Bruce et } \\
\text { al. }(2018) \\
\text { Bueche et } \\
\text { al. }(2017)\end{array}$ \\
\hline$\Delta z_{\max }$ & maximum layer thickness & $\mathrm{m}$ & 1.5 & & \\
\hline$\Delta z_{\text {ice }}$ & $\begin{array}{l}\text { combined thickness of the white ice and blue } \\
\text { ice }\end{array}$ & $\mathrm{m}$ & computed & $\Delta z_{\text {white }}+\Delta z_{\text {blue }}$ & \\
\hline$\Delta z_{\text {ice, snow }}$ & $\begin{array}{l}\text { thickness of top layer of ice cover, depending } \\
\text { on ice or snow presence }\end{array}$ & $\mathrm{m}$ & computed & Eq. (32) & \\
\hline$\Delta z_{\text {snow }}$ & thickness of snow & $\mathrm{m}$ & variable & Eq. (32); Fig. 6 & \\
\hline$\Delta z_{\text {white }}$ & thickness of white ice & $\mathrm{m}$ & variable & Eq. (32) & \\
\hline$\Delta z_{\text {blue }}$ & thickness of blue ice & $\mathrm{m}$ & variable & Eq. (38) & \\
\hline$\Delta z_{\text {inf }_{0}}$ & $\begin{array}{l}\text { thickness of an inflow parcel before transport } \\
\text { into the lake }\end{array}$ & $\mathrm{m}$ & computed & Eq. (62) & \\
\hline$\Delta z_{\inf _{j}}$ & thickness of inflow parcel $j$ & $\mathrm{~m}$ & variable & Eq. (64) & \\
\hline$\delta z_{\sigma}$ & $\begin{array}{l}\text { vertical length scale of } 1 \text { standard deviation } \\
\text { about the centre of the } N^{2} \text { distribution }\end{array}$ & $\mathrm{m}$ & computed & & \\
\hline$\delta z_{\text {inf }_{j}}$ & vertical transport length of inflow parcel $j$ & $\mathrm{~m}$ & variable & $\begin{array}{l}\delta z_{\text {inf }_{j}} \\
h_{i_{j}-1}\end{array}=\left(h_{\mathrm{s}}-z_{\text {inf }_{j}}\right)-$ & \\
\hline$\delta z_{\text {wave }}$ & significant wave height of surface waves & $\mathrm{m}$ & computed & Eq. (82) & \\
\hline$\delta z_{\text {soil }}$ & depth of soil layer & $\mathrm{m}$ & 0.5 & $\begin{array}{l}\text { relevant soil depth for } \\
\text { computing sediment heat } \\
\text { diffusion or water seep- } \\
\text { age }\end{array}$ & \\
\hline
\end{tabular}


Table 1. Continued.

\begin{tabular}{|c|c|c|c|c|c|}
\hline Symbol & Description & Units & Value* & Comments & Reference \\
\hline \multicolumn{6}{|c|}{ Other notation (sorted alphabetically) } \\
\hline$a$ & Charnock constant & - & 0.012 & $\begin{array}{l}\text { relates roughness length to wind } \\
\text { speed }\end{array}$ & \\
\hline$a_{\mathrm{W}}$ & $\begin{array}{l}\text { constant relating precipitable water } \\
\text { vapour, } W \text {, to } T_{\mathrm{d}}\end{array}$ & - & $0.07-0.09$ & & $\begin{array}{l}\text { Luo et } \\
\text { al. (2010) }\end{array}$ \\
\hline AM & air mass factor & - & computed & Eq. (A7) & \\
\hline $\mathrm{AM}_{p}$ & air mass factor at pressure $p$ & - & computed & Eq. (A7) & \\
\hline $\mathrm{AOD}_{500}$ & aerosol optical depth at $500 \mathrm{~nm}$ & - & $0.033-0.10$ & set in $\& b i r d$ & $\begin{array}{l}\text { Luo et } \\
\text { al. (2010) }\end{array}$ \\
\hline $\mathrm{AOD}_{380}$ & aerosol optical depth at $380 \mathrm{~nm}$ & - & $0.038-0.15$ & & \\
\hline$b_{\mathrm{W}}$ & $\begin{array}{l}\text { constant relating precipitable water } \\
\text { vapour, } W \text {, to } T_{\mathrm{d}}\end{array}$ & - & $1.88-2.12$ & & $\begin{array}{l}\text { Luo et } \\
\text { al. }(2010)\end{array}$ \\
\hline$c$ & internal wave speed & $\mathrm{ms}^{-1}$ & computed & Eq. (48) & \\
\hline$c_{\mathrm{a}}$ & specific heat capacity of air & $\mathrm{J} \mathrm{kg}^{-1}{ }^{\circ} \mathrm{C}^{-1}$ & 1005 & & \\
\hline$c_{\mathrm{i}}$ & specific heat capacity of ice & $\mathrm{J} \mathrm{kg}^{-1 \circ} \mathrm{C}^{-1}$ & 2050 & & \\
\hline$c_{\mathrm{W}}$ & specific heat capacity of liquid water & $\mathrm{J} \mathrm{kg}^{-1 \circ} \mathrm{C}^{-1}$ & 4185.5 & & \\
\hline$c_{\text {damp }}$ & $\begin{array}{l}\text { coefficient related to damping rate of in- } \\
\text { ternal waves }\end{array}$ & - & 104.1 & & Spigel (1978) \\
\hline$c_{\mathrm{wn}}$ & $\begin{array}{l}\text { coefficient related to wavenumber cal- } \\
\text { culation }\end{array}$ & - & 12.4 & & \\
\hline $\mathbb{C}$ & set of scalars being simulated & various & variable & $\begin{array}{l}\text { variable number of scalars managed } \\
\text { by GLM, which are subject to mix- } \\
\text { ing and mass conservation }\end{array}$ & \\
\hline$C_{i}$ & $\begin{array}{l}\text { concentration of relevant scalar in the } \\
i \text { th layer }\end{array}$ & various & variable & & \\
\hline $\bar{C}$ & $\begin{array}{l}\text { mean concentration of two or more lay- } \\
\text { ers }\end{array}$ & various & computed & & \\
\hline$\Delta C$ & $\begin{array}{l}\text { difference in concentration of two lay- } \\
\text { ers }\end{array}$ & various & computed & & \\
\hline$C_{\text {inf }}$ & $\begin{array}{l}\text { concentration of relevant scalar in the } \\
\text { outflowing water }\end{array}$ & various & time series input & & \\
\hline$C_{\text {outf }}$ & $\begin{array}{l}\text { concentration of relevant scalar in the } \\
\text { outflowing water }\end{array}$ & various & variable & & \\
\hline$C_{\mathrm{KH}}$ & $\begin{array}{l}\text { mixing efficiency - Kelvin-Helmholtz } \\
\text { billows }\end{array}$ & - & 0.3 & set in \&mixing & $\begin{array}{l}\text { Sherman et } \\
\text { al. (1978) }\end{array}$ \\
\hline$C_{\mathrm{HYP}}$ & $\begin{array}{l}\text { mixing efficiency - hypolimnetic turbu- } \\
\text { lence }\end{array}$ & - & 0.5 & $\begin{array}{l}\text { applied differently based on } \\
\text { deep_mixing model (see text), } \\
\text { set in \&mixing }\end{array}$ & $\begin{array}{l}\text { Weinstock } \\
\text { (1981); } \\
\text { general diffu- } \\
\text { sivities in } \\
\text { Jellison and } \\
\text { Melack (1993) }\end{array}$ \\
\hline$C_{\mathrm{T}}$ & $\begin{array}{l}\text { mixing efficiency - unsteady turbulence } \\
\text { (acceleration) }\end{array}$ & - & 0.51 & & $\begin{array}{l}\text { Sherman et } \\
\text { al. (1978) }\end{array}$ \\
\hline$C_{\mathrm{S}}$ & mixing efficiency - shear production & - & 0.3 & set in \&mixing & $\begin{array}{l}\text { Spigel et } \\
\text { al. (1986) }\end{array}$ \\
\hline$C_{\mathrm{W}}$ & mixing efficiency - wind stirring & - & 0.23 & & $\begin{array}{l}\text { Yeates and Im- } \\
\text { berger }(2003)\end{array}$ \\
\hline$C_{\mathrm{K}}$ & mixing efficiency - convective overturn & - & 0.2 & & $\mathrm{Wu}(1973)$ \\
\hline$C_{\mathrm{D}_{\text {inf }}}$ & stream-bed drag of an inflowing river & - & 0.016 & $\begin{array}{l}\text { set based on inflow bed roughness } \\
\text { in \&inflow }\end{array}$ & \\
\hline$C_{\mathrm{D}_{\text {weir }}}$ & drag associated with weir crest & - & 0.62 & set in \&outflow & \\
\hline$C_{\mathrm{D}}$ & $\begin{array}{l}\text { bulk aerodynamic coefficient for mo- } \\
\text { mentum }\end{array}$ & - & 0.0013 & $\begin{array}{l}\text { see also Appendix B; } \\
\text { Eq. (B1) }\end{array}$ & $\begin{array}{l}\text { Fischer et } \\
\text { al. (1979) }\end{array}$ \\
\hline$C_{\mathrm{E}}$ & $\begin{array}{l}\text { bulk aerodynamic coefficient for latent } \\
\text { heat transfer }\end{array}$ & - & 0.0013 & $\begin{array}{l}\text { from the Hicks (1972) collation of } \\
\text { ocean and lake data; many studies }\end{array}$ & $\begin{array}{l}\text { Bruce et } \\
\text { al. (2018) }\end{array}$ \\
\hline$C_{\mathrm{H}}$ & $\begin{array}{l}\text { bulk aerodynamic coefficient for sensi- } \\
\text { ble heat transfer }\end{array}$ & - & 0.0013 & $\begin{array}{l}\text { since use similar values; internally } \\
\text { calculated if atmospheric stability } \\
\text { correction is on }\end{array}$ & $\begin{array}{l}\text { Bueche et } \\
\text { al. (2017) }\end{array}$ \\
\hline
\end{tabular}


Table 1. Continued

\begin{tabular}{|c|c|c|c|c|c|}
\hline Symbol & Description & Units & Value* & Comments & Reference \\
\hline$C_{X \mathrm{~N}}$ & $\begin{array}{l}\text { generic notation for neutral value of bulk- } \\
\text { transfer coefficient }\end{array}$ & - & selected & $X=H$ or $E$ & \\
\hline$C_{\mathrm{DN}-10}$ & $\begin{array}{l}\text { value of bulk-transfer coefficient for momen- } \\
\text { tum under neutral atmospheric conditions, ref- } \\
\text { erenced to } 10 \mathrm{~m} \text { of height }\end{array}$ & - & computed & see also Appendix B & \\
\hline$C_{\mathrm{HEN}}$ & $\begin{array}{l}\text { value of bulk-transfer coefficient for heat- } \\
\text { moisture under neutral atmospheric conditions, } \\
\text { referenced to } 10 \mathrm{~m} \text { of height }\end{array}$ & - & 0.0013 & & \\
\hline$C_{x}$ & cloud cover fraction & - & time series input & & \\
\hline$d_{T_{z}}$ & $\begin{array}{l}\text { day of the year when the soil temperature peaks } \\
\text { for the } z \text { th zone }\end{array}$ & - & $1-365$ & & \\
\hline$D_{Z}$ & effective vertical diffusivity of scalars in water & $\mathrm{m}^{2} \mathrm{~s}^{-1}$ & computed & & \\
\hline$D_{\varepsilon}$ & $\begin{array}{l}\text { diffusivity of scalars in water due to turbulent } \\
\text { mixing }\end{array}$ & $\mathrm{m}^{2} \mathrm{~s}^{-1}$ & computed & & \\
\hline$D_{\mathrm{m}}$ & molecular diffusivity for scalars in water & $\mathrm{m}^{2} \mathrm{~s}^{-1}$ & $1.25 \times 10^{-9}$ & & \\
\hline$D_{\mathrm{a}}$ & molecular heat diffusivity of air & $\mathrm{m}^{2} \mathrm{~s}^{-1}$ & $2.14 \times 10^{-5}$ & $\begin{array}{l}\text { reported as } \\
0.077 \mathrm{~m}^{2} \mathrm{~h}^{-1}\end{array}$ & TVA (1972) \\
\hline$D_{\text {outf }}$ & $\begin{array}{l}\text { average vertical diffusivity of scalars in layers } \\
\text { spanning the withdrawal thickness }\end{array}$ & $\mathrm{m}^{2} \mathrm{~s}^{-1}$ & computed & $\begin{array}{l}\text { values from Eq. (57) } \\
\text { averaged over the rele- } \\
\text { vant layers }\end{array}$ & $\begin{array}{l}\text { Imberger and } \\
\text { Patterson } \\
(1981)\end{array}$ \\
\hline$e_{\mathrm{S}}$ & saturation vapour pressure & $\mathrm{hPa}$ & computed & Eq. (24) & Tabata (1973) \\
\hline$e_{\mathrm{a}}$ & atmospheric vapour pressure & $\mathrm{hPa}$ & computed & Eq. (25) & \\
\hline$e_{*}$ & humidity scale & $\mathrm{hPa}$ & computed & & \\
\hline$E_{\mathrm{TKE}}$ & $\begin{array}{l}\text { turbulent kinetic energy per unit mass available } \\
\text { for mixing, integrated over layer depth }\end{array}$ & $\mathrm{m}^{3} \mathrm{~s}^{-2}$ & computed & Eq. (41) & $\begin{array}{l}\text { Imberger and } \\
\text { Patterson } \\
(1981)\end{array}$ \\
\hline$E_{\mathrm{PE}}$ & $\begin{array}{l}\text { potential energy within the stratified water col- } \\
\text { umn integrated over layer depth }\end{array}$ & $\mathrm{m}^{3} \mathrm{~s}^{-2}$ & computed & Eq. (42) & $\begin{array}{l}\text { Hamilton and } \\
\text { Schladow } \\
(1997)\end{array}$ \\
\hline$E$ & evaporation mass flux & $\mathrm{ms}^{-1}$ & variable & $E=\phi_{\mathrm{E}} / \lambda_{\mathrm{v}} \rho_{\mathrm{s}}$ & \\
\hline$E_{\text {inf }}$ & inflow entrainment & - & computed & Eq. $(60)$ & \\
\hline EQT & equation of time & - & computed & Eq. (A4) & \\
\hline$F$ & fetch & $\mathrm{m}$ & computed & $\begin{array}{l}\text { approximated from the } \\
\text { square root of the lake } \\
\text { area, Eq. (78) }\end{array}$ & \\
\hline$F r$ & $\begin{array}{l}\text { internal Froude number of the lake subject to a } \\
\text { water withdrawal }\end{array}$ & - & computed & Eq. (68) & \\
\hline$f_{\mathrm{R}}, f_{\mathrm{S}}$ & rainfall, snowfall scaling factor & - & 1 & & \\
\hline$f_{\mathrm{SW}}$ & solar radiation scaling factor & - & 1 & used to adjust and/or & \\
\hline$f_{U}$ & wind speed scaling factor & - & 1 & calibrate model to me- & \\
\hline$f_{\mathrm{AT}}$ & air temperature scaling factor & - & 1 & teorological data & \\
\hline$f_{\mathrm{RH}}$ & relative humidity scaling factor & - & 1 & & \\
\hline$f_{\text {inf }}$ & inflow rate scaling factor & - & 1 & used to adjust flow & \\
\hline$f_{\text {outf }}$ & outflow rate scaling factor & - & 1 & boundary condition & \\
\hline$f_{\text {SWE }}$ & snow-water-equivalent fraction & $\mathrm{m}$ rain $/ \mathrm{m}$ snow & 0.1 & data & \\
\hline$f_{\text {snow }}$ & snow compaction constant & - & computed & Fig. (6) & \\
\hline$f_{\mathrm{WS}}$ & wind-sheltering scaling factor & - & 1 & $\begin{array}{l}\text { function used to scale } \\
\text { the wind-sheltering } \\
\text { length scale or lake } \\
\text { surface area based on } \\
\text { the direction of the } \\
\text { wind }\end{array}$ & \\
\hline$f_{\text {ro }}$ & run-off coefficient & $\mathrm{m}$ run-off / $\mathrm{m}$ rain & 0.2 & $\begin{array}{l}\text { depends on land slope } \\
\text { and soil type }\end{array}$ & \\
\hline$f_{\mathrm{PAR}}$ & $\begin{array}{l}\text { fraction of global incoming radiation flux which } \\
\text { is photosynthetically active }\end{array}$ & - & 0.45 & & $\begin{array}{l}\text { Jellison and } \\
\text { Melack (1993) }\end{array}$ \\
\hline$f_{\mathrm{VIS}}$ & visible bandwidth fraction & - & 0.3 & & $\begin{array}{l}\text { Rogers et } \\
\text { al. (1995) }\end{array}$ \\
\hline$f_{\mathrm{BEN}_{\text {crit }}}$ & $\begin{array}{l}\text { fraction of surface irradiance at the benthos, } \\
\text { which is considered critical for productivity }\end{array}$ & - & 0.2 & set in \&light & \\
\hline
\end{tabular}


Table 1. Continued.

\begin{tabular}{|c|c|c|c|c|c|}
\hline Symbol & Description & Units & Value* & Comments & Reference \\
\hline$f_{\mathrm{W}}$ & friction factor used for current stress calculation & - & computed & Eq. (87) & $\begin{array}{l}\text { Kleinhans and } \\
\text { Grasmeijer } \\
(2006)\end{array}$ \\
\hline$f_{\mathrm{c}}$ & friction factor used for wave stress calculation & - & computed & & \\
\hline$f_{0}$ & $\begin{array}{l}\text { roughness correction coefficient for the lake } \\
\text { surface }\end{array}$ & - & 0.5 & & TVA (1972) \\
\hline$f_{\text {dif }}$ & smoothing factor used for diffusion & - & computed & Eq. (59) & \\
\hline$f_{\alpha}$ & snow albedo scaling factor & - & 1.0 & set in \&snow ice & \\
\hline$g$ & acceleration due to gravity & $\mathrm{m} \mathrm{s}^{-2}$ & 9.81 & & \\
\hline$g_{k^{\prime}}$ & $\begin{array}{l}\text { reduced gravity between the mixed layer and } \\
\text { the } k-1 \text { layer }\end{array}$ & $\mathrm{ms}^{-2}$ & computed & & \\
\hline$g_{\mathrm{EH}^{\prime}}$ & $\begin{array}{l}\text { reduced gravity between the epilimnion and the } \\
\text { hypolimnion }\end{array}$ & $\mathrm{ms}^{-2}$ & computed & & \\
\hline$g_{\text {inf }}^{\prime}$ & $\begin{array}{l}\text { reduced gravity between the inflowing water } \\
\text { and adjacent lake water }\end{array}$ & $\mathrm{m} \mathrm{s}^{-2}$ & computed & & \\
\hline$G$ & seepage rate & $\mathrm{m} \mathrm{day}^{-1}$ & 0 & & \\
\hline$G r$ & Grashof number related to an outflow extraction & - & computed & Eq. (69) & $\begin{array}{l}\text { Imberger and } \\
\text { Patterson (1981) }\end{array}$ \\
\hline$k_{\mathrm{TKE}}$ & turbulence wavenumber & $\mathrm{m}^{-1}$ & computed & Eq. (56) & \\
\hline$K_{\mathrm{W}}$ & light extinction coefficient & $\mathrm{m}^{-1}$ & 0.5 & $\begin{array}{l}\text { set in \&light or up- } \\
\text { dated via the linked wa- } \\
\text { ter quality model; } \\
\text { can be estimated from } \\
\text { Secchi depth data }\end{array}$ & \\
\hline$K_{\mathrm{w}_{l}}$ & $\begin{array}{l}\text { light extinction coefficient of the } l \text { th bandwidth } \\
\text { fraction }\end{array}$ & $\mathrm{m}^{-1}$ & configurable & $\begin{array}{l}\text { set in \&light and } \\
\text { used if light_model }=2\end{array}$ & $\begin{array}{l}\text { Cengel and } \\
\text { Ozisk (1984) }\end{array}$ \\
\hline$K_{\mathrm{w} 1}$ & waveband 1 , white ice light extinction & $\mathrm{m}^{-1}$ & 48.0 & & \\
\hline$K_{\mathrm{w} 2}$ & waveband 2 , white ice light extinction & $\mathrm{m}^{-1}$ & 20.0 & & Rogers \\
\hline$K_{\mathrm{b} 1}$ & waveband 1 , blue ice light extinction & $\mathrm{m}^{-1}$ & 1.5 & & al. (1995), \\
\hline$K_{\mathrm{b} 2}$ & waveband 2 , blue ice light extinction & $\mathrm{m}^{-1}$ & 20.0 & & Patterson and \\
\hline$K_{\mathrm{s} 1}$ & waveband 1 , snow light extinction & $\mathrm{m}^{-1}$ & 6 & & Hamblin (1988) \\
\hline$K_{\mathrm{s} 2}$ & waveband 2 , snow light extinction & $\mathrm{m}^{-1}$ & 20 & & Ashton (1986) \\
\hline$K_{\text {snow }}$ & molecular heat conductivity of snow & $\mathrm{J} \mathrm{m}^{-1} \mathrm{~s}^{-1}{ }^{\circ} \mathrm{C}^{-1}$ & computed & $\begin{array}{l}\text { dependent on snow } \\
\text { density according to } \\
\text { Eq. (35) }\end{array}$ & $\begin{array}{l}\text { Yao } \\
\text { al. (2014) }\end{array}$ \\
\hline$K_{\text {white }}$ & molecular heat conductivity of white ice & $\mathrm{J} \mathrm{m}^{-1} \mathrm{~s}^{-1}{ }^{\circ} \mathrm{C}^{-1}$ & 2.3 & & \\
\hline$K_{\text {blue }}$ & molecular heat conductivity of blue ice & $\mathrm{J} \mathrm{m}^{-1} \mathrm{~s}^{-1}{ }^{\circ} \mathrm{C}^{-1}$ & 2.0 & & \\
\hline$K_{\text {water }}$ & molecular heat conductivity of water & $\mathrm{J} \mathrm{m}^{-1} \mathrm{~s}^{-1}{ }^{\circ} \mathrm{C}^{-1}$ & 0.57 & & \\
\hline$K_{\text {air }}$ & molecular heat conductivity of air & $\mathrm{J} \mathrm{m}^{-1} \mathrm{~s}^{-1{ }^{\circ}} \mathrm{C}^{-1}$ & $2.8 \times 10^{-3}$ & $\begin{array}{l}\text { reported as } \\
0.1 \mathrm{~kJ} \mathrm{~m}^{-1} \mathrm{~h}^{-1} \mathrm{~K}^{-1}\end{array}$ & TVA (1972) \\
\hline$K_{\text {soil }}$ & heat conductivity of soil-sediment & $\mathrm{J} \mathrm{m}^{-1} \mathrm{~s}^{-1}{ }^{\circ} \mathrm{C}^{-1}$ & 1.2 & $\begin{array}{l}\text { varies from } 0.25 \text { for or- } \\
\text { ganic soil to } 2.9 \text { for in- } \\
\text { organic particles }\end{array}$ & \\
\hline$K_{\text {seep }}$ & hydraulic conductivity of soil below the lake & $\mathrm{m} \mathrm{day}^{-1}$ & configurable & set in \&outflows & \\
\hline Lat & latitude & degrees, + for $\mathrm{N}$ & configurable & set in \&morphometry & \\
\hline Long & longitude & degrees + for $E$ & configurable & & \\
\hline$L_{\mathrm{D}}$ & equivalent circular diameter of the lake & $\mathrm{m}$ & computed & & \\
\hline$L_{\mathrm{META}}$ & $\begin{array}{l}\text { length of the lake at the depth of the thermocline } \\
\text { region (metalimnion) }\end{array}$ & $\mathrm{m}$ & computed & & \\
\hline$L_{\text {outf }}$ & $\begin{array}{l}\text { length of the lake at the height of the relevant } \\
\text { outflow }\end{array}$ & $\mathrm{m}$ & computed & & \\
\hline$L_{\text {crest }}$ & $\begin{array}{l}\text { length of the lake at the uppermost height of the } \\
\text { domain }\end{array}$ & $\mathrm{m}$ & configurable & & \\
\hline$m$ & $\begin{array}{l}\text { constant used to compute the rate at which work } \\
\text { from the wind is converted }\end{array}$ & - & $4.6 \times 10^{-7}$ & & \\
\hline$N^{2}$ & $\begin{array}{l}\text { the buoyancy frequency, a measure of water col- } \\
\text { umn stratification }\end{array}$ & $s^{-2}$ & computed & Eq. (53) & \\
\hline
\end{tabular}


Table 1. Continued.

\begin{tabular}{|c|c|c|c|c|c|}
\hline Symbol & Description & Units & Value* & Comments & Reference \\
\hline$N_{\text {outf }}^{2}$ & $\begin{array}{l}\text { the buoyancy frequency, a measure of water col- } \\
\text { umn stratification, about the layers impacted by } \\
\text { the water outflow }\end{array}$ & $s^{-2}$ & computed & Eq. (74) & \\
\hline $\mathrm{Oz}$ & ozone concentration & atm-cm & $0.279-0.324$ & set in \&bird & $\begin{array}{l}\text { Luo et } \\
\text { al. }(2010)\end{array}$ \\
\hline$p$ & air pressure & $\mathrm{hPa}$ & 1013 & $\begin{array}{l}\text { assumed constant or set in } \\
\text { \&bird }\end{array}$ & \\
\hline$Q_{\text {inf }_{x}}$ & $\begin{array}{l}\text { rate of a single water inflow provided by the } \\
\text { user as input to the model }\end{array}$ & $\mathrm{m}^{3} \mathrm{ss}^{-1}$ & time series input & $\begin{array}{l}\text { based on the non_avg flag } \\
\text { in \&glm_setup; the supplied } \\
\text { value at the current time step or } \\
\text { the average of the current and } \\
\text { past time step is used, } \\
\text { depending on whether the daily } \\
\text { data are referenced from mid- } \\
\text { day or midnight }\end{array}$ & \\
\hline$Q_{\text {outf }_{x}}$ & $\begin{array}{l}\text { rate of a single water outflow provided by the } \\
\text { user as input to the model }\end{array}$ & $\mathrm{m}^{3} \mathrm{~s}^{-1}$ & time series input & & \\
\hline$Q_{\text {inf }_{0}}$ & $\begin{array}{l}\text { rate of a single water inflow prior to the inflow } \\
\text { entering the lake }\end{array}$ & $\mathrm{m}^{3} \mathrm{~s}^{-1}$ & computed & $Q_{\text {inf }_{0}}=f_{\text {inf }} Q_{\text {inf }_{x}}$ & \\
\hline$Q_{\inf _{j}}$ & $\begin{array}{l}\text { flow rate of inflow water parcel during transit at } \\
\text { the } j \text { th increment }\end{array}$ & $\mathrm{m}^{3} \mathrm{~s}^{-1}$ & variable & $\begin{array}{l}\text { Eq. (67) used to increment be- } \\
\text { tween } j \text { steps }\end{array}$ & \\
\hline$\Delta Q_{\text {inf }_{j}}$ & $\begin{array}{l}\text { rate of entrained water for an inflow at the } j \text { th } \\
\text { increment }\end{array}$ & $\mathrm{m}^{3} \mathrm{~s}^{-1}$ & computed & & \\
\hline$Q_{\text {inf }_{\text {ins }_{I}}}$ & $\begin{array}{l}\text { flow rate of inflowing water at the point of in- } \\
\text { sertion for inflow } I\end{array}$ & $\mathrm{~m}^{3} \mathrm{~s}^{-1}$ & variable & Fig. 11 & \\
\hline$Q_{\text {outf }}$ & rate of a single water outflow exiting the lake & $\mathrm{m}^{3} \mathrm{~s}^{-1}$ & computed & $Q_{\text {outf }}=f_{\text {outf }} Q_{\text {outf }_{x}}$ & \\
\hline$Q_{\text {outf }_{i}}$ & $\begin{array}{l}\text { flow rate of water being extracted from the } i \text { th } \\
\text { layer }\end{array}$ & $m^{3} s^{-1}$ & computed & $Q_{\text {outf }}=\sum_{i}^{N_{\text {LEV }}} Q_{\text {outf }_{i}}$ & \\
\hline$Q_{\text {ovfl }}$ & rate of overflowing water leaving the lake & $\mathrm{m}^{3} \mathrm{~s}^{-1}$ & computed & Eq. (77) & \\
\hline$Q_{\text {weir }}$ & $\begin{array}{l}\text { flow rate of water discharging over the crest, be- } \\
\text { fore flooding }\end{array}$ & $\mathrm{m}^{3} \mathrm{~s}^{-1}$ & computed & Eq. (76) & \\
\hline$Q_{\text {seepage }}$ & $\begin{array}{l}\text { flow rate of water discharging from the lake bot- } \\
\text { tom via seepage }\end{array}$ & $\mathrm{m}^{3} \mathrm{~s}^{-1}$ & computed & Eq. (75) & \\
\hline$Q_{\mathrm{R}}$ & boundary run-off into the lake surface layer & $\mathrm{m}^{3} \mathrm{~s}^{-1}$ & computed & Eq. (8) & \\
\hline$r$ & water vapour mixing ratio & - & computed & $\begin{array}{l}\text { ratio of water mass to total air } \\
\text { mass }\end{array}$ & \\
\hline$R$ & $\begin{array}{l}\text { dimensionless parameter describing a water } \\
\text { withdrawal flow regime }\end{array}$ & - & computed & Eq. (70) & \\
\hline$R_{x}$ & rainfall rate supplied in the input file & $\mathrm{m} \mathrm{day}^{-1}$ & time series input & user-supplied rainfall rate & \\
\hline$R_{L}$ & rainfall intensity threshold before run-in occurs & $\mathrm{m} \mathrm{day}^{-1}$ & 0.04 & $\begin{array}{l}\text { depends on land slope and soil } \\
\text { type }\end{array}$ & \\
\hline$R_{\text {snow }}$ & $\begin{array}{l}\text { critical rainfall rate incident on snow that con- } \\
\text { trols densification }\end{array}$ & $\mathrm{m} \mathrm{day}^{-1}$ & configurable & set in \&snow ice & \\
\hline$R_{\mathrm{F}}$ & rainfall rate entering the water column & $\mathrm{ms} \mathrm{s}^{-1}$ & computed & Eq. (6) & \\
\hline${ }^{*} R_{\mathrm{F}}$ & rainfall rate incident on the ice-snow layer & $\mathrm{m} \mathrm{s}^{-1}$ & computed & ${ }^{*} R_{\mathrm{F}}=f_{\mathrm{R}} R_{x} / c_{\text {secday }}$ & \\
\hline$R i_{\text {inf }}$ & Richardson number of the inflow water & - & computed & Eq. (61) & \\
\hline$R i_{\mathrm{B}}$ & $\begin{array}{l}\text { bulk Richardson number of the atmosphere over } \\
\text { the lake }\end{array}$ & - & computed & Eq. (A34) & \\
\hline $\mathrm{RH}_{x}$ & relative humidity & $\%$ & time series input & user-supplied humidity & \\
\hline$S_{x}$ & snowfall rate supplied in the input file & $\mathrm{m} \mathrm{day}^{-1}$ & time series input & user-supplied snowfall rate & \\
\hline$S_{\mathrm{F}}$ & snowfall rate entering the water column & $\mathrm{m} \mathrm{s}^{-1}$ & computed & Eq. (7) & \\
\hline${ }^{*} S_{\mathrm{F}}$ & snowfall rate incident on the ice-snow layer & $\mathrm{m} \mathrm{s}^{-1}$ & computed & ${ }^{*} S_{\mathrm{F}}=f_{\mathrm{S}} S_{x} / c_{\text {secday }}$ & \\
\hline$S_{i}$ & salinity of the $i$ th layer & $\%$ & variable & & \\
\hline$S_{\text {inf }_{x}}$ & salinity of water entering in an inflow & $\mathrm{g} \mathrm{m}^{-3}$ & time series input & & \\
\hline$S_{\text {outf }}$ & salinity of outflowing water & $\mathrm{g} \mathrm{m}^{-3}$ & variable & & \\
\hline SZA & solar zenith angle & degrees & variable & $\mathrm{SZA}=\Phi_{\mathrm{zen}} 180 / \pi$ & \\
\hline$T_{\mathrm{S}}$ & temperature of the surface layer & ${ }^{\circ} \mathrm{C}$ & variable & Eq. (9) & \\
\hline$T_{x}$ & air temperature supplied by the user & ${ }^{\circ} \mathrm{C}$ & time series input & user-supplied air temperature & \\
\hline
\end{tabular}


Table 1. Continued.

\begin{tabular}{|c|c|c|c|c|c|}
\hline Symbol & Description & Units & Value* & Comments & Reference \\
\hline$T_{\mathrm{a}}$ & air temperature & ${ }^{\circ} \mathrm{C}$ & computed & $T_{\mathrm{a}}=f_{\mathrm{AT}} T_{x}$ & \\
\hline$T_{\mathrm{d}}$ & dew point temperature & ${ }^{\circ} \mathrm{C}$ & computed & & \\
\hline$T_{i}$ & temperature of the $i$ th layer & ${ }^{\circ} \mathrm{C}$ & variable & & \\
\hline$T_{\mathrm{m}}$ & meltwater temperature & ${ }^{\circ} \mathrm{C}$ & 0 & & \\
\hline$T_{0}$ & temperature at the solid (ice-snow) surface & ${ }^{\circ} \mathrm{C}$ & variable & & \\
\hline$T_{\text {inf }_{x}}$ & temperature of water entering in an inflow & ${ }^{\circ} \mathrm{C}$ & time series input & & \\
\hline$T_{\text {outf }}$ & temperature of outflowing water & ${ }^{\circ} \mathrm{C}$ & variable & & \\
\hline$T_{z_{i}}$ & $\begin{array}{l}\text { temperature of the sediment zone } z \text {, which un- } \\
\text { derlies layer } i\end{array}$ & ${ }^{\circ} \mathrm{C}$ & computed & Eq. (40) & \\
\hline$T_{z_{\text {mean }}}$ & $\begin{array}{l}\text { annual mean temperature of the } z \text { th sediment } \\
\text { zone }\end{array}$ & ${ }^{\circ} \mathrm{C}$ & configurable & $\begin{array}{l}\text { set in } \& \text { sediment; corre- } \\
\text { sponds to the sediment tem- } \\
\text { perature at a depth of } \delta z_{\text {soil }}\end{array}$ & \\
\hline$\delta T_{z}$ & $\begin{array}{l}\text { seasonal amplitude of the soil temperature vari- } \\
\text { ation }\end{array}$ & ${ }^{\circ} \mathrm{C}$ & configurable & set in $\&$ sediment & \\
\hline$T_{\mathrm{aa}}$ & $\begin{array}{l}\text { aerosol absorptance of incoming light in the at- } \\
\text { mosphere }\end{array}$ & - & computed & Eq. (A17) & \\
\hline$T_{\text {aerosol }}$ & $\begin{array}{l}\text { light scattering due to aerosols in the atmo- } \\
\text { sphere }\end{array}$ & - & computed & Eq. (A16) & \\
\hline$T_{\operatorname{mix}}$ & $\begin{array}{l}\text { light absorptance due to mixed gases in the at- } \\
\text { mosphere }\end{array}$ & - & computed & Eq. (A11) & \\
\hline$T_{\text {ozone }}$ & $\begin{array}{l}\text { ozone absorptance of incident light in the atmo- } \\
\text { sphere }\end{array}$ & - & computed & Eq. (A10) & \\
\hline$T_{\text {rayleigh }}$ & $\begin{array}{l}\text { Rayleigh scattering of incident light in the at- } \\
\text { mosphere }\end{array}$ & - & computed & Eq. (A9) & \\
\hline$T_{\text {watvap }}$ & $\begin{array}{l}\text { absorptance of incident light in the atmosphere } \\
\text { due to water vapour }\end{array}$ & - & computed & Eq. (A14) & \\
\hline$U_{10}$ & $\begin{array}{l}\text { wind speed above the lake referenced to } 10 \mathrm{~m} \text { of } \\
\text { height }\end{array}$ & $\mathrm{m} \mathrm{s}^{-1}$ & computed & $\begin{array}{l}\text { wind speed corrected to ref- } \\
\text { erence height }\end{array}$ & \\
\hline$U_{x}$ & $\begin{array}{l}\text { wind speed above the lake surface provided by } \\
\text { the user }\end{array}$ & $\mathrm{ms}^{-1}$ & time series input & user-supplied snowfall rate & \\
\hline$U_{\text {orb }_{i}}$ & $\begin{array}{l}\text { orbital wave velocity experienced at the bottom } \\
\text { of the } i \text { th layer }\end{array}$ & $\mathrm{m} \mathrm{s}^{-1}$ & variable & Eq. (84) & \\
\hline$U_{\mathrm{m}_{i}}$ & mean layer velocity of the $i$ th layer & $\mathrm{m} \mathrm{s}^{-1}$ & variable & Eq. (86) & \\
\hline$u_{\text {inf }_{j}}$ & $\begin{array}{l}\text { average velocity of an inflow parcel being } \\
\text { tracked, prior to insertion }\end{array}$ & $\mathrm{m} \mathrm{s}^{-1}$ & variable & Eq. (66) & \\
\hline$u_{*}$ & friction velocity & $\mathrm{m} \mathrm{s}^{-1}$ & computed & Eq. (44) & \\
\hline$u_{\mathrm{b}}$ & velocity shear at the base of the thermocline & $\mathrm{ms}^{-1}$ & variable & Eq. (46) & \\
\hline$u_{\mathrm{b}_{\text {old }}}$ & $\begin{array}{l}\text { velocity shear at the thermocline at the previous } \\
\text { time step }\end{array}$ & $\mathrm{m} \mathrm{s}^{-1}$ & variable & reset between shear events & \\
\hline$w_{*}^{3}$ & $\begin{array}{l}\text { turbulent velocity scale within the surfaced } \\
\text { mixed layer due to convective cooling }\end{array}$ & $\mathrm{m}^{3} \mathrm{~s}^{-3}$ & computed & Eq. (43) & $\begin{array}{l}\text { Imberger and } \\
\text { Patterson } \\
(1981)\end{array}$ \\
\hline$W$ & total precipitable water vapour & atm-cm & $1.1-2.2$ & Eq. (A13) & $\begin{array}{l}\text { Luo et } \\
\text { al. (2010) }\end{array}$ \\
\hline $\mathrm{Wm}$ & $\begin{array}{l}\text { atmospheric water mass factor computed for } \\
\text { calculating water scattering }\end{array}$ & - & computed & Eq. (A12) & \\
\hline$W_{\text {crest }}$ & width of the lake at the uppermost point & $\mathrm{m}$ & configurable & set in \&morphometry & \\
\hline$W_{\text {outf }}$ & width of the lake at the height of an outflow & $\mathrm{m}$ & computed & Eq. (72) & \\
\hline$x_{\mathrm{WS}}$ & $\begin{array}{l}\text { default sheltering distance defined as the dis- } \\
\text { tance from the shoreline at which wind stress } \\
\text { is no longer affected by sheltering }\end{array}$ & $\mathrm{m}$ & configurable & $\begin{array}{l}\text { set in \&fetch; approxi- } \\
\text { mated as } 50 \times \text { the verti- } \\
\text { cal height of the sheltering } \\
\text { obstacle-landform }\end{array}$ & $\begin{array}{l}\text { Markfort et } \\
\text { al. }(2010)\end{array}$ \\
\hline$x_{\mathrm{WS}}^{\Phi}$ & $\begin{array}{l}\text { sheltering distance adjusted for changes in wind } \\
\text { direction }\end{array}$ & $\mathrm{m}$ & computed & $\begin{array}{l}x_{\mathrm{WS}}^{\Phi}= \\
x_{\mathrm{WS}}\left(1-\min \left(f_{\mathrm{WS}}\left[\Phi_{\text {wind }}\right], 1\right.\right.\end{array}$ & \\
\hline$\delta x_{\text {wave }}$ & wavelength of surface waves & $\mathrm{m}$ & computed & Eq. (81) & \\
\hline$\Delta x_{\text {inf }_{j}}$ & $\begin{array}{l}\text { lateral distance travelled by an inflow parcel per } \\
j \text { increment, prior to insertion }\end{array}$ & $\mathrm{m}$ & computed & Eq. (65) & \\
\hline
\end{tabular}


Table 1. Continued.

\begin{tabular}{|c|c|c|c|c|c|}
\hline Symbol & Description & Units & Value* & Comments & Reference \\
\hline$\alpha_{\text {inf }}$ & $\begin{array}{l}\text { angle describing the width of an inflow river } \\
\text { channel }\end{array}$ & degrees & configurable & $\begin{array}{l}\text { user-supplied in \&inflow } \\
\text { based on width and depth of } \\
\text { the relevant river }\end{array}$ & \\
\hline$\alpha_{\mathrm{h}}$ & coefficient for sensible heat flux into still air & $\mathrm{J} \mathrm{m}^{-2} \mathrm{~s}^{-1}{ }^{\circ} \mathrm{C}^{-1}$ & computed & Eq. $(29 b)$ & TVA (1972) \\
\hline$\alpha_{\mathrm{e}}$ & coefficient for evaporative flux into still air & $\mathrm{ms}^{-1}$ & computed & Eq. (29a) & TVA (1972) \\
\hline$\alpha_{\mathrm{LW}}$ & longwave albedo & - & 0.03 & & \\
\hline$\alpha_{\mathrm{SW}}$ & $\begin{array}{l}\text { albedo of shortwave radiation at the water sur- } \\
\text { face }\end{array}$ & - & computed & $\begin{array}{l}\text { Eq. (13) for water; uses } \\
\text { empirical algorithm for ice } \\
\text { cover }\end{array}$ & \\
\hline$\alpha_{\mathrm{SW}_{\text {mean }}}$ & annual mean albedo of shortwave radiation & & 0.08 & $\begin{array}{l}\text { active if albedo_mode }=1 \text { in } \\
\text { \&light }\end{array}$ & \\
\hline$\alpha_{\mathrm{SW}_{G}}$ & $\begin{array}{l}\text { function to compute albedo of shortwave radi- } \\
\text { ation as a function of latitude and day number }\end{array}$ & & computed & $\begin{array}{l}\text { function } \alpha_{\mathrm{SW}_{G}}[d, \text { Lat }] \text { is } \\
\text { called if albedo_mode }=4 \text { in } \\
\text { \&light }\end{array}$ & $\begin{array}{l}\text { Table } 5 \text { in } \\
\text { Cogley (1979) }\end{array}$ \\
\hline$\alpha_{\mathrm{SKY}}$ & scattered radiation within the sky & - & computed & Eq. (A22) & Bird (1984) \\
\hline$\alpha_{\text {sed }}$ & $\begin{array}{l}\text { reflected fraction of radiation reaching the } \\
\text { sediment }\end{array}$ & - & configurable & $\begin{array}{l}\text { set in \&sediment and can } \\
\text { vary with depth if sediment } \\
\text { zones are configured }\end{array}$ & \\
\hline$\alpha_{\mathrm{b}}$ & interpolation coefficient for volume & - & computed & Eq. (3) & \\
\hline$\beta_{\mathrm{b}}$ & interpolation coefficient for area & - & computed & Eq. (3) & \\
\hline$\delta_{\mathrm{wi}}$ & $\begin{array}{l}\text { length scale associated with conduction of } \\
\text { heat at the ice-water interface }\end{array}$ & $\mathrm{m}$ & 0.1 & & $\begin{array}{l}\text { Rogers et } \\
\text { al. (1995) }\end{array}$ \\
\hline$\delta_{\mathrm{KH}}$ & $\begin{array}{l}\text { length scale associated with formation of } \\
\text { Kelvin-Helmholtz billows at the interface of } \\
\text { two-layer stratification }\end{array}$ & $\mathrm{m}$ & computed & $\delta_{\mathrm{KH}}=C_{\mathrm{KH}} u_{\mathrm{b}}^{2} / g_{\mathrm{EH}^{\prime}}$ & $\begin{array}{l}\text { Imberger and } \\
\text { Patterson } \\
(1981)\end{array}$ \\
\hline$\delta_{\text {epi }}$ & length scale associated with the epilimnion & $\mathrm{m}$ & computed & Eq. (49) & \\
\hline$\delta_{\text {hyp }}$ & length scale associated with the hypolimnion & $\mathrm{m}$ & computed & Eq. (49) & \\
\hline$\delta_{\text {outf }}$ & $\begin{array}{l}\text { length scale associated with the vertical thick- } \\
\text { ness of the zone of influence of a withdrawal }\end{array}$ & $\mathrm{m}$ & computed & Eq. (73) & $\begin{array}{l}\text { Imberger and } \\
\text { Patterson } \\
(1981)\end{array}$ \\
\hline$\delta_{\text {outf }}$ & $\begin{array}{l}\text { thickness of withdrawal layer above the with- } \\
\text { drawal height }\end{array}$ & $\mathrm{m}$ & computed & & \\
\hline$\delta_{\text {outf }}$ bot & $\begin{array}{l}\text { thickness of withdrawal layer below the with- } \\
\text { drawal height }\end{array}$ & $\mathrm{m}$ & computed & & \\
\hline$\delta \alpha_{\mathrm{SW}}$ & seasonal amplitude of albedo change & - & $0.01-0.08$ & $\begin{array}{l}\text { active if albedo_mode }=1 \text { in } \\
\text { \&light }\end{array}$ & Cogley (1979) \\
\hline$\delta_{\mathrm{ss}}$ & particle diameter of bottom sediment & $\mathrm{m}$ & $80 \times 10^{-6}$ & & \\
\hline$\varepsilon$ TKE & TKE dissipation flux per unit mass & $\mathrm{m}^{2} \mathrm{~s}^{-3}$ & - & Eq. (54) & \\
\hline$\overline{\varepsilon \mathrm{TKE}}$ & $\begin{array}{l}\text { steady-state-equilibrium TKE dissipation flux } \\
\text { per unit mass }\end{array}$ & $\mathrm{m}^{2} \mathrm{~s}^{-3}$ & computed & Eq. (55) & \\
\hline$\varepsilon$ WIND & $\begin{array}{l}\text { TKE dissipation flux created by power intro- } \\
\text { duced by the wind }\end{array}$ & $\mathrm{m}^{2} \mathrm{~s}^{-3}$ & computed & Eq. (55) & \\
\hline$\varepsilon_{\text {INFLOW }}$ & $\begin{array}{l}\text { TKE dissipation flux caused by inflow plung- } \\
\text { ing creating seiching }\end{array}$ & $\mathrm{m}^{2} \mathrm{~s}^{-3}$ & computed & Eq. (55) & \\
\hline$\varepsilon_{\mathrm{W}}$ & emissivity of the water surface & - & 0.985 & & \\
\hline$\varepsilon_{\mathrm{a}}$ & $\begin{array}{l}\text { emissivity of the atmosphere under cloud-free } \\
\text { conditions }\end{array}$ & - & computed & $\varepsilon_{\mathrm{a}}^{*}\left[T_{\mathrm{a}}, e_{\mathrm{a}}, C_{x}=0\right]$ & \\
\hline$\varepsilon_{\mathrm{a}}^{*}$ & $\begin{array}{l}\text { emissivity of the atmosphere including cloud } \\
\text { effects }\end{array}$ & - & computed & $\begin{array}{l}\text { Eq. ( } 21) \text {; options are chosen } \\
\text { via the cloud_mode vari- } \\
\text { able in \&meteorology }\end{array}$ & $\begin{array}{l}\text { Henderson- } \\
\text { Sellers (1986) }\end{array}$ \\
\hline$\epsilon$ & $\begin{array}{l}\text { factor for incident radiation from atmospheric } \\
\text { calculation }\end{array}$ & - & computed & Eq. (A18) & Bird (1984) \\
\hline$\phi_{\mathrm{SW}_{x}}$ & $\begin{array}{l}\text { shortwave radiation flux provided in the input } \\
\text { file }\end{array}$ & $\mathrm{W} \mathrm{m}^{-2}$ & time series input & $\begin{array}{l}\text { user-supplied solar radia- } \\
\text { tion data }\end{array}$ & \\
\hline$\phi_{\mathrm{SW}_{0}}$ & $\begin{array}{l}\text { shortwave radiation flux crossing the water } \\
\text { surface }\end{array}$ & $\mathrm{W} \mathrm{m}{ }^{-2}$ & computed & Eq. (10) & \\
\hline$\phi_{\mathrm{SW}_{\mathrm{S}}}$ & $\begin{array}{l}\text { shortwave radiation flux heating the surface } \\
\text { mixed layer }\end{array}$ & $\mathrm{W} \mathrm{m}^{-2}$ & computed & & \\
\hline$\phi_{\mathrm{SW}_{i_{l}}}$ & $\begin{array}{l}\text { radiation flux at the top of the } i \text { th layer for the } \\
l \text { th bandwidth class }\end{array}$ & $\mathrm{W} \mathrm{m}^{-2}$ & computed & $\begin{array}{l}\text { bandwidth-specific light at- } \\
\text { tenuation is computed if } \\
\text { light_model=2 in \&light }\end{array}$ & \\
\hline
\end{tabular}


Table 1. Continued.

\begin{tabular}{|c|c|c|c|c|c|}
\hline Symbol & Description & Units & Value* & Comments & Reference \\
\hline$\hat{\phi}_{\mathrm{SW}}$ & $\begin{array}{l}\text { total incident shortwave radiation flux computed } \\
\text { from the BCSM assuming clear-sky conditions }\end{array}$ & $\mathrm{W} \mathrm{m}^{-2}$ & computed & Eq. (11) and Appendix A & Bird (1984) \\
\hline$\hat{\phi}_{\mathrm{DB}}$ & $\begin{array}{l}\text { direct beam radiation on a horizontal surface at } \\
\text { ground level on a clear day }\end{array}$ & $\mathrm{W} \mathrm{m}{ }^{-2}$ & computed & Eq. (A19) & \\
\hline$\hat{\phi}_{\mathrm{AS}}$ & $\begin{array}{l}\text { radiation from atmospheric scattering hitting } \\
\text { ground level on a clear day }\end{array}$ & $\mathrm{W} \mathrm{m}^{-2}$ & computed & Eq. (A20) & \\
\hline$\hat{\phi}_{\mathrm{ETR}}$ & $\begin{array}{l}\text { extraterrestrial radiation hitting the top of the atmo- } \\
\text { sphere }\end{array}$ & $\mathrm{W} \mathrm{m}^{-2}$ & computed & Eq. (A1) & \\
\hline$\phi_{\mathrm{PAR}}$ & $\begin{array}{l}\text { downwelling photosynthetically active radiation in- } \\
\text { tensity within the water column }\end{array}$ & $\mathrm{W} \mathrm{m}^{-2}$ & computed & Eq. (14) & Kirk (1994) \\
\hline$\phi_{\mathrm{PAR}_{\mathrm{BEN}}}$ & $\begin{array}{l}\text { light incident on the bottom of a layer correspond- } \\
\text { ing to the benthic area }\end{array}$ & $\mathrm{W} \mathrm{m}^{-2}$ & variable & & \\
\hline$\phi_{\mathrm{LW}_{\text {in }}}$ & $\begin{array}{l}\text { longwave radiation incident heat flux at the water } \\
\text { surface }\end{array}$ & $\mathrm{W} \mathrm{m}{ }^{-2}$ & variable & Eq. (20) & \\
\hline$\phi_{\mathrm{LW}_{\text {out }}}$ & $\begin{array}{l}\text { longwave radiation outgoing heat flux from the wa- } \\
\text { ter surface }\end{array}$ & $\mathrm{W} \mathrm{m}^{-2}$ & variable & Eq. (19) & \\
\hline$\phi_{\mathrm{LW}_{\text {net }}}$ & net longwave radiation flux across the lake surface & $\mathrm{W} \mathrm{m}^{-2}$ & computed & Eq. (18) & \\
\hline$\phi_{\mathrm{H}}$ & sensible heat flux across the water surface & $\mathrm{W} \mathrm{m}^{-2}$ & computed & Eq. (22) & \\
\hline$\phi_{\mathrm{E}}$ & latent heat flux & $\mathrm{W} \mathrm{m}^{-2}$ & computed & Eq. (23) & \\
\hline$\phi_{\mathrm{E}_{0}}$ & latent heat flux under zero-wind conditions & $\mathrm{W} \mathrm{m}^{-2}$ & computed & Eq. (28a) & \\
\hline$\phi_{\mathrm{H}_{0}}$ & sensible heat flux under zero-wind conditions & $\mathrm{W} \mathrm{m}^{-2}$ & computed & Eq. (28b) & \\
\hline$\phi_{X}$ & generic identifier for either of $\phi_{\mathrm{E}}$ or $\phi_{\mathrm{H}}$ & $\mathrm{W} \mathrm{m}^{-2}$ & computed & & \\
\hline$\phi_{X_{0}}$ & generic identifier for either of $\phi_{E_{0}}$ or $\phi_{H_{0}}$ & $\mathrm{~W} \mathrm{~m}^{-2}$ & computed & & \\
\hline$\phi_{X}^{*}$ & maximum value of either $\phi_{X_{0}}$ or $\phi_{X}$ & $\mathrm{~W} \mathrm{~m}^{-2}$ & selected & Eq. (27) & \\
\hline$\phi_{0}$ & $\begin{array}{l}\text { upward conductive heat flux through the ice and } \\
\text { snow cover to the atmosphere }\end{array}$ & $\mathrm{W} \mathrm{m}^{-2}$ & computed & Eq. (34) & \\
\hline$\phi_{\text {net }}$ & $\begin{array}{l}\text { net incoming heat flux at the ice-atmosphere inter- } \\
\text { face }\end{array}$ & $\mathrm{W} \mathrm{m}^{-2}$ & computed & Eq. (33) & $\begin{array}{l}\text { Rogers et } \\
\text { al. (1995) }\end{array}$ \\
\hline$\phi_{\mathrm{R}}$ & heat flux due to rainfall & $\mathrm{W} \mathrm{m}^{-2}$ & computed & & $\begin{array}{l}\text { Rogers et } \\
\text { al. (1995) }\end{array}$ \\
\hline$\phi_{\mathrm{f}}$ & heat flux in the blue ice near the ice-water interface & $\mathrm{W} \mathrm{m}^{-2}$ & computed & Eq. (36) & \\
\hline$\phi_{\mathrm{w}}$ & heat flux from the water to the blue ice & $\mathrm{W} \mathrm{m}^{-2}$ & computed & Eq. (37) & \\
\hline$\phi_{\mathrm{si}}$ & $\begin{array}{l}\text { heat flux per unit volume due to formation of white } \\
\text { ice by flooding }\end{array}$ & $\mathrm{W} \mathrm{m}^{-3}$ & computed & & $\begin{array}{l}\text { Rogers et } \\
\text { al. (1995) }\end{array}$ \\
\hline$\Phi_{\text {zen }}$ & solar zenith angle & radians & variable & Eq. (A6) & \\
\hline$\Phi_{\text {day }}$ & day angle & radians & computed & Eq. (A2) & \\
\hline$\Phi_{\mathrm{dec}}$ & solar declination angle & radians & computed & Eq. (A3) & \\
\hline$\Phi_{\mathrm{hr}}$ & hour angle & radians & computed & Eq. (A5) & \\
\hline$\Phi_{\text {wind }}$ & wind direction & degrees & time series input & $\begin{array}{l}\text { optionally provided as a } \\
\text { boundary condition based } \\
\text { on fetch_mode, set in } \\
\text { \&fetch }\end{array}$ & \\
\hline$\Phi_{\text {inf }}$ & $\begin{array}{l}\text { angle of the lakebed slope in the region where the } \\
\text { inflow enters the lake }\end{array}$ & degrees & configurable & user-provided in \&inflow & \\
\hline$\kappa$ & von Karman's constant & - & 0.41 & & \\
\hline$\lambda_{\mathrm{V}}$ & latent heat of evaporation & $\mathrm{J} \mathrm{kg}^{-1}$ & $2.453 \times 10^{6}$ & & \\
\hline$\lambda_{\mathrm{f}}$ & latent heat of fusion & $\mathrm{J} \mathrm{kg}^{-1}$ & $3.340 \times 10^{5}$ & & \\
\hline$\lambda_{\text {snow }}$ & $\begin{array}{l}\text { coefficient controlling the rate of densification of } \\
\text { snow following rainfall }\end{array}$ & - & computed & $\begin{array}{l}\lambda_{\text {snow }}= \\
{ }^{*} R_{\mathrm{F}} c_{\text {secday }} / R_{\text {snow }}\end{array}$ & $\begin{array}{l}\text { adapted from } \\
\text { Rogers et } \\
\text { al. (1995) }\end{array}$ \\
\hline$\Lambda$ & $\begin{array}{l}\text { dimensionless variable associated with light pene- } \\
\text { tration through ice required }\end{array}$ & - & computed & $\begin{array}{l}\text { for heat conduction calcula- } \\
\text { tion }\end{array}$ & \\
\hline$\theta_{\mathrm{V}}$ & $\begin{array}{l}\text { virtual temperature of the atmospheric boundary } \\
\text { layer above the lake }\end{array}$ & $\mathrm{K}$ & computed & & \\
\hline$\theta_{\mathrm{a}}$ & $\begin{array}{l}\text { temperature of the atmospheric boundary layer } \\
\text { above the lake }\end{array}$ & $\mathrm{K}$ & computed & $\theta_{\mathrm{a}}=f_{\mathrm{AT}} T_{x}+273.15$ & \\
\hline$\theta_{\mathrm{s}}$ & temperature of the atmosphere at the lake surface & $\mathrm{K}$ & variable & $\theta_{\mathrm{s}}=T_{\mathrm{S}}+273.15$ & \\
\hline
\end{tabular}


Table 1. Continued.

\begin{tabular}{|c|c|c|c|c|c|}
\hline Symbol & Description & Units & Value* & Comments & Reference \\
\hline$\theta_{*}$ & temperature scale & $\mathrm{K}$ & computed & & \\
\hline$\rho_{\mathrm{a}}$ & air density & $\mathrm{kg} \mathrm{m}^{-3}$ & computed & $\begin{array}{l}\text { computed as a function of } \\
\text { air temperature, humidity, } \\
\text { and pressure in atm_density }\end{array}$ & TVA (1972) \\
\hline$\rho_{o}$ & $\begin{array}{l}\text { density of saturated air at the water surface temper- } \\
\text { ature }\end{array}$ & $\mathrm{kg} \mathrm{m}^{-3}$ & computed & & \\
\hline \multirow[t]{3}{*}{$\rho_{i}$} & density of the $i$ th layer & $\mathrm{kg} \mathrm{m}^{-3}$ & variable & $\begin{array}{l}\text { compute for each layer } \\
\text { based on temperature and } \\
\text { salinity using TEOS-10 }\end{array}$ & $\begin{array}{l}\text { TEOS-10: http: } \\
\text { //teos-10.org } \\
\text { (last ac- }\end{array}$ \\
\hline & & & & $\begin{array}{l}\text { or UNESCO (1981); } \\
\text { set density model in }\end{array}$ & $\begin{array}{l}\text { cess: } 14 \text { Jan- } \\
\text { uary } 2019)\end{array}$ \\
\hline & & & & \&glm_setup & $\begin{array}{l}\text { UNESCO } \\
(1981)\end{array}$ \\
\hline$\rho_{\mathrm{S}}$ & density of the surface water layer $\left(i=N_{\mathrm{LEV}}\right)$ & $\mathrm{kg} \mathrm{m}^{-3}$ & variable & & \\
\hline$\rho_{\mathrm{W}}$ & reference water density & $\mathrm{kg} \mathrm{m}^{-3}$ & 1000 & & \\
\hline$\rho_{\mathrm{SML}}$ & mean density of the mixed layer & $\mathrm{kg} \mathrm{m}^{-3}$ & variable & & \\
\hline$\rho_{\text {ref }}$ & $\begin{array}{l}\text { average of layer densities over which reduced grav- } \\
\text { ity is being computed }\end{array}$ & $\mathrm{kg} \mathrm{m}^{-3}$ & computed & & \\
\hline$\rho_{\text {ice, snow }}$ & density of the snow or ice & $\mathrm{kg} \mathrm{m}^{-3}$ & selected & & \\
\hline$\rho_{\text {white }}$ & density of white ice & $\mathrm{kg} \mathrm{m}^{-3}$ & 890 & & \\
\hline$\rho_{\text {blue }}$ & density of blue ice & $\mathrm{kg} \mathrm{m}^{-3}$ & 917 & & \\
\hline$\rho_{\text {snow }}$ & density of snow & $\mathrm{kg} \mathrm{m}^{-3}$ & variable & & \\
\hline$\rho_{\mathrm{s}, \min }$ & assigned minimum snow density & $\mathrm{kg} \mathrm{m}^{-3}$ & 50 & set in \&snow ice & \\
\hline$\rho_{\mathrm{S}, \max }$ & assigned maximum snow density & $\mathrm{kg} \mathrm{m}^{-3}$ & 300 & set in \&snow ice & \\
\hline$\rho_{\text {snow } *}$ & intermediate snow density estimate & $\mathrm{kg} \mathrm{m}^{-3}$ & computed & see Fig. 6 & \\
\hline$\rho_{\text {outf }}$ & $\begin{array}{l}\text { density of the lake layer corresponding to the height } \\
\text { of withdrawal, } i_{\text {outf }}\end{array}$ & $\mathrm{kg} \mathrm{m}^{-3}$ & computed & & \\
\hline$\rho_{i j}$ & $\begin{array}{l}\text { density of the lake layer, } i \text {, which is at an equivalent } \\
\text { depth to inflow parcel } j\end{array}$ & $\mathrm{~kg} \mathrm{~m}^{-3}$ & computed & & \\
\hline$\rho_{\mathrm{inf}}$ & density of inflowing water as it enters the lake & $\mathrm{kg} \mathrm{m}^{-3}$ & computed & & \\
\hline$\rho_{\text {inf }_{j}}$ & $\begin{array}{l}\text { density of inflowing water parcel at the } j \text { th incre- } \\
\text { ment during its transit }\end{array}$ & $\mathrm{kg} \mathrm{m}^{-3}$ & computed & & \\
\hline$\rho_{\text {inf }_{\text {ins }}}$ & $\begin{array}{l}\text { density of the inflow parcel associated with inflow } \\
I \text { when it inserted }\end{array}$ & $\mathrm{kg} \mathrm{m}^{-3}$ & computed & & \\
\hline$\rho_{i_{\text {ins }_{I}}}$ & $\begin{array}{l}\text { density of the lake layer, } i \text {, for which the inflow } I \\
\text { inserted }\end{array}$ & $\mathrm{kg} \mathrm{m}^{-3}$ & computed & & \\
\hline$\sigma$ & Stefan-Boltzmann constant & $\mathrm{W} \mathrm{m}^{-2} \mathrm{~K}^{-4}$ & $5.67 \times 10^{-8}$ & & \\
\hline$\tau_{i}$ & $\begin{array}{l}\text { total shear stress experienced at the lakebed portion } \\
\text { of layer } i\end{array}$ & $\mathrm{Nm}^{-2}$ & computed & Eq. (85) & \\
\hline$\vartheta_{\mathrm{s}}$ & $\begin{array}{l}\text { dimensionless moisture content of air at the water } \\
\text { surface }\end{array}$ & - & computed & $\vartheta_{\mathrm{S}}=\kappa e_{\mathrm{S}} / p$ & TVA (1972) \\
\hline$\vartheta_{\mathrm{a}}$ & $\begin{array}{l}\text { dimensionless moisture content of the air above the } \\
\text { lake }\end{array}$ & - & computed & $\vartheta_{\mathrm{a}}=\kappa e_{\mathrm{a}} / p$ & \\
\hline$v_{\mathrm{a}}$ & kinematic viscosity of air & $\mathrm{m}^{2} \mathrm{~s}^{-1}$ & $1.52 \times 10^{-5}$ & $\begin{array}{l}\text { reported as } \\
0.0548 \mathrm{~m}^{2} \mathrm{~h}^{-1}\end{array}$ & \\
\hline$v_{\mathrm{W}}$ & kinematic viscosity of water & $\mathrm{m}^{2} \mathrm{~s}^{-1}$ & $1.14 \times 10^{-6}$ & & \\
\hline$\omega$ & $\begin{array}{l}\text { ratio of molecular weight of water to molecular } \\
\text { weight of air }\end{array}$ & - & 0.622 & & \\
\hline$\psi_{\mathrm{M}}$ & $\begin{array}{l}\text { similarity function for momentum in the air above } \\
\text { the lake }\end{array}$ & - & computed & Eq. A30 & \\
\hline$\psi_{\mathrm{E}}$ & $\begin{array}{l}\text { similarity function for moisture in the air above the } \\
\text { lake }\end{array}$ & - & computed & & \\
\hline$\psi_{\mathrm{H}}$ & similarity function for heat in the air above the lake & - & computed & & \\
\hline$\xi$ & $\begin{array}{l}\text { dimensionless parameter used for wave period cal- } \\
\text { culation }\end{array}$ & - & computed & Eq. (80) & \\
\hline$\zeta$ & $\begin{array}{l}\text { dimensionless parameter used for wave height cal- } \\
\text { culation }\end{array}$ & - & computed & Eq. (83) & \\
\hline$\varsigma$ & percentage of atmospheric diffuse radiation & $\%$ & 6 & & $\begin{array}{l}\text { Yajima and Ya- } \\
\text { mamoto (2015) }\end{array}$ \\
\hline
\end{tabular}

* Either a numeric value for fixed constants or descriptors of the source of the value are provided. Descriptors include index, computed, configurable (default), variable, selected, or time series input, with supporting information in the comment column. 


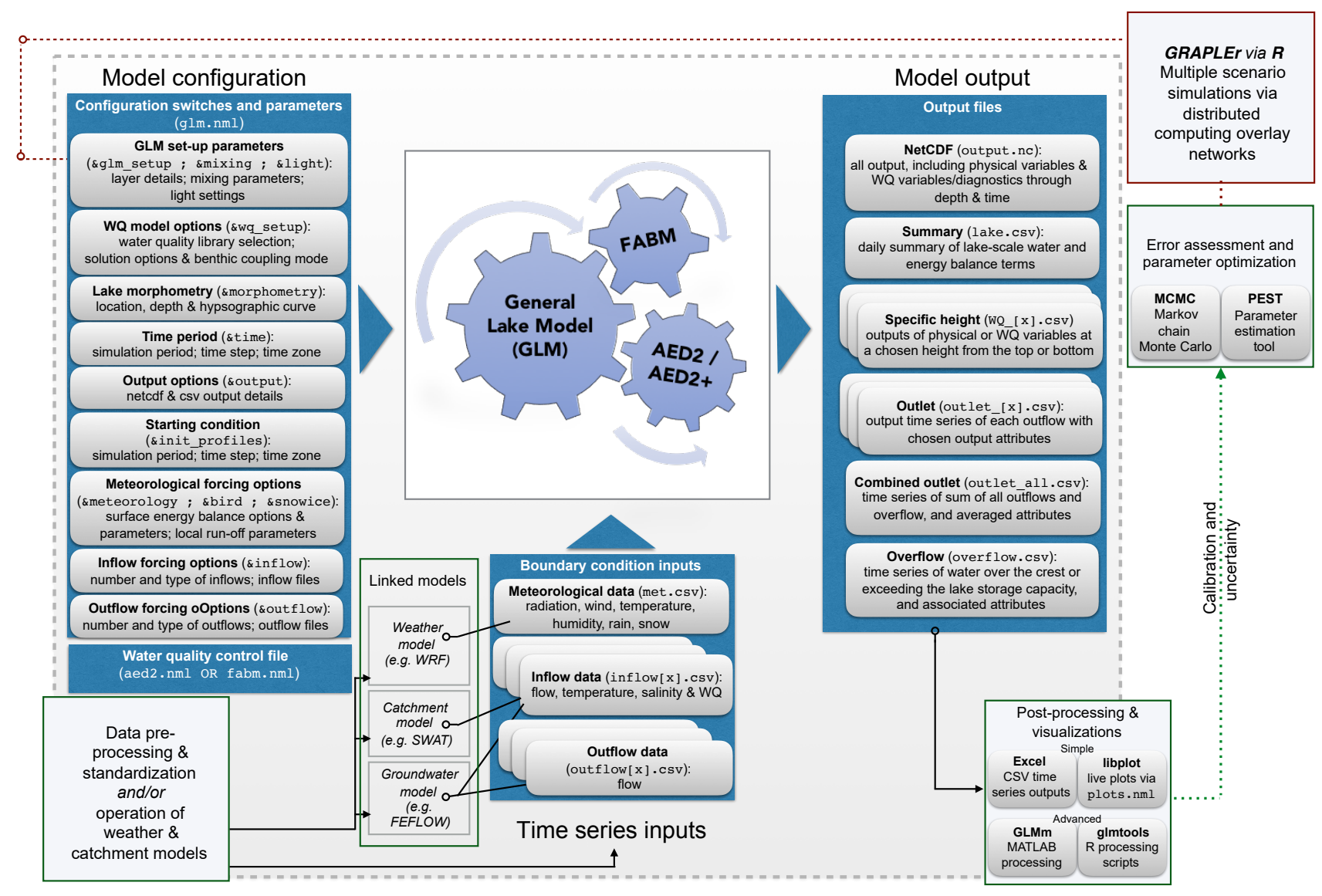

Figure 17. Flow diagram showing the input information required for operation of the model, the outputs, and analysis pathways.

quires running the model using these data sources, we have created GLM interfaces in the R and MATLAB analysis environments. These tools support user-friendly access to the model and include routines that streamline the process of calibrating models or running various scenarios. In addition, for assessment of lake dynamics in response to catchment or climatic forcing, it is desirable to be able to connect GLM with other model platforms associated with surface and groundwater simulation and weather prediction (Read et al., 2016).

\subsection{R and MATLAB libraries for model set-up and post-processing}

The $\mathrm{R}$ and MATLAB scientific languages are commonly used in aquatic research, often as part of automated modelling and analysis workflows. GLM has a client library for both, and these tools are shared freely online. The R package is called "glmtools" and the MATLAB library is called "GLMm"(available via the GLM website). Both tools have utilities for model output pre- and post-processing. The preprocessing components can be used to format and modify data inputs and configuration files and define options for how GLM executes. Post-processing tools include visualizations of simulation results (as shown in the figures above), comparisons to field observations, and various evaluations of model performance.

\subsection{Utilities for assessing model performance, parameter identification, and uncertainty analysis}

In order to compare the performance of the model for various types of lakes, numerous metrics of model performance are relevant. These include simple measures like surface or bottom temperature and ice thickness. It is also possible to assess the model's performance in capturing higher-order metrics relevant to lake dynamics, including Schmidt stability, thermocline depth, and ice on-off dates (see also Bruce et al., 2018, for a detailed assessment of the model's accuracy across a wide diversity of lakes across the globe). With particular interest in the model's ability to interface with highfrequency sensor data for the calculation of key lake stability metrics (Read et al., 2011), continuous wavelet transform comparisons are also possible (Kara et al., 2012), allowing for the assessment of the timescales over which the model is able to capture the observed variability within the data. 


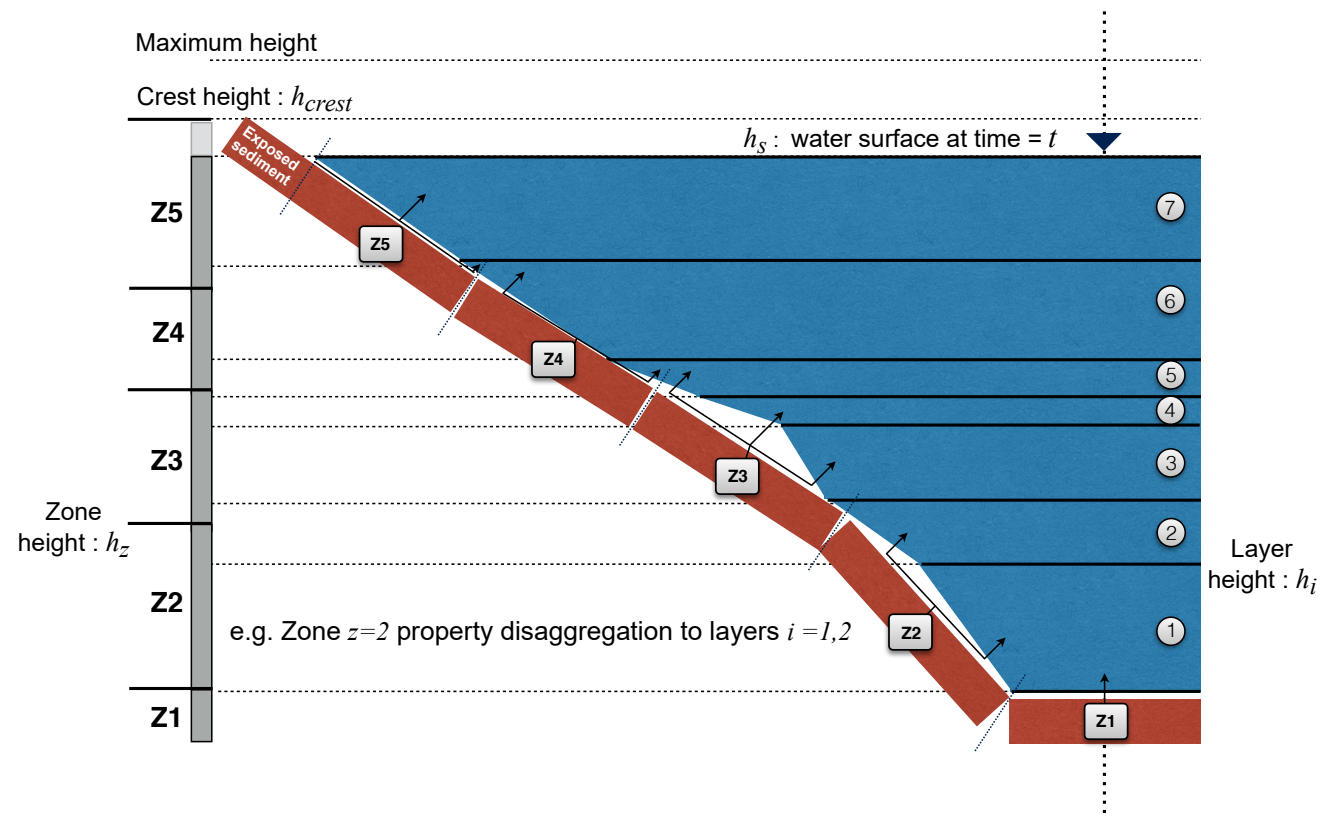

Figure 18. Schematic of a lake model layer structure (indicated by layers $i=1: 7$ ), in conjunction with five sediment "zones" (Z1-Z5) activated when benthic_mode $=2$. The dynamically varying layer structure is remapped to the fixed sediment zone locations at each time step in order for the sediment zone to receive the average overlying water properties and for the water to receive the appropriate information from benthic-sediment variables.

As part of the modelling process, it is common to adjust parameters to get the best fit with available field data and, as such, the use of a Bayesian hierarchical framework in the aquatic ecosystem modelling community has become increasingly useful (e.g. Zhang and Arhonditsis, 2009; Romarheim et al., 2015). Many parameters described throughout Sect. 2 are physically based descriptions in which there is relatively little variation (Bruce et al., 2018), thereby reducing the number of parameters that remain uncertain. For others, however, their variation reflects the imperfect formulation of some processes that are not completely described numerically. Therefore, within MATLAB, support scripts for GLM to work with the Markov chain Monte Carlo (MCMC) code outlined in Haario et al. (2006) can be used to provide improved parameter estimates and uncertainty assessment (Fig. 19; see also Huang et al., 2017). Example setups for use of GLM within the PEST (Parameter Estimation Tool) have also been developed, giving users access to a wide range of assessment methodologies. The PEST framework allows for the calibration of complex models using highly parameterized regularization with pilot points (Doherty, 2015). Sensitivity matrices derived from the calibration process can also be utilized in linear and non-linear uncertainty analysis.

\subsection{Operation in the cloud: GRAPLEr}

Questions relevant to land use and climate changes are driving scientists to develop numerous scenarios for how lake ecosystems might respond to changing exogenous drivers.
An important approach to addressing these questions is to simulate lake or reservoir physical-biological interactions in response to changing hydrology, nutrient loads, or meteorology and then infer consequences from the emergent properties of the simulation, such as changes in water clarity, extent of anoxia, mixing regime, or habitability to fishes (Hipsey et al., 2015). Often, it takes years or even decades for lakes to respond fully to changes in exogenous drivers, requiring simulations to recreate lake behaviour over extended periods. While most desktop computers can run a decade-long, low-resolution simulation in less than $1 \mathrm{~min}$, high-resolution simulations of the same extent may require minutes to hours of processor time. When questions demand hundreds, thousands, or even millions of simulations, the desktop approach is no longer suitable.

Through access to distributed computing resources, modellers can run thousands of GLM simulations in the time it takes to run a few simulations on a desktop computer. Collaborations between computer scientists in the Pacific Rim Applications and Grid Middleware Assembly (PRAGMA) and GLEON have led to the development of GRAPLEr (GLEON Research and PRAGMA Lake Expedition in R), a software written in $\mathrm{R}$ that enables modellers to distribute batches of GLM simulations to pools of computers (Subratie et al., 2017). Modellers use GRAPLEr in two ways: by submitting a single simulation to the GRAPLEr Web service, along with instructions for running that simulation under different climate scenarios, or by configuring many simulations 

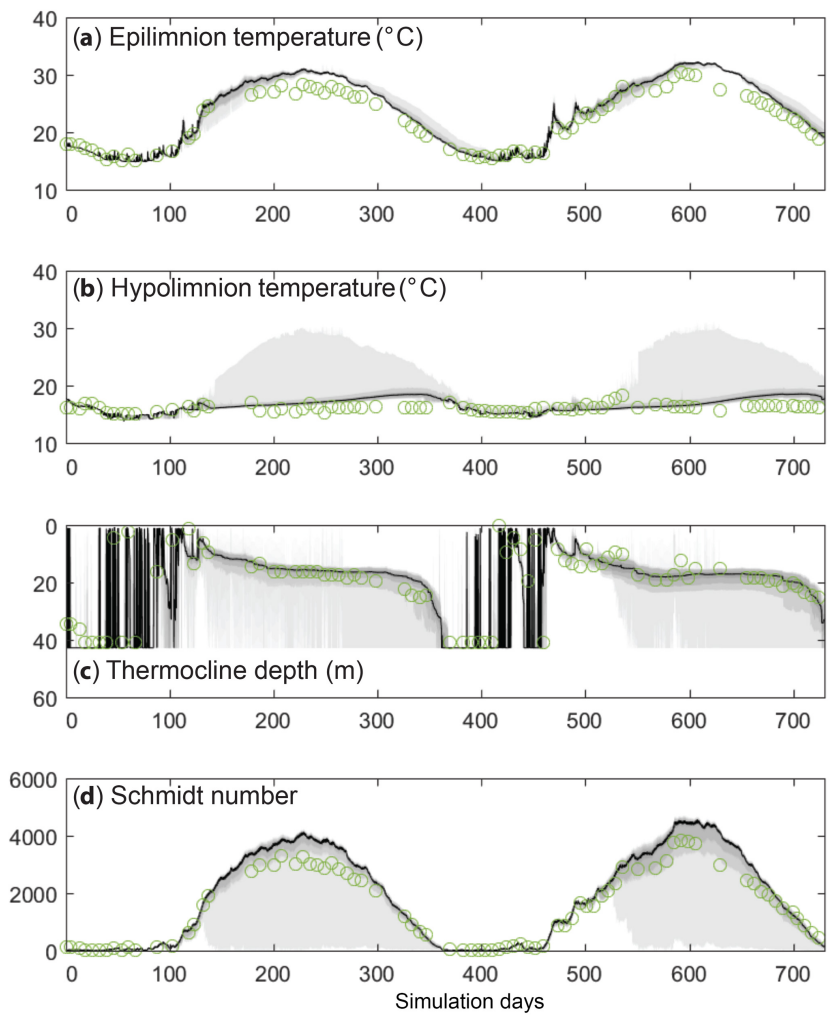

Figure 19. Depiction of parameter uncertainty for a GLM simulation of Lake Kinneret, Israel, following calibration against observations (green circles) via MCMC for (a) epilimnion temperature, (b) hypolimnion temperature, (c) thermocline depth, and (d) Schmidt number. The black line indicates the 50th percentile likelihood of the prediction, and the grey bands depict the 40th, 60 th, and 80th percentile.

on the user's desktop computer and then submitting them as a batch to the Web service. The first approach provides a high degree of automation that is well suited to training and instruction, and the second approach has the full flexibility often needed for research projects. In all approaches, GRAPLEr converts the submitted job to a script that is used by the scheduling programme HTCondor (Thain et al., 2005) to distribute and manage jobs among the computer pool and ensure that all simulations run and return results. An iPOP overlay network (Ganguly et al., 2006) allows the compute services to include resources from multiple institutions and cloud-computing services.

GRAPLEr's Web service front end shields the modeller from the compute environment, greatly reducing the need for modellers to understand distributed computing; they therefore only need to install the R package, know the URL of the GRAPLEr Web service, and decide how the simulations should be set up.

\subsection{Integration with catchment and climate models}

GLM simulations may be coupled with catchment models, such as the Soil Water Assessment Tool (SWAT) or similar catchment models, simply by converting the catchment model output into the inflow file format via conversion scripts (e.g. Bucak et al., 2018). Similarly, scripts exist for coupling GLM with the Weather Research Forecasting (WRF) model or similar climate models for the specification of the meteorological input file from weather prediction simulations (e.g. Hansen et al., 2017).

The above coupling approaches require the models to be run in sequence. For the simulation of lake-wetlandgroundwater systems, however, two-way coupling is required to account for the flow of water into and out of the lake throughout the simulation. For these applications, the interaction has been simulated using GLM coupled with the 3-D groundwater flow model FEFLOW (https://www. mikepoweredbydhi.com/products/feflow, last access: 16 December 2018). For this case, the GLM code is compiled as a dynamic link library (DLL), termed libGLM, and loaded into FEFLOW as a plug-in module. The coupling between GLM and FEFLOW is implemented using a one-step lag between the respective solutions of the groundwater and lake models. This approach in most simulations does not introduce significant error; however, error can be assessed and reduced using smaller time step lengths. The GLM module was designed to accommodate situations of variable lake geometry by using a dry-lake-wet-lake approach, whereby dry-lake areas are defined as those above the current lake level and wet-lake areas as below the current lake level. Different boundary types in FEFLOW are assigned to dry-lake and wet-lake areas (Fig. 20). The calibration of such coupled models is often complex given the large number of parameters and sensitivities when different sources of information are utilized (for example, flow and water level measurements). The FEFLOW-GLM coupling structure allows for a relatively straightforward integration with PEST based on existing FEFLOW workflows.

\section{GLM as a tool for teaching environmental science and ecology}

Environmental modelling is integral for understanding complex ecosystem responses to anthropogenic and natural drivers and also provides a valuable tool for engaging students learning environmental science (Carey and Gougis, 2017). Previous pedagogical studies have demonstrated that engaging students in modelling provides cognitive benefits, enabling them to build new scientific knowledge and conceptual understanding (Stewart et al., 2005; Schwarz et al., 2009). For example, modelling forces students to analyse patterns in data, create evidence-based hypotheses for those patterns, make their hypotheses explicit, and develop predic- 


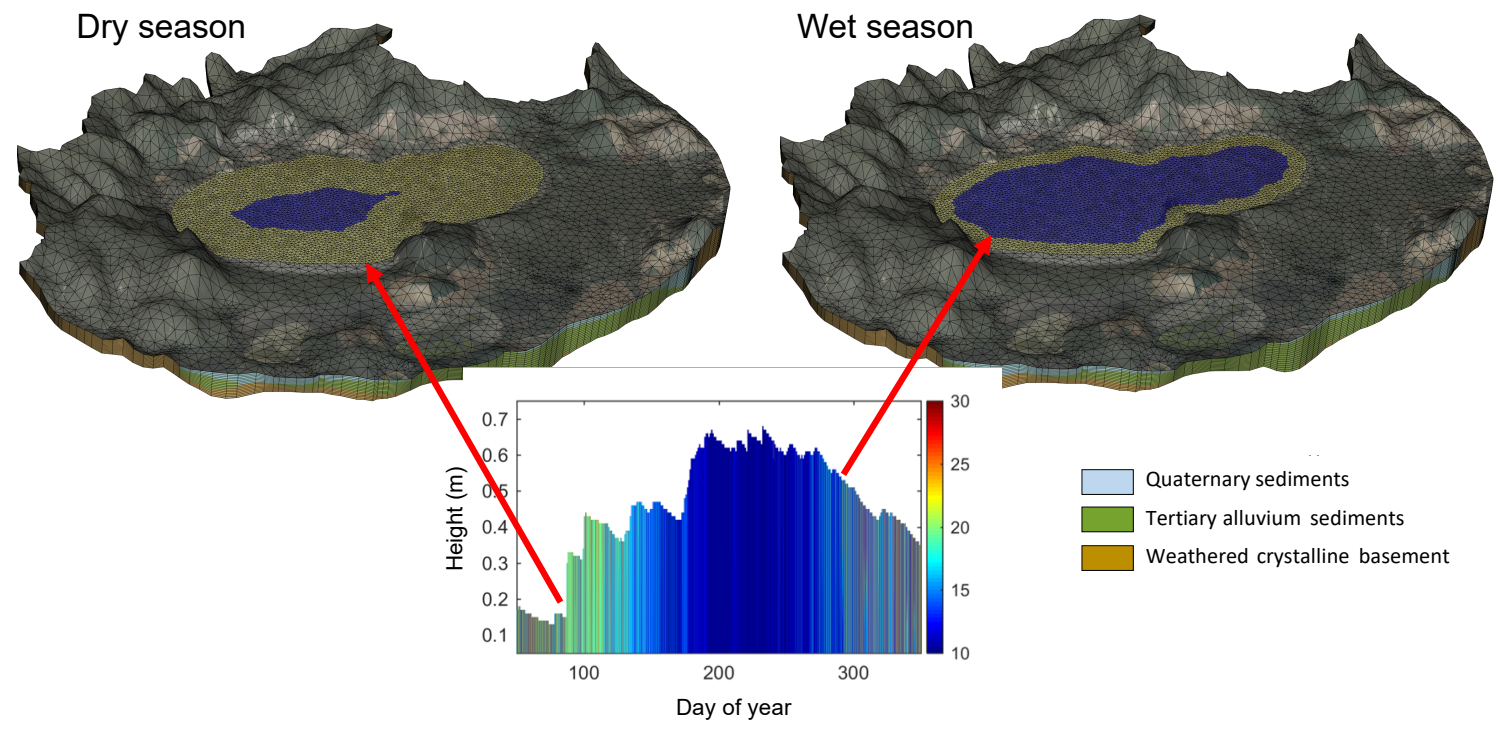

Figure 20. Example of water level changes during a seasonal cycle from Lake Muir, Australia. GLM water level is periodically communicated to the 3-D FEFLOW groundwater model via a plug-in calling libGLM and used as a constant head boundary condition for all wet cells within the FEFLOW mesh.

tions of future conditions (Stewart et al., 2005). As a result, the U.S. National Research Council has recently integrated modelling into the Next Generation Science Standards, which provide recommendations for primary and secondary school science pedagogy in the United States (NRC, 2013). However, it remains rare for undergraduate and graduate science courses to include the computer-based modelling that environmental scientists need to manage natural ecosystems.

A teaching module for the use of GLM within undergraduate and graduate classrooms has been developed to explore lake responses to climate change (Carey and Gougis, 2017). The GLM module, called the "Climate Change Effects on Lake Temperatures", teaches students how to set up a simulation for a model lake within R. After they are able to successfully run their lake simulations, they force the simulation with climate scenarios of their own design to examine how lakes may change in the future. To improve computational efficiency, students also learn how to submit, retrieve, and analyse hundreds of model simulations through distributed computing overlay networks embedded via the GRAPLEr interface (Sect. 5.3). Hence, students participating in the module learn computing and quantitative skills in addition to improving their understanding of how climate change affects lake ecosystems.

Initial experiences teaching GLM as well as pre- and post-assessments indicate that participation in the module improves students' understanding of lake responses to climate change (Carey and Gougis, 2017). By modifying GLM boundary condition data and exploring model output, students are able to better understand the processes that control lake responses to altered climate and improve their predictions of future lake change. Moreover, the module exposes students to computing and modelling tools not commonly experienced in most university classrooms, building competence with manipulating data files, scripting, creating figures and other visualizations, and statistical and time series analysis; these are all skills that are transferrable to many other applications.

\section{Conclusions}

As part of GLEON activities, the emergence of complex questions about how different lake types across the world are responding to climate change and land use change has created the need for a robust, accessible community code suitable for a diverse range of lake types and simulation contexts. Here, GLM is presented as a tool that meets many of the needs of network participants with suitability for a wide array of lake types and sizes, whilst also meeting the need for a distributed simulation across tens to thousands of lakes as is required for regional- and global-scale assessments (e.g. Kirillin et al., 2011). Recent examples have included an application of the model for assessing how the diversity of $>2000$ lakes in a lake-rich landscape in Wisconsin respond to climate, including projected warming (Read et al., 2014; Winslow et al., 2017). Given its computationally efficient nature, it is envisioned that GLM can be made available as a library for use within in land surface models (e.g. the Community Land Model, CLM), allowing for an improved representation of lake dynamics in regional hydrological or climate 
assessments. With further advances in the degree of resolution and scope of Earth system models, we further envisage GLM as an option suitable to be embedded within these models to better allow for the simulation of lake stratification, air-water interaction of momentum and heat, and also biogeochemically relevant variables associated with contemporary questions about greenhouse gas emissions such as $\mathrm{CO}_{2}$, $\mathrm{CH}_{4}$, and $\mathrm{N}_{2} \mathrm{O}$.

Since the model is one-dimensional, it assumes no horizontal variability in the simulated water layers and users must therefore ensure that their application of the model is suited to this simplifying assumption. For stratified systems, the parameterization of mixing due to internal wave and inflow intrusion dynamics is relatively simple, making the model ideally suited to longer-term investigations ranging from weeks to decades (depending on the domain size) and for coupling with biogeochemical models to explore the role that stratification and vertical mixing play in lake ecosystem dynamics. However, the model can also be used for shallow lakes, ponds, and wetland environments in which the water column is relatively well mixed. In cases in which the assumption of one-dimensionality is not met for a particular lake application, a two- or three-dimensional model may be preferred.

This paper has focused on a description of the hydrodynamic model, but we highlight the fact that the model is a platform for coupling with advanced biogeochemical and ecological simulation libraries for water quality prediction and integrated ecosystem assessments. As with most coupled hydrodynamic-ecological modelling platforms, GLM handles the boundary conditions and transport of variables simulated within these libraries, including the effects of inflows, vertical mixing, and evapo-concentration. Whilst the interface to these libraries is straightforward, the Lagrangian approach adopted within GLM for simulation of the water column necessitates the adoption of sediment zones on a static grid that is independent from the water column numerical grid.

More advanced workflows for operation of the model within distributed computing environments and with data assimilation algorithms is an important application when used within GLEON capabilities related to high-frequency data and their interpretation. The 1-D nature of the model makes the runtimes modest and therefore the model suitable for application within more intensive parameter identification and uncertainty assessment procedures. This is particularly relevant to the needs of network participants to expand model configurations to further include biogeochemical and ecological state variables. It is envisioned that continued application of the model will allow us to improve parameter estimates and ranges, and this will ultimately support other users of the model in identifying parameter values and assigning parameter prior distributions. Since many of the users the model is intended for may not have access to the necessary cyber-infrastructure, the use of GLM with the open-source GRAPLEr software in the R environment provides access to otherwise unavailable distributed computing resources. This has the potential to allow non-expert modellers within the science community to apply good modelling practices by automating boundary condition and parameter sensitivity assessments, with technical aspects of simulation management abstracted from the user.

Finally, the role of models in informing and educating members of the network and the next generation of hydrologic and ecosystem modellers has been identified as a critical element of synthesis activities and supporting crossdisciplinary collaboration (Weathers et al., 2016). Initial use of GLM within the classroom has shown that teaching modules integrating GLM into classes improves students' understanding of lake ecosystems.

Code availability. The GLM code is provided as open source under the GNU GPLv3 licence and version controlled via the GitHub repository: https://github.com/AquaticEcoDynamics/ (last access: 14 January 2019) GLM (https://doi.org/10.5281/zenodo.2538486; Hipsey et al., 2019a).

Data availability. The five example lakes used to demonstrate the model operation are described along with model input files (and the associated hydrologic and meteorological forcing data) within the GitHub repository: https://github. com/AquaticEcoDynamics/GLM_Examples (last access: 14 January 2019) (https://doi.org/10.5281/zenodo.2538489; Hipsey et al., 2019b). 


\section{Appendix A: Bird solar radiation model}

The Bird Clear Sky Model (BCSM) was developed by Bird (1984) to predict clear-sky direct beam, hemispherical diffuse, and total hemispherical broadband solar radiation on a horizontal surface. Average solar radiation is computed at the model time step (e.g. hourly) based on 10 user-specified input parameters (Table 1).

The solar constant in the model is taken as $1367 \mathrm{~W} \mathrm{~m}^{-2}$, which is corrected due to the elliptical nature of the Earth's orbit and consequent change in distance to the sun. This calculation gives us the extraterrestrial radiation $\left(\hat{\phi}_{\mathrm{ETR}}\right)$ at the top of the atmosphere:

$$
\begin{aligned}
\hat{\phi}_{\mathrm{ETR}}= & 1367\left(1.00011+0.034221 \cos \left[\Phi_{\text {day }}\right]+0.00128 \sin \right. \\
& {\left.\left[\Phi_{\text {day }}\right]+0.000719 \cos \left[\Phi_{\text {day }}\right]\right), }
\end{aligned}
$$

where the day angle, $\Phi_{\text {day }}$, is computed using $d$, the day number:

$\Phi_{\text {day }}=2 \pi\left(\frac{d-1}{365}\right)$.

The solar declination, $\Phi_{\mathrm{dec}}$ (radians), is computed from

$$
\begin{aligned}
& 0.006918-0.399912 \cos \left[\Phi_{\text {day }}\right]+0.070257 \\
\Phi_{\text {dec }}=\quad & \sin \left[\Phi_{\text {day }}\right]-0.006758 \cos \left[2 \Phi_{\text {day }}\right] \\
+ & 0.000907 \sin \left[2 \Phi_{\text {day }}\right]-0.002697 \cos \left[3 \Phi_{\text {day }}\right] \\
& +0.00148 \sin \left[3 \Phi_{\text {day }}\right] .
\end{aligned}
$$

We then solve the equation of time:

$\mathrm{EQT}=$

$$
\begin{aligned}
& \left(\begin{array}{l}
0.0000075+0.001868 \cos \left[\Phi_{\text {day }}\right]-0.032077 \sin \left[\Phi_{\text {day }}\right] \\
-0.014615 \cos \left[2 \Phi_{\text {day }}\right]-0.040849 \sin \left[2 \Phi_{\text {day }}\right]
\end{array}\right) \\
& \times 229.18 \text {. }
\end{aligned}
$$

In order to compute the hour angle, $\Phi_{\mathrm{hr}}$ is calculated with noon zero and morning positive as

$$
\Phi_{\mathrm{hr}}=15(\mathrm{hr}-12.5)+\text { Long }-15 \mathrm{TZ}+\left(\frac{\mathrm{EQT}}{4}\right),
$$

where TZ is the time zone shift from GMT. The zenith angle, $\Phi_{\text {zen }}$ (radians), is calculated from

$$
\begin{aligned}
& \cos \left[\Phi_{\mathrm{zen}}\right]=\cos \left[\Phi_{\mathrm{dec}}\right] \cos \left[\Phi_{\mathrm{hr}}\right] \cos [\text { Lat }] \\
& \quad+\sin \left[\Phi_{\mathrm{dec}}\right] \sin [\text { Lat }]
\end{aligned}
$$

For $\Phi_{\text {zen }}<90^{\circ}$, the air mass factor is calculated as

$\mathrm{AM}=\left(\cos \left[\Phi_{\mathrm{zen}}\right]+\frac{0.15}{\left(93.885-\Phi_{\mathrm{zen}}\right)^{1.25}}\right)^{-1}$,

which is corrected for atmospheric pressure, $p(\mathrm{hPa})$ :

$\mathrm{AM}_{p}=\frac{\mathrm{AM} p}{1013}$.
$\mathrm{AM}_{p}$ is then used to calculate the Rayleigh scattering as

$$
\begin{aligned}
T_{\text {rayleigh }}= & \exp \left[\left(-0.0903 \mathrm{AM}_{p}^{0.84}\right)\right. \\
& \left.+\left(1+\mathrm{AM}_{p}-\mathrm{AM}_{p}^{1.01}\right)\right] .
\end{aligned}
$$

The effect of ozone scattering is calculated by computing ozone mass, which for positive air mass is

$$
\begin{aligned}
T_{\text {ozone }}= & \left(1-\left(0.1611(\mathrm{Oz} \text { AM })(1+139.48(\mathrm{Oz} \mathrm{AM}))^{-0.3035}\right)\right. \\
& \left.-\frac{0.002715(\mathrm{Oz} \mathrm{AM})}{1+0.044(\mathrm{Oz} \mathrm{AM})+0.0003(\mathrm{Oz} \mathrm{AM})^{2}}\right) . \quad \text { (A10) }
\end{aligned}
$$

The scattering due to mixed gases for positive air mass is calculated as

$$
T_{\text {mix }}=\exp \left[-0.0127 \mathrm{AM} p^{0.26}\right] \text {. }
$$

Then the water scattering is calculated by computing a water mass factor:

$\mathrm{Wm}=W \mathrm{AM}_{p}$,

where $W$ is the precipitable water vapour which defaults to 1.1. This can be approximated from dew point temperature, $T_{\mathrm{d}}$, using

$\ln [W]=a_{\mathrm{W}} T_{\mathrm{d}}+b_{\mathrm{W}}$,

where regression coefficients are $0.09,0.07,0.07$, and 0.08 for $a_{\mathrm{W}}$, while $b_{\mathrm{W}}$ values of $1.88,2.11,2.12$, and 2.01 in spring, summer, autumn, and winter have been assumed (Luo et al., 2010). Then, the water scattering effect is calculated as

$$
T_{\text {watvap }}=\left(1-\frac{(2.4959 \mathrm{Wm})}{1+(79.034 \mathrm{Wm})^{0.6828}+6.385 \mathrm{Wm}}\right) .
$$

The scattering due to aerosols requires the aerosol optical depth at 380 and $500 \mathrm{~nm}$,

TauA $=0.2758 \mathrm{AOD}_{380}+0.35 \mathrm{AOD}_{500}$,

and is calculated as

$T_{\text {aerosol }}=$

$\exp \left[(-\operatorname{TauA})^{0.873}\left(1+\operatorname{TauA}-\operatorname{TauA}^{0.7088}\right) \mathrm{AM}^{0.9108}\right]$.

The absorptance of aerosols is then computed from

$$
T_{\text {aa }}=1-\left(0.1\left(1-\mathrm{AM}+\mathrm{AM}^{1.06}\right)\left(1-T_{\text {aerosol }}\right)\right),
$$

and we also define

$\epsilon=\frac{0.5\left(1-T_{\text {rayleigh }}\right)+0.84\left(1-T_{\text {aerosol }} / T_{\text {aa }}\right)}{1-\mathrm{AM}+\mathrm{AM}^{1.02}}$,

where the 0.84 value used is actually the proportion of scattered radiation reflected in the same direction as incoming radiation. 
The direct beam (DB) radiation on a horizontal surface at ground level on a clear day is given by

$\hat{\phi}_{\mathrm{DB}}=0.9662 \hat{\phi}_{\mathrm{ETR}} T_{\text {rayleigh }} T_{\text {ozone }} T_{\text {mix }} T_{\text {watvap }} T_{\text {aerosol }} \cos \left[\Phi_{\text {zen }}\right]$,

and the atmospheric scattering (AS) component is

$\hat{\phi}_{\text {AS }}=0.79 \hat{\phi}_{\text {ETR }} T_{\text {ozone }} T_{\text {mix }} T_{\text {watvap }} T_{\text {aa }} \cos \left[\Phi_{\text {zen }}\right] \epsilon$.

The total irradiance hitting the surface $\left(\mathrm{W} \mathrm{m}^{-2}\right)$ is therefore

$\hat{\phi}_{\mathrm{SW}}=\frac{\hat{\phi}_{\mathrm{DB}}+\hat{\phi}_{\mathrm{AS}}}{1-\left(\alpha_{\mathrm{SW}} \alpha_{\mathrm{SKY}}\right)}$.

The albedo is computed for the sky as

$\alpha_{\mathrm{SKY}}=0.068+(1-0.84)\left(1-\frac{T_{\mathrm{aerosol}}}{T_{\mathrm{aa}}}\right)$.

\section{Appendix B: Non-neutral bulk-transfer coefficients}

The iterative procedure used in this analysis to update-correct the bulk-transfer coefficients based on atmospheric conditions is conceptually similar to the methodology discussed in detail in Launiainen and Vihma (1990). The first estimate for the neutral drag coefficient, $C_{\mathrm{DN}}$, is specified as a function of wind speed as it is commonly observed to increase with $U_{10}$. This is modelled by first estimating the value referenced to $10 \mathrm{~m}$ of height above the water from

$C_{\mathrm{DN}-10}=$

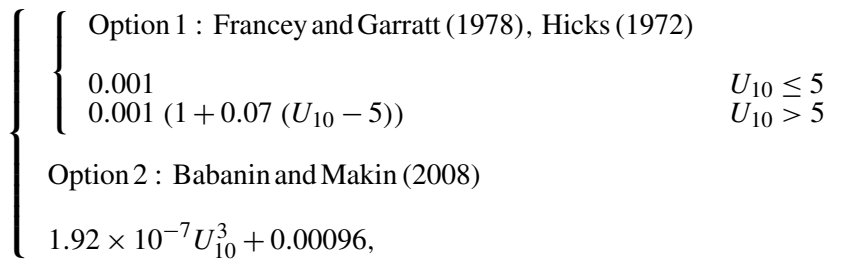

and then computing the Charnock formula with the smooth flow transition (e.g. Vickers et al., 2013):

$z_{o}=\frac{a u_{*}^{2}}{g}+0.11 \frac{v_{\mathrm{a}}}{u_{*}}$,

where $a$ is the Charnock constant, and here $u_{*}$ is the approximated friction velocity of the atmosphere near the surface $\left(\sqrt{C_{\mathrm{DN}-10} U_{10}^{2}}\right)$ initially estimated using Eq. (B1). The drag is recomputed using

$C_{\mathrm{DN}-10}=\left(\frac{\kappa}{\ln \left[\frac{10}{z_{o}}\right]}\right)^{2}$

where $\kappa$ is the von Karman constant (Fig. B1). Note that the neutral humidity-temperature coefficient, $C_{\mathrm{HWN}-10}$, is held constant at the user-defined $C_{\mathrm{H}}$ value and is assumed not to vary with wind speed.

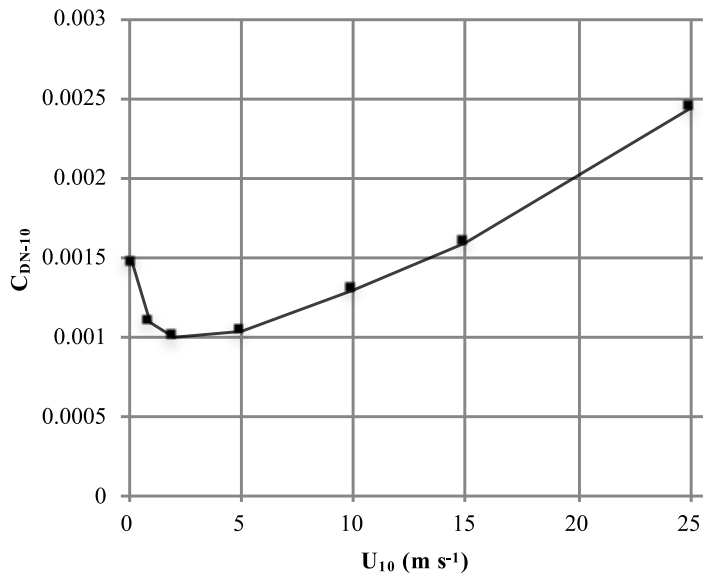

Figure B1. Scaling of the $10 \mathrm{~m}$ neutral drag coefficient with wind speed, $U_{10}$ (Eqs. B1-B3).

Under non-neutral conditions in the atmospheric boundary layer, the transfer coefficients vary due to stratification in the air column, as was parameterized by Monin and Obukhov (1954) using the now well-known stability parameter $z / L$, where $L$ is the Obukhov length defined as

$L=\frac{-\rho_{\mathrm{a}} u_{*}^{3} \theta_{\mathrm{V}}}{\kappa g\left(\frac{\phi_{\mathrm{H}}}{c_{\mathrm{a}}}+0.61 \frac{\theta_{\mathrm{a}} \phi_{\mathrm{E}}}{\lambda_{\mathrm{V}}}\right)}$,

where $\theta_{\mathrm{V}}=\theta_{\mathrm{a}}\left(1+0.61 e_{\mathrm{a}}\right)$ is the virtual air temperature, and $\phi_{\mathrm{H}}$ and $\phi_{\mathrm{E}}$ are the bulk fluxes. Paulson (1970) presented a solution for the vertical profiles of wind speed, temperature, and moisture in the developing boundary layer as a function of the Monin-Obukhov stability parameter; this is the so-called flux-profile relationship:

$U_{z}=\frac{u_{*}}{\kappa}\left(\ln \left[\frac{z}{z_{o}}\right]-\psi_{\mathrm{M}}\left[\frac{z}{L}\right]\right)$,

$\theta_{\mathrm{a}}-\theta_{\mathrm{s}}=\frac{\theta_{*}}{\kappa}\left(\ln \left[\frac{z}{z_{\theta}}\right]-\psi_{\mathrm{H}}\left[\frac{z}{L}\right]\right)$,

$e_{\mathrm{a}}-e_{\mathrm{S}}=\frac{e_{*}}{\kappa}\left(\ln \left[\frac{z}{z_{q}}\right]-\psi_{\mathrm{E}}\left[\frac{z}{L}\right]\right)$,

where $\psi_{\mathrm{M}}, \psi_{\mathrm{H}}$, and $\psi_{\mathrm{E}}$ are the similarity functions for momentum, heat, and moisture, respectively, and $z_{o}, z_{\theta}$, and $z_{q}$ are their respective roughness lengths. For unstable conditions $(L<0)$, the stability functions are defined as (Paulson, 1970; Businger et al., 1971; Dyer, 1974)

$$
\begin{aligned}
& \psi_{\mathrm{M}}=2 \ln \left[\frac{1+x}{2}\right]+\ln \left[\frac{1+x^{2}}{2}\right]-2 \tan ^{-1} x+\frac{\pi}{2}, \\
& \psi_{\mathrm{E}}=\psi_{\mathrm{H}}=2 \ln \left[\frac{1+x^{2}}{2}\right],
\end{aligned}
$$

where

$x=\left[1-16\left(\frac{z}{L}\right)\right]^{1 / 4}$. 


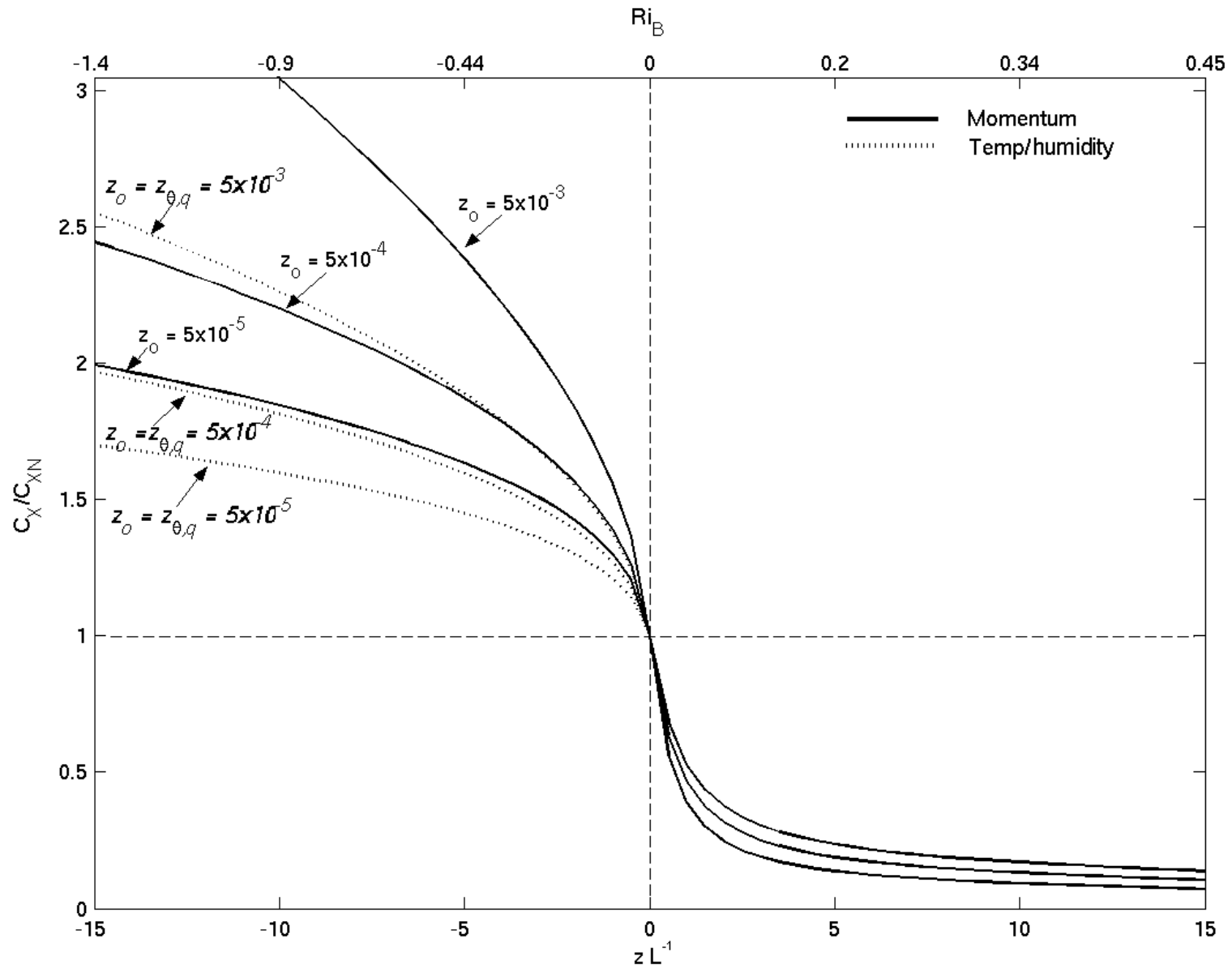

Figure B2. Relationship between atmospheric stability (bottom axis $-z / L$, top axis $-R i_{\mathrm{B}}$ ) and the bulk-transfer coefficients relative to their neutral value $\left(C_{X} / C_{X \mathrm{~N}}\right.$, where $X$ represents $D, H$, or $\left.E\right)$ for several roughness values (computed from Eq. B10). The solid line indicates the momentum coefficient of variation $\left(C_{\mathrm{D}} / C_{\mathrm{DN}}\right)$ and the broken line indicates humidity and temperature coefficient $\left(C_{\mathrm{HE}} / C_{\mathrm{HEN}}\right)$ variation.

During stable stratification $(L>0)$ they are assumed to take a form modified from Hicks (1976).

$$
\begin{aligned}
& \psi_{\mathrm{M}}=\psi_{\mathrm{E}}=\psi_{\mathrm{H}}= \\
& \begin{cases}-5\left(\frac{z}{L}\right) & 0<\frac{z}{L}<0.5 \\
0.5\left(\frac{z}{L}\right)^{-2}-4.25\left(\frac{z}{L}\right)^{-1}-7 \ln \left[\frac{z}{L}\right]-0.852 & 0.5<\frac{z}{L}<10 \\
\ln \left[\frac{z}{L}\right]-0.76\left(\frac{z}{L}\right)-12.093 & \frac{z}{L}>10\end{cases}
\end{aligned}
$$

Substituting Eqs. (22)-(23) into (B5a, b, c) and ignoring the similarity functions leaves us with neutral transfer coefficients as a function of the roughness lengths:

$C_{X \mathrm{~N}}=\kappa^{2}\left(\ln \left[\frac{z}{z_{o}}\right]\right)^{-1}\left(\ln \left[\frac{z}{z_{X}}\right]\right)^{-1}$

where the $\mathrm{N}$ subscript denotes the neutral value and $X$ signifies either $D, H$, or $E$ for the transfer coefficient and $o$, $\theta$, or $q$ for the roughness length scale. Inclusion of the stability functions into the substitution and some manipulation
(Imberger and Patterson, 1990; Launianen and Vihma, 1990) yields the transfer coefficients relative to these neutral values.

$$
\frac{C_{X}}{C_{X \mathrm{~N}}}=\left[1+\frac{C_{X \mathrm{~N}}}{\kappa^{2}}\left(\psi_{\mathrm{M}} \psi_{X}-\frac{\kappa \psi_{X}}{\sqrt{C_{\mathrm{DN}}}}-\frac{\kappa \psi_{\mathrm{M}} \sqrt{C_{\mathrm{DN}}}}{C_{X \mathrm{~N}}}\right)\right]
$$

Hicks (1975) and Launianen and Vihma (1990) suggested an iterative procedure to solve for the stability-corrected transfer coefficient using Eq. (B10) based on some initial estimate of the neutral values (as input by the user). The surface flux is subsequently estimated according to Eqs. (22)-(23) and used to provide an initial estimate for $L$ (Eq. B4). The partially corrected transfer coefficient is then recalculated and so the cycle goes. Strub and Powell (1987) and Launiainen (1995) presented an alternative based on estimation of the bulk Richardson number, $R i_{\mathrm{B}}$, defined as

$R i_{\mathrm{B}}=\frac{g z}{\theta_{\mathrm{V}}}\left(\frac{\Delta \theta+0.61 \theta_{\mathrm{V}} \Delta \mathrm{e}}{U_{z}^{2}}\right)$ 
and related as a function of the stability parameter, $z / L$, according to

$R i_{\mathrm{B}}=\frac{z}{L}\left(\frac{\kappa \sqrt{C_{\mathrm{DN}}} / C_{\mathrm{HEN}}-\psi_{\mathrm{H}, \mathrm{E}}}{\left[\kappa / \sqrt{C_{\mathrm{DN}}}-\psi_{\mathrm{M}}\right]^{2}}\right)$,

where it is specified that $C_{\mathrm{HN}}=C_{\mathrm{EN}}=C_{\mathrm{HEN}}$. Figure B2 illustrates the relationship between the degree of atmospheric stratification (as described by both the bulk Richardson number and the Monin-Obukhov stability parameter) and the transfer coefficients scaled by their neutral value. 
Author contributions. The main model code was written by $\mathrm{CB}$, MRH, and LCB, with contributions from DPH, JSR, MW, and LAW. Model applications in this paper were undertaken primarily by LCB, MRH, BB, LAW, and MW, with inputs from all authors. The main paper was written by MRH with contributions from all authors. All authors edited the paper.

Competing interests. The authors declare that they have no conflict of interest.

Acknowledgements. The primary code for GLM has been developed by Matthew R. Hipsey, Louise C. Bruce, Casper Boon, Brendan Busch, and David P. Hamilton at the University of Western Australia in collaboration with researchers participating in GLEON, with support provided by a National Science Foundation (NSF) (USA) Research Coordination Network Award. Whilst GLM is a new code, it is based on the large body of historical research and publications produced by the Centre for Water Research at the University of Western Australia, which we acknowledge for the inspiration, development, and testing of several of the model approaches that have been adopted. Funding for the initial development of the GLM code was from the U.S. NSF Cyber-enabled Discovery and Innovation grant awarded to Paul C. Hanson (lead investigator) and colleagues from 2009-2014 (NSF CDI-0941510); subsequent development was supported by the Australian Research Council projects awarded to Matthew R. Hipsey and colleagues (ARC projects LP0990428, LP130100756, and DP130104078). Funding for the optimization and improvement of the snow and ice model was provided by NSF MSB-1638704. Funding for the development of the GLM teaching module and GRAPLEr was provided by NSF ACI-1234983 and NSF EF-1702506 awarded to Cayelan C. Carey. Funding for glmtools was provided by the Department of the Interior Northeast Climate Science Center. Any use of trade, firm, or product names is for descriptive purposes only and does not imply endorsement by the U.S. Government. Provision of the environmental symbols used for the GLM scientific diagrams are courtesy of the Integration and Application Network, University of Maryland Center for Environmental Science. Joanne Moo and Aditya Singh also provided support in model set-up and testing. We gratefully acknowledge the anonymous reviewers whose contribution and editing have significantly improved the paper and model.

Edited by: Simon Unterstrasser

Reviewed by: four anonymous referees

\section{References}

Ashton, G. D. (Ed.): River and lake ice engineering. Water Resources Publications, Littleton, Colorado, USA, 1986.

Antenucci, J. P., Brookes, J. D., and Hipsey, M. R.: A simple model for quantifying Cryptosporidium transport, dilution, and potential risk in reservoirs, J. Am. Water Works Ass., 97, 86-93, 2005.

Ayala, A. I., Cortés, A., Fleenor, W. E., and Rueda, F. J.: Seasonal scale modeling of river inflows in stratified reservoirs: Structural vs. parametric uncertainty in inflow mixing, Environ. Modell. Softw., 60, 84-98, 2014.
Babanin, A. V. and Makin, V. K.: Effects of wind trend and gustiness on the sea drag: Lake George study, J. Geophys. Res.Oceans, 113, C02015, https://doi.org/10.1029/2007JC004233, 2008.

Bird, R. E.: A simple, solar spectral model for direct-normal and diffuse horizontal irradiance, Sol. Energy, 32, 461-471, 1984.

Briegleb, B. P., Minnis, P., Ramanathan, V., and Harrison, E.: Comparison of regional clear-sky albedos inferred from satellite observations and model computations. J. Clim. Appl. Meteorol., 25, 214-226, 1986.

Bruce, L. C., Frassl, M. A., Arhonditsis, G. B., Gal, G., Hamilton, D. P., Hanson, P. C., Hetherington, A. L., Melack, J. M., Read, J. S., Rinke, K. and Rigosi, A., Trolle, D., Winslow, L., Adrian, R., Ayala, A. I, Bocaniov, S. A., Boehrer, B., Boon, C., Brookes, J. D., Bueche, T., Busch, B. D., Copetti, D., Cortés, A., de Eyto, E., Elliott, J.A., Gallina, N., Gilboa, Y., Guyennon, N., Huang, L., Kerimoglu, O., Lenters, J.D., MacIntyre, S., Makler-Pick, V., McBride, C. G., Moreira, S., Özkundakci, D., Pilotti, M., Rueda, F. J., Rusak, J. A., Samal, N. R., Schmid, M., Shatwell, T., Snorthheim, C., Soulignac, F., Valerio, G., van der Linden, L., Vetter, M., Vinçon-Leite, B., Wang, J., Weber, M., Wickramaratne, C., Woolway, R. I., Yao, H., and Hipsey, M. R.: A multi-lake comparative analysis of the General Lake Model (GLM): Stress-testing across a global observatory network, Environ. Modell. Softw., 102, 274-291, 2018.

Bruggeman, J. and Bolding, K.: A general framework for aquatic biogeochemical models, Environ. Modell. Softw., 61, 249-265, 2014.

Brutsaert, W.: On a derivable formula for long-wave radiation from clear skies, Water Resour. Res., 11, 742-744, 1975.

Bucak, T., Trolle, D., Tavşanoğlu, Ü. N., Çakıroğlu, A. İ., Özen, A., Jeppesen, E., and Beklioğlu, M.: Modeling the effects of climatic and land use changes on phytoplankton and water quality of the largest Turkish freshwater lake: Lake Beyşehir, Sci. Total Environ., 621, 802-816, 2018.

Bueche, T., Hamilton, D. P., and Vetter, M.: Using the General Lake Model (GLM) to simulate water temperatures and ice cover of a medium-sized lake: a case study of Lake Ammersee, Germany, Environ. Earth Sci., 76, 461, https://doi.org/10.1007/s12665-017-6790-7, 2017.

Businger, J. A., Wyngaard, J. C., Izumi, Y., and Bradley, E. F.: Flux profile relationships in the atmospheric surface layer, J. Atmos. Sci., 28, 181-189, 1971.

Carey, C. C. and Gougis, R. D.: Simulation modeling of lakes in undergraduate and graduate classrooms increases comprehension of climate change concepts and experience with computational tools, J. Sci. Educ. Technol., 26, 1-11, 2017.

Cengel, Y. A. and Ozisk, M. N.: Solar radiation absorption in solar ponds, Sol. Energy, 33, 581-591, 1984.

Chung, E. G., Schladow, S. G., Perez-Losada, J., and Robertson, D. M.: A linked hydrodynamic and water quality model for the Salton Sea, Hydrobiologia, 604, 57-75, 2008.

Chung, S. W., Imberger, J., Hipsey, M. R., and Lee, H. S.: The influence of physical and physiological processes on the spatial heterogeneity of a Microcystis bloom in a stratified reservoir, Ecol. Model., 289, 133-149, 2014.

Cogley, J. G.: The albedo of water as a function of latitude, Mon. Weather Rev., 107, 775-781, 1979. 
Cole, J. J., Prairie, Y. T., Caraco, N. F., McDowell, W. H., Tranvik, L. J., Striegl, R. G., Duarte, C. M., Kortelainen, P., Downing, J. A., Middelburg, J. J., and Melack, J.: Plumbing the global carbon cycle: Integrating inland waters into the terrestrial carbon budget, Ecosystems, 10, 172-185, 2007.

Doherty, J.: Calibration and Uncertainty Analysis for Complex Environmental Models, Watermark Numerical Computing, Brisbane, Australia, 2015.

Dyer, A. J.: A review of flux-profile relationships, Bound-Lay. Meteorol., 7, 363-372, 1974.

Fenocchi, A., Rogora, M., Sibilla, S., and Dresti, C.: Relevance of inflows on the thermodynamic structure and on the modeling of a deep subalpine lake (Lake Maggiore, Northern Italy/Southern Switzerland), Limnologica, 63, 42-56, 2017.

Fischer, H. B., List, E. G., Koh, R. C. Y., Imberger, J., and Brooks, N. H. (Eds.): Mixing in Inland and Coastal Waters, Academic Press, New York, USA, 1979.

Flerchinger, G. N., Xaio, W., Marks, D., Sauer, T. J., and Yu, Q.: Comparison of algorithms for incoming atmospheric long-wave radiation, Water Resour. Res., 45, W03423, https://doi.org/10.1029/2008WR007394, 2009.

Francey, R. J. and Garratt, J. R.: Eddy flux measurements over the ocean and related transfer coefficients, Bound-Lay. Meteorol., 14, 153-166, 1978.

Gal, G., Imberger, J., Zohary, T., Antenucci, J., Anis, A., and Rosenberg, T.: Simulating the thermal dynamics of Lake Kinneret, Ecol. Model., 162, 69-86, 2003.

Gal, G., Hipsey, M. R., Parparov, A., Wagner, U., Makler, V., and Zohary, T.: Implementation of ecological modeling as an effective management and investigation tool: Lake Kinneret as a case study, Ecol. Model., 220, 1697-1718, 2009.

Ganguly, A., Agrawal, A., Boykin, P. O., and Figueiredo, R.: IP over P2P: Enabling self-configuring virtual IP networks for grid computing, in: International Parallel and Distributed Processing Symposium, Rhodes Island, Greece, 5-29 April 2006.

$\mathrm{Gu}, \mathrm{R}$. and Stefan, H. G.: Validation of cold climate lake temperature simulation, Cold Reg. Sci. Technol., 22, 99-104, 1993.

Haario, H., Laine, M., Mira, A., and Saksman, E.: DRAM: Efficient adaptive MCMC, Stat. Comput., 16, 339-354, 2006.

Hamilton, D. P. and Schladow, S. G.: Water quality in lakes and reservoirs. Part I Model description, Ecol. Model., 96, 91-110, 1997.

Hamilton, D. P., Carey, C. C., Arvola, L., Arzberger, P., Brewer, C., Cole, J. J., Gaiser, E., Hanson, P. C., Ibelings, B. W., Jennings, E., and Kratz, T. K.: A Global Lake Ecological Observatory Network (GLEON) for synthesising high-frequency sensor data for validation of deterministic ecological models, Inland Waters, 5, 49-56, 2015.

Hansen, G. J., Read, J. S., Hansen, J. F., and Winslow, L. A.: Projected shifts in fish species dominance in Wisconsin lakes under climate change, Glob. Change Biol., 23, 1463-1476, 2017.

Hanson, P. C., Weathers, K. C., and Kratz, T. K.: Networked lake science: how the Global Lake Ecological Observatory Network (GLEON) works to understand, predict, and communicate lake ecosystem response to global change, Inland Waters, 6, 543-554, 2016.

Harvey, L. D. D.: Testing alternative parameterizations of lateral melting and upward basal heat flux in a thermodynamic sea ice model, J. Geophys. Res., 95, 7359-7365, 1990.
Henderson-Sellers, B.: Calculating the surface energy balance for lake and reservoir modeling: A review, Rev. Geophys., 24, 625649, 1986.

Hicks, B. B.: Some evaluations of drag and bulk transfer coefficients over water, Bound-Lay. Meteorol., 3, 201-213, 1972.

Hicks, B. B.: A procedure for the formulation of bulk transfer coefficients over water, Bound-Lay. Meteorol., 8, 515-524, 1975.

Hicks, B. B.: Wind Profile Relationships from the "Wangara" Experiment, Q. J. Roy. Meteor. Soc., 102, 535-551, 1976.

Hipsey, M. R. and Sivapalan, M.: Parameterizing the effect of a wind-shelter on evaporation from small waterbodies, Water Resour. Res., 39, 1339, https://doi.org/10.1029/2002WR001784, 2003.

Hipsey, M. R., Hamilton, D. P., Hanson, P. C., Carey, C. C., Coletti, J. Z., Read, J. S., Ibelings, B. W., Valesini, F. J., and, Brookes, J. D.: Predicting the resilience and recovery of aquatic systems: A framework for model evolution within environmental observatories, Water Resour. Res., 51, 7023-7043, 2015.

Hipsey, M. R., Boon, C., Bruce, L. C., Weber, M., Winslow, L., Read, J. S., and Hamilton, D. P.: AquaticEcoDynamics/GLM: v3.0.0_rc2, https://doi.org/10.5281/zenodo.2538486, 2019a.

Hipsey, M. R., Boon, C., Busch, B., Bruce, L. C., Weber, M., Winslow, L., Read, J. S., and Hamilton, D. P.: AquaticEcoDynamics/GLM_Examples: v3.0.0_rc2, https://doi.org/10.5281/zenodo.2538489, 2019 b.

Hipsey, M. R., Boon, C., Paraska, D., Bruce, L. C., and Huang, P.: AquaticEcoDynamics/libaed2: v1.3.0-rc2, Aquatic EcoDynamics (AED) Model Library \& Science Manual, 1-34, https://doi.org/10.5281/zenodo.2538495, 2019c.

Hocking, G. C. and Patterson, J. C.: Quasi-two-dimensional reservoir simulation model, J. Environ. Eng., 117, 595-613, 1991.

Hu, F., Bolding, K., Bruggeman, J., Jeppesen, E., Flindt, M. R., van Gerven, L., Janse, J. H., Janssen, A. B. G., Kuiper, J. J., Mooij, W. M., and Trolle, D.: FABM-PCLake - linking aquatic ecology with hydrodynamics, Geosci. Model Dev., 9, 2271-2278, https://doi.org/10.5194/gmd-9-2271-2016, 2016.

Huang, L., Wang, J., Zhu, L., Ju, J., and Daut, G.: The warming of large lakes on the Tibetan Plateau: Evidence from a lake model simulation of Nam Co, China, during 1979-2012, J. Geophys. Res.-Atmos., 122, 13095-13107, 2017.

Idso, S. B. and Jackson, R. D.: Thermal radiation from the atmosphere, J. Geophys. Res., 74, 5397-5403, 1969.

Imberger, J. and Patterson, J. C.: A dynamic reservoir simulation model-DYRESM:5, in: Transport Models for Inland and Coastal Waters, edited by: Fischer, H. B., Academic Press, New York, 310-361, 1981.

Imberger, J. and Patterson, J. C.: Physical Limnology, in: Advances in Applied Mechanics, edited by: Wu, T., 27, Academic Press, Boston, USA, 1990.

Imberger, J., Patterson, J., Hebbert, B., and Loh, I.: Dynamics of reservoir of medium size, J. Hydraul. Eng.-ASCE, 104, 725-743, 1978.

Imboden, D. M. and Wüest, A.: Mixing Mechanisms in Lakes, in: Physics and Chemistry of Lakes, edited by: Lerman, A., Imboden, D. M., and Gat, J. R., Springer-Verlag, 83-138, 1995.

Janssen, A. B. G., Arhonditsis, G. B., Beusen, A., Bolding, K., Bruce, L., Bruggeman, J., Couture, R. M., Downing, A. S., Elliott, J. A., Frassl, M. A., Gal, G., Gerla, D. J., Hipsey, M. R., Hu, F., Ives, S. C., Janse, J., Jeppesen, E., Jöhnk, K. D., Kneis, D., 
Kong, X., Kuiper, J. K., Lehmann, M., Lemmen, C., Ozkundakci, D., Petzoldt, T., Rinke, K., Robson, B. J., Sachse, R., Schep, S., Schmid, M., Scholten, H., Teurlincx, S., Trolle, D., Troost, T. A., Van Dam, A., Van Gerven, L. A., Weijerman, M., Wells S. A., and Mooij, W. M.: Exploring, exploiting and evolving diversity of aquatic ecosystem models: a community perspective, Aquat. Ecol., 49, 513-548, 2015.

Jellison, R. and Melack, J. M.: Meromixis and vertical diffusivities in hypersaline Mono Lake, California, Limnol. Oceanogr., 38, 1008-1019, 1993.

Jeong, S.: Understanding snow process uncertainties and their impacts, PhD thesis, University of California, Berkeley, 2009.

Ji, Z. G.: Hydrodynamics and water quality: modeling rivers, lakes, and estuaries, John Wiley \& Sons, 2008.

Kara, E. L., Hanson, P., Hamilton, D., Hipsey, M. R., McMahon, K. D., Read, J. S., Winslow, L., Dedrick, J., Rose, K., Carey, C. C., and Bertilsson, S.: Time-scale dependence in numerical simulations: assessment of physical, chemical, and biological predictions in a stratified lake at temporal scales of hours to months, Environ. Modell. Softw., 35, 104-121, 2012.

Kim, J.-W.: A generalized bulk model of the oceanic mixed layer, J. Phys. Oceanogr., 6, 686-695, 1976.

Kirillin, G., Hochschild, J., Mironov, D., Terzhevik, A., Golosov, S., and Nützmann, G.: FLake-Global: Online lake model with worldwide coverage, Environ. Modell. Softw., 26, 683-684, 2011.

Kirk, J. T. O.: Light and photosynthesis in aquatic ecosystems, Cambridge University Press, 1994.

Kleinhans, M. G. and Grasmeijer, B. T.: Bed load transport on the shoreface by currents and waves, Coast. Eng., 53, 983-996, 2006.

Klug, J. L., Richardson, D. C., Ewing, H. A., Hargreaves, B. R., Samal, N. R., Vachon, D., Pierson, D. C., Lindsey, A. M., O'Donnell, D. M., Effler, S. W., and Weathers, K. C.: Ecosystem effects of a tropical cyclone on a network of lakes in northeastern North America, Environ. Sci. Technol., 46, 11693-11701, 2012.

Kraus, E. B. and Turner, J. S.: A one-dimensional model of the seasonal thermocline: II The general theory and its consequences, Tellus, 19, 98-106, 1967.

Laenen, A. and LeTourneau, A. P.: Upper Klamath Lake nutrient loading study - Estimate of wind-induced resuspension of bed sediment during periods of low lake elevation, U.S. Geological Survey Open-File Report, 95-414, 11 pp., 1996.

Launiainen, J.: Derivation of the relationship between the Obukhov stability parameter and the bulk Richardson number for fluxprofile studies, Bound-Lay. Meteorol., 76, 165-179, 1995.

Launiainen, J. and Cheng, B.: Modelling of ice thermodynamics in natural water bodies, Cold Reg. Sci. Technol., 27, 153-178, 1998.

Launiainen, J. and Vihma, T.: Derivation of turbulent surface fluxes - An iterative flux-profile method allowing arbitrary observing heights, Environ. Softw., 5, 113-124, 1990.

Luo, L., Hamilton, D. P., and Han, B. Estimation of total cloud cover from solar radiation observations at Lake Rotorua, New Zealand, Sol. Energy, 84, 501-506, 2010.

Magee, M. R., Wu, C. H., Robertson, D. M., Lathrop, R. C., and Hamilton, D. P.: Trends and abrupt changes in 104 years of ice cover and water temperature in a dimictic lake in response to air temperature, wind speed, and water clarity drivers, Hydrol. Earth
Syst. Sci., 20, 1681-1702, https://doi.org/10.5194/hess-20-16812016, 2016.

Makler-Pick, V., Gal, G., Shapiro, J., and Hipsey, M. R.: Exploring the role of fish in a lake ecosystem (Lake Kinneret, Israel) by coupling an individual-based fish population model to a dynamic ecosystem model, Can. J. Fish. Aquat. Sci., 68, 12651284, 2011.

Markfort, C. D., Perez, A. L. S., Thill, J. W., Jaster, D. A., PortéAgel, F., and Stefan, H. G.: Wind sheltering of a lake by a tree canopy or bluff topography, Water Resour. Res., 46, 1-13, 2010.

Martynov, A., Sushama, L., Laprise, R., Winger, K., and Dugas, B.: Interactive lakes in the Canadian Regional Climate Model, version 5: The role of lakes in the regional climate of North America, Tellus A, 64, 1-22, 2012.

Matzinger, A., Schmid, M., Veljanoska-Sarafiloska, E., Patceva, S., Guseska, D., Wagner, B., Müller, B., Sturm, M., and Wüest, A.: Eutrophication of ancient Lake Ohrid: global warming amplifies detrimental effects of increased nutrient inputs, Limnol. Oceanogr., 52, 338-353, 2007.

McCord, S. A. and Schladow, S. G.: Numerical simulations of degassing scenarios for $\mathrm{CO}_{2}$-rich Lake Nyos, Cameroon, J. Geophys. Res., 103, 12355-12364, 1998.

McKay, G. A.: Problems of measuring and evaluating snow cover, in: Proceedings of Workshop Seminar of Snow Hydrology, Secretariat Canadian National Committee for the IHD, Ottawa, 4962, 1968.

Menció, A., Casamitjana, X., Mas-Pla, J., Coll, N., Compte, J., Martinoy, M., Pascual, J., and Quintana, X. D.: Groundwater dependence of coastal lagoons: The case of La Pletera salt marshes (NE Catalonia), J. Hydrol., 552, 793-806, 2017.

Mooij, W. M., Trolle, D., Jeppesen, E., Arhonditsis, G., Belolipetsky, P. V., Chitamwebwa, D. B. R., Degermendzhy, A. G., DeAngelis, D. L., De Senerpont Domis, L. N., Downing, A. S., Elliott, A. E., Fragoso Jr., C.R., Gaedke, U., Genova, S.N., Gulati, R. D., Håkanson, L., Hamilton, D. P., Hipsey, M. R., Hoen, J., Hülsmann, S., Los, F. J., Makler-Pick, V., Petzoldt, T., Prokopkin, I. G., Rinke, K., Schep, S. A., Tominaga, K., Van Dam, A. A., Van Nes, E. H., Wells, S. A., and Janse, J. H.: Challenges and opportunities for integrating lake ecosystem modelling approaches, Aquat. Ecol., 44, 633-667, 2010.

Monin, A. S. and Obukhov, A. M.: Basic laws of turbulent mixing in the atmosphere near the ground, Jr. Akad. Nauk SSSR Geofiz. Inst., 24, 163-187, 1954.

Mueller, H., Hamilton, D. P., and Doole, G. J.: Evaluating services and damage costs of degradation of a major lake ecosystem, Ecosyst. Serv., 22, 370-380, 2016.

NRC (National Research Council): Next generation science standards: For states, by states, The National Academies Press, Washington DC, USA, 2013.

O'Reilly, C. M., Sharma, S., Gray, D. K., Hampton, S. E., Read, J. S., Rowley, R. J., Schneider, P., Lenters, J. D., McIntyre, P. B., Kraemer, B. M., Weyhenmeyer, G. A., Straile, D., Dong, B., Adrian, R., Allan, M. G., Anneville, O., Arvola, L., Austin, J., Bailey, J. L., Baron, J. S., Brookes, J. D., de Eyto, E., Dokulil, M. T., Hamilton, D. P., Havens, K., Hetherington, A. L., Higgins, S. N., Hook, S., Izmest'eva, L. R., Joehnk, K. D., Kangur, K., Kasprzak, P., Kumagai, M., Kuusisto, E., Leshkevich, G., Livingstone, D. M., MacIntyre, S., May, L., Melack, J. M., MuellerNavarra, D. C., Naumenko, M., Noges, P., Noges, T., North, R. 
P., Plisnier, P.-D., Rigosi, A., Rimmer, A., Rogora, M., Rudstam, L. G., Rusak, J. A., Salmaso, N., Samal, N. R., Schindler, D. E., Schladow, S. G., Schmid, M., Schmidt, S. R., Silow, E., Soylu, M. E., Teubner, K., Verburg, P., Voutilainen, A., Watkinson, A., Williamson, C. E., and Zhang, G.,: Rapid and highly variable warming of lake surface waters around the globe, Geophys. Res. Lett., 42, 10773-10781, 2015.

Patterson, J. C. and Hamblin, P. F.: Thermal simulation of a lake with winter ice cover, Limnol. Oceanogr., 33, 323-338, 1988.

Patterson, J. C., Hamblin, P. F., and Imberger, J.: Classification and dynamics simulation of the vertical density structure of lakes, Limnol. Oceanogr., 29, 845-861, 1984.

Paulson, C. A.: The mathematical representation of wind speed and temperature profiles in the unstable atmospheric surface layer, J. Appl. Meteorol., 9, 857-861, 1970.

Peeters, F., Straile, D.m Loke, A., and Livingstone, D. M.: Earlier onset of the spring phytoplankton bloom in lakes of the temperate zone in a warmer climate, Glob, Change Biol., 13, 1898-1909, 2007.

Perroud, M., Goyette, S., Martynov, A., Beniston, M., and Anneville, O.: Simulation of multiannual thermal profiles in deep Lake Geneva: A comparison of one-dimensional lake models, Limnol. Oceanogr., 54, 1574-1594, 2009.

Porter, J. H., Hanson, P. C., and Lin, C. C.: Staying afloat in the sensor data deluge, Trends Ecol. Evol., 27, 121-129, 2012.

Read, J. S., Hamilton, D. P., Jones, I. D., Muraoka, K., Winslow, L. A., Kroiss, R., Wu, C. H., and Gaiser, E.: Derivation of lake mixing and stratification indices from high-resolution lake buoy data, Environ. Modell. Softw., 26, 1325-1336, 2011.

Read, J. S., Hansen, G., Van Den Hoek, J., Hanson, P. C., Bruce, L. C., and Markfort, C. D.: Simulating 2368 temperate lakes reveals weak coherence in stratification phenology, Ecol. Model., 291, 142-150, 2014.

Read, J. S., Gries, C., Read, E. K., Klug, J., Hanson, P. C., Hipsey, M. R., Jennings, E., O'Reilly, C., Winslow, L., Pierson, D., McBride, C., and Hamilton, D. P.: Generating community-built tools for data sharing and analysis in environmental networks, Inland Waters, 6, 637-644, 2016.

Rigosi, A., Hanson, P. C., Hamilton, D. P., Hipsey, M. R., Rusak, J. A., Bois, J., Sparber, K., Chorus, I., Watkinson, A. J., Qin, B., Kim, B., and Brookes, J. D.: Determining the probability of cyanobacterial blooms: the application of Bayesian networks in multiple lake systems, Ecol. Appl., 25, 186-199, 2015.

Riley, M. and Stefan, H.: MINLAKE: A dynamic lake water quality simulation model, Ecol. Model., 43, 155-182, 1988.

Rogers, C. K., Lawrence, G. A., and Hamblin, P. F.: Observations and numerical simulation of a shallow ice-covered mid-latitude lake, Limnol. Oceanogr., 40, 374-385, 1995.

Romarheim, A. T., Tominaga, K., Riise, G., and Andersen, T.: The importance of year-to-year variation in meteorological and runoff forcing for water quality of a temperate, dimictic lake, Hydrol. Earth Syst. Sci., 19, 2649-2662, https://doi.org/10.5194/hess-192649-2015, 2015.

Salmon, S. U., Hipsey, M. R., Wake, G. W., Ivey, G. N., and Oldham, C. E. Quantifying lake water quality evolution: Coupled geochemistry, hydrodynamics, and aquatic ecology in an acidic pit lake, Environ. Sci. Technol., 51, 9864-9875, 2017.
Saloranta, T. M. and Andersen, T.: MyLake - A multi-year lake simulation model code suitable for uncertainty and sensitivity analysis simulations, Ecol. Model., 207, 45-60, 2007.

Schwarz, C. V., Reiser, B. J., Davis, E. A., Kenyon, L., Achér, A., Fortus, D., Shwartz, Y., Hug, B., and Krajcik, J.: Developing a learning progression for scientific modeling: Making scientific modeling accessible and meaningful for learners, J. Res. Sci. Teach., 46, 632-654, 2009.

Sheng, Y. P. and Lick, W.: The transport and resuspension of sediments in a shallow lake, J. Geophys. Res., 84, 1809-1826, 1979.

Sherman, F. S., Imberger, J., and Corcos, G. M.: Turbulence and mixing in stably stratified waters, Annu. Rev. Fluid Mech., 10, 267-288, 1978.

Snortheim, C. A., Hanson, P. C., McMahon, K. D., Read, J. S., Carey, C. C., and Dugan, H. A.: Meteorological drivers of hypolimnetic anoxia in a eutrophic, north temperate lake, Ecol. Model., 343, 39-53, 2017.

Spigel, R. H.: Wind mixing in lakes, $\mathrm{PhD}$ thesis, University of California, Berkeley, USA, 1978.

Spigel, R. H. and Imberger, J.: The classification of mixed-layer dynamics in lakes of small to medium size, J. Phys. Oceanogr., 10, 1104-1121, 1980.

Spigel, R. H., Imberger, J., and Rayner, K. N. Modeling the diurnal mixed layer, Limnol. Oceanogr., 31, 533-556, 1986.

Stepanenko, V., Mammarella, I., Ojala, A., Miettinen, H., Lykosov, V., and Vesala, T.: LAKE 2.0: a model for temperature, methane, carbon dioxide and oxygen dynamics in lakes, Geosci. Model Dev., 9, 1977-2006, https://doi.org/10.5194/gmd-9-1977-2016, 2016.

Stepanenko, V. M., Martynov, A., Jöhnk, K. D., Subin, Z. M., Perroud, M., Fang, X., Beyrich, F., Mironov, D., and Goyette, S.: A one-dimensional model intercomparison study of thermal regime of a shallow, turbid midlatitude lake, Geosci. Model Dev., 6, 1337-1352, https://doi.org/10.5194/gmd-6-1337-2013, 2013.

Stewart, J., Cartier, J. L., and Passmore, C. M.: Developing understanding through model-based inquiry, in: How Students Learn, edited by: Donovan, M. S. and Bransford, J. D., National Research Council, Washington DC, USA, 515-565, 2005.

Strub, P. T. and Powell, T. M. Surface temperature and transport in Lake Tahoe: inferences from satellite (AVHRR) imagery, Cont. Shelf Res., 7, 1001-1013, 1987.

Subratie, K., Aditya, S., Figueiredo, R., Carey, C. C., and Hanson, P. C.: GRAPLEr: A distributed collaborative environment for lake ecosystem modeling that integrates overlay networks, high-throughput computing, and web services, Concurr. Comp.Pract. E, 29, e4139, https://doi.org/10.1002/cpe.4139, 2017.

Swinbank, W. C.: Longwave radiation from clear skies, Q. J. Roy. Meteor. Soc., 89, 339-348, 1963.

Tabata, S.: A simple but accurate formula for the saturation vapour pressure over liquid water, J. Appl. Meteorol., 12, 1410-1411, 1973.

Thain, D., Tannenbaum, T., and Livny, M.: Distributed computing in practice: The Condor experience, Concurr. Comp.-Pract. E, 17, 323-356, 2005.

Ticehurst J. L., Newham, L. T. H., Rissik, D., Letcher, R. A., and Jakeman, A. J.: A Bayesian network approach for assessing the sustainability of coastal lakes in New South Wales, Australia, Environ. Modell. Softw., 22, 1129-1139, 2007. 
Tranvik, L. J., Downing, J. A., Cotner, J. B., Loiselle, S. A., Striegl, R. G., Ballatore, T. J., Dillon, P., Finlay, K., Fortino, K., Knoll, L. B., and Kortelainen, P. L.: Lakes and reservoirs as regulators of carbon cycling and climate, Limnol. Oceanogr., 54, 2298-2314, 2009.

Trolle, D., Hamilton, D. P., Hipsey, M. R., Bolding, K., Bruggeman, J., Mooij, W. M., Janse, J. H., Nielsen, A., Jeppesen, E., Elliott, J. E., Makler-Pick, V., Petzoldt, T., Rinke, K., Flindt, M. R., Arhonditsis, G. B., Gal, G., Bjerring, R., Tominaga, K., Hoen, J., Downing, A. S., Marques, D. M., Fragoso Jr., C. R., Søndergaard, M., and Hanson, P. C.: A community-based framework for aquatic ecosystem models, Hydrobiologia, 683, 25-34, 2012.

TVA (Tennessee Valley Authority): Heat and mass transfer between a water surface and the atmosphere, Water Resources Research Laboratory Report 14, Report No. 0-6803, 1972.

UNESCO: The Practical Salinity Scale 1978 and the International Equation of State of Sea water 1980, UNESCO Technical Paper Marine Science, 36, 1981.

Vavrus, S. J., Wynne, R. H., and Foley, J. A.: Measuring the sensitivity of southern Wisconsin lake ice to climate variations and lake depth using a numerical model, Limnol. Oceanogr., 41, 822-831, 1996.

Vickers, D., Mahrt, L., and Andreas, E. L.: Estimates of the 10-m neutral sea surface drag coefficient from aircraft eddy-covariance measurements, J. Phys. Oceanogr., 43, 301-310, 2013.

Weathers, K. C., Groffman, P. M., Van Dolah, E., Bernhardt, E. S., Grimm, N. B., McMahon, K. D., Schimel, J., Paolisso, M., Maranger, R. J., Baer, S., Brauman, K. A., and Hinckley, E.: Frontiers in ecosystem ecology from a community perspective: The future is boundless and bright, Ecosystems, 19, 753-770, 2016.

Weber, M., Rinke, K., Hipsey, M. R., and Boehrer, B.: Optimizing withdrawal from drinking water reservoirs to reduce downstream temperature pollution and reservoir hypoxia, J. Environ. Manage., 197, 96-105, 2017.
Weinstock, J.: Vertical turbulence diffusivity for weak or strong stable stratification, J. Geophys. Res., 86, 9925-9928, 1981.

Williamson, C. E., Saros, J. E., Vincent, W. F., and Smol, J. P.: Lakes and reservoirs as sentinels, integrators, and regulators of climate change, Limnol. Oceanogr., 5, 2273-2282, 2009.

Winslow, L. A., Hansen, G. J. A., Read, J. S., and Notaro, M.: Data Descriptor: Large-scale modeled contemporary and future water temperature estimates for 10774 Midwestern U.S. Lakes, Scientific Data, 4, 170053, https://doi.org/10.1038/sdata.2017.53, 2017.

Woolway, R. I., Verburg, P., Merchant, C. J., Lenters, J. D., Hamilton, D. P., Brookes, J., Kelly, S., Hook, S., Laas, A., Pierson, D., and Rimmer, A.: Latitude and lake size are important predictors of over-lake atmospheric stability, Geophys. Res. Lett., 44, 8875-8883, 2017.

$\mathrm{Wu}, \mathrm{J} .:$ Wind induced entrainment across a stable density interface, J. Fluid Mech., 61, 275-278, 1973.

Xenopoulos, M. A. and Schindler, D. W.: The environmental control of near-surface thermoclines in boreal lakes, Ecosystems, 4, 699707, 2001.

Yajima, H. and Yamamoto, S.: Improvements of radiation estimations for a simulation of water temperature in a reservoir, Journal of Japan Society of Civil Engineers, Ser. B1 (Hydraulic Engineering), 71, 775-780, 2015.

Yao, H., Samal, N. R., Joehnk, K. D., Fang, X., Bruce, L. C., Pierson, D. C., Rusak, J. A., and James, A.: Comparing ice and temperature simulations by four dynamic lake models in Harp Lake: past performance and future predictions, Hydrol. Process., 28, 4587-4601, 2014.

Yeates, P. S. and Imberger, J.: Pseudo two-dimensional simulations of internal and boundary fluxes in stratified lakes and reservoirs, International Journal of River Basin Research, 1, 1-23, 2003.

Zhang, W. and Arhonditsis G. B.: A Bayesian hierarchical framework for calibrating aquatic biogeochemical models, Ecol Model., 220, 2142-2161, 2009. 